\title{
Strategic Sustainability: \\ The case of the New Zealand energy sector
}

By

Sebastian Kramer

\begin{abstract}
A thesis
submitted to the Victoria University of Wellington

in partial fulfilment of the requirements of the degree of

Master of Management Studies
\end{abstract}

Victoria University of Wellington

2009 


\section{Abstract}

This thesis takes an in-depth look at the current sustainability practices of two specific energy companies in the New Zealand energy sector to develop a framework for how they might strategically implement sustainable practices. This is done through investigating and subsequently comparing New Zealand's and Germany's sustainability practices at both government and corporate level in order to draw conclusions on how New Zealand could improve in both sectors. In addition to the framework this thesis aims to clearly outline the difficulties companies might encounter when implementing sustainable practices, and the potential payoff they can expect from it.

This thesis used a multiple case-study approach in combination with a comparative study to highlight the differences between each country's government and corporate approaches to sustainability. A framework of how to best integrate sustainability into corporations was developed using an extensive literature review of sustainability topics. Interviews were conducted with two New Zealand 'cases' using interviews as the primary means of data collection. In addition to this, extensive secondary data was used for both the New Zealand and German cases as well as for government policies.

The findings of this thesis were diverse. The multiple cases-studies found vast differences within the corporations' implementation policies, as well as their intentions behind integrating sustainability practices. The comparative study found notable differences between both governments' sustainability policies, demonstrating a potential to learn from one another's policy implementations. Moreover, the findings illustrated differences between the New Zealand and German energy markets and government policies, and more importantly, how that could restrict each country’s potential for sustainable development.

The key practical implication of this thesis is that energy companies in New Zealand can employ the developed framework as a guideline on how to integrate sustainability into their companies. Furthermore, companies can use this thesis as a reference list for sustainability issues, as this paper combines many aspects of sustainability. On an academic level this thesis may well offer new insights into sustainable practice on both government and corporate level.

This thesis is a valid contribution to the field of sustainability, especially in the context of the New Zealand energy sector. Furthermore, a comparative study between New 
Zealand and Germany in the context of sustainability on both government and corporate level has not been done before and as such has unique value.

Key words: Sustainability, Multiple Case-study, Comparative-study, Sustainable development, Corporate Social Responsibility, Triple-bottom-line 


\section{Acknowledgements}

This thesis evolved due my interest in sustainability and environmental protection. I hope that this thesis will help companies and governments alike to embrace sustainability in order to save and preserve our environment and our planet.

This thesis would not have been possible without the help of the following people and organisations who I would like to thank for their support and assistance:

- Stephen Cummings: Thesis Supervisor, whose comments, suggestions and support were helpful.

- Stephen Ward: Helped with comments and insights into the New Zealand energy sector.

- Starfish Consultancy: Ron Stuart and Alan Barrett from Starfish supplied valuable information about the New Zealand sector as well as support in the field of sustainability.

- Meridian Energy: Chris Montgomery was very supportive in answering questions in the interview about Meridian Energy's sustainability practices.

- Contact Energy: Bruce Parks was also very supportive and helpful in answering questions in the interview at Contact Energy.

- Sophia Lum: Sophia's support for the master students at Victoria University is outstanding and without her help the master thesis would not have been as organised and well supported.

I would like to thank everyone who has contributed to this thesis, without the help of everyone involved this thesis would not have been possible. 


\section{Table of Contents}

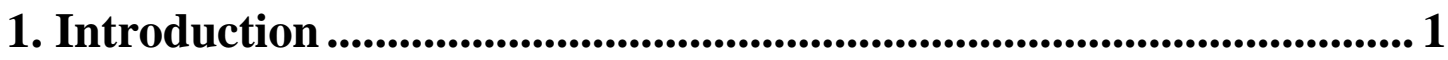

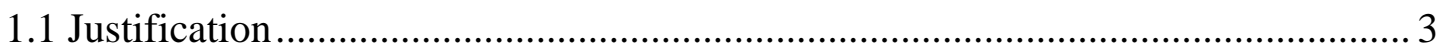

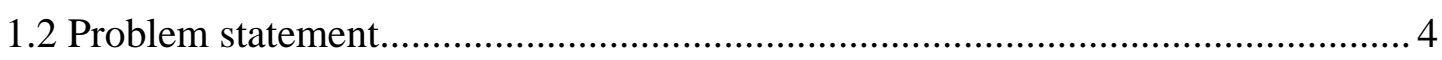

2. Literature Review.........................................................................................6 6

2.1 Sustainability and strategic sustainability ........................................................... 6

2.2 Corporate Social Responsibility ……………………....................................... 9

2.3 CSR and the resource-based perspective ........................................................ 14

2.4 Stakeholder Theory ………………………………………………………….... 17

2.5 Triple Bottom Line ......................................................................................... 20

2.6 Triple Bottom Line Reporting ............................................................................... 23

2.7 Triple Bottom Line Reporting in New Zealand................................................... 25

2.8 Performance Measurement (PM) and Sustainability Performance Indicators (SPI)

2.8.1 Types of PM indicators ............................................................................... 27

2.8.2 Opportunities and constraints of implementing PM indicators ....................... 30

2.8.3 Developing and implementing KPIs............................................................... 31

2.9 Sustainability tools............................................................................................. 34

2.9.1 ISO 14001, Environmental Management System (EMS)................................. 34

2.9.2 Total Quality Environmental Management (TQEM) ………………………... 36

2.9.3 Sustainability Balanced Scorecard (SBSC) …………………………………..... 38

2.10 Strategic Sustainability Framework (SSF) ………………………………….... 41

2.11 Summary …………………………………………………………………. 44

\section{Best Practice Germany? A review of Germany's energy sector and}

policies ........................................................................................................... 46

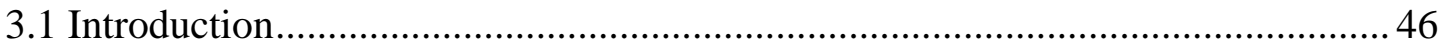

3.2 The German energy sector ………………………………………………… 4 .

3.3 The German Renewable Energy Act (EEG)........................................................ 48

3.4 European Emission Trading Scheme (EETS/EU ETS) ………………………....... 50

3.5 Market-forces and government incentives.............................................................. 53

3.6 Case examples............................................................................................... 54

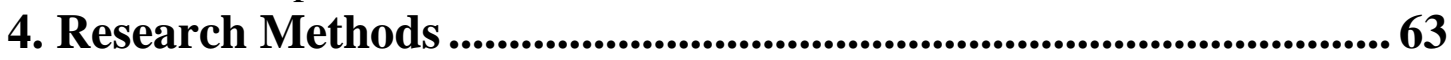

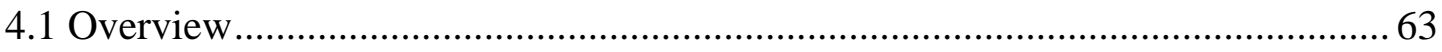

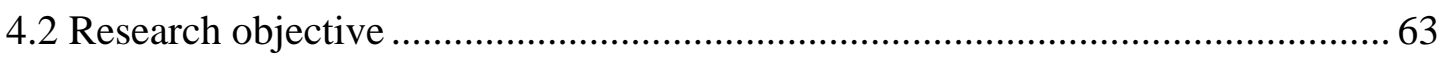

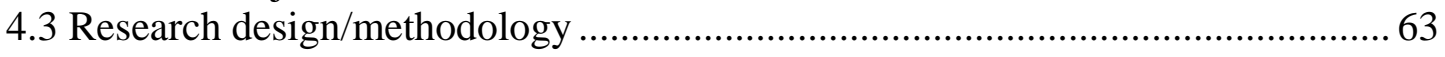

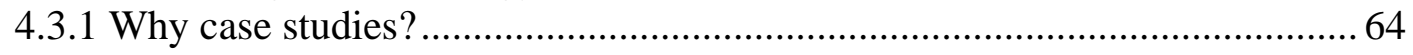

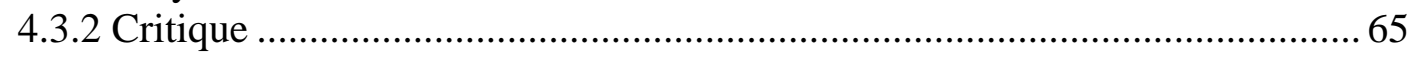

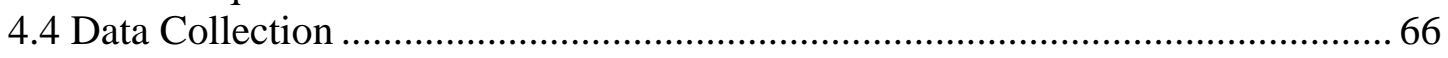

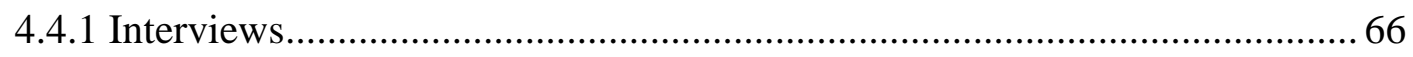

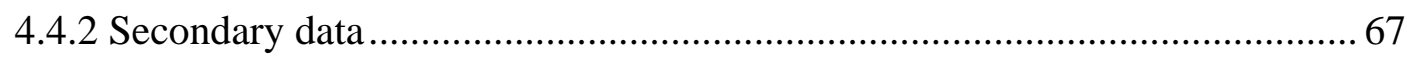

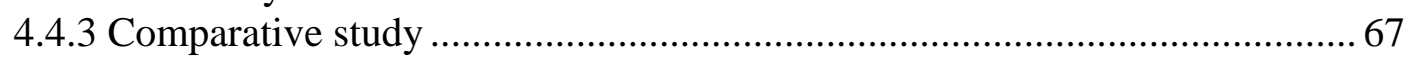

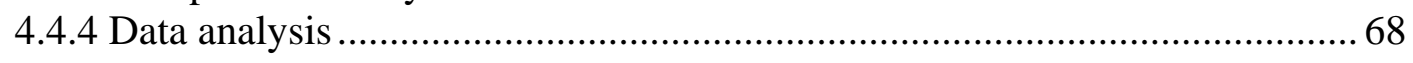

4.4.5 Limitations ............................................................................................... 70

4.5.1 Ethical issues......................................................................................... 72

4.5.2 Confidentiality issues..................................................................................... 72

5. The Case of New Zealand's Energy Sector......................................... 73

5.1 Case Study A ……………………………………………………………. 80 


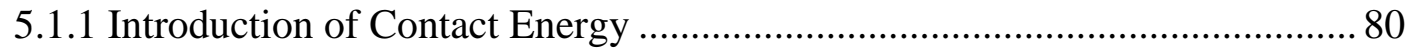

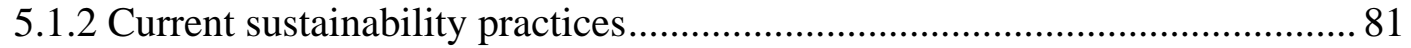

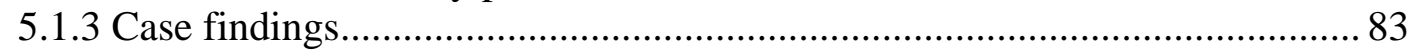

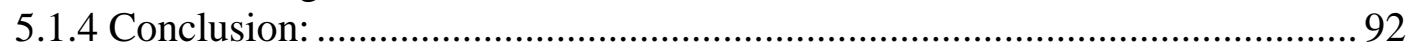

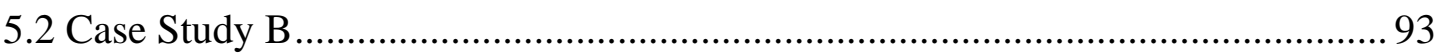

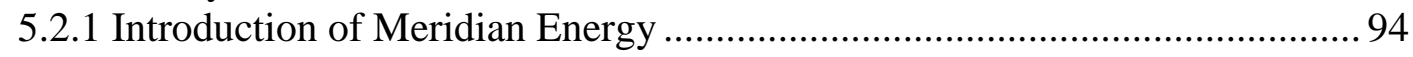

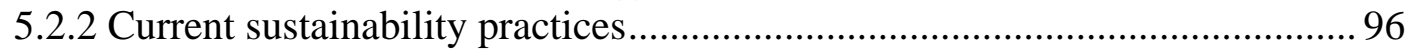

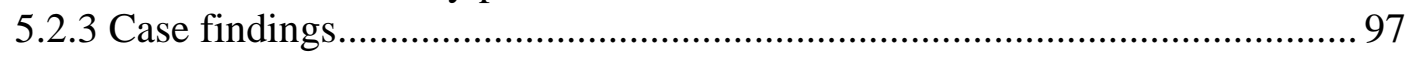

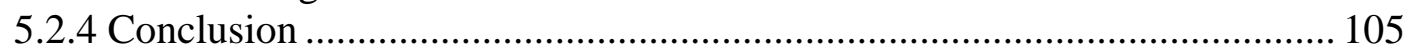

5.3.1 A comparison of Germany's and New Zealand's energy and sustainability

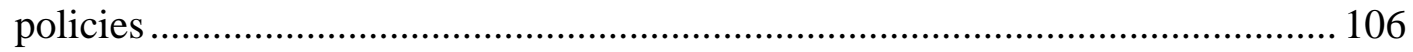

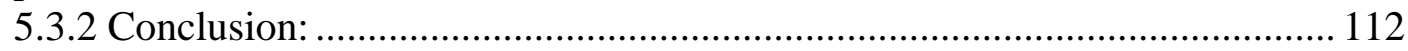

5.4 Applying the Strategic Sustainability Framework to RWE ................................ 113

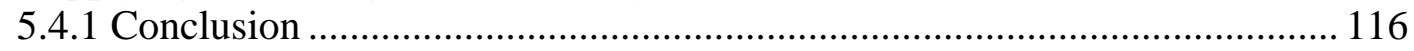

6. General Conclusion, Recommendations \& Limitations................ 117

6.1 Concluding remarks on the seven steps of the SSF ........................................ 117

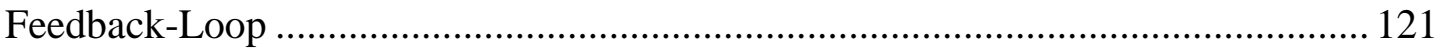

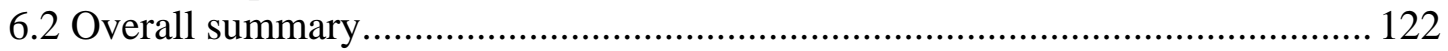

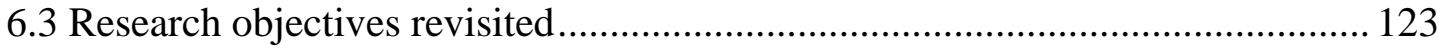

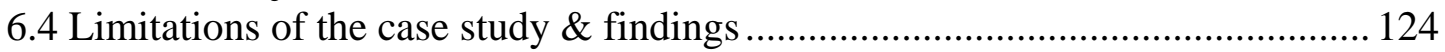

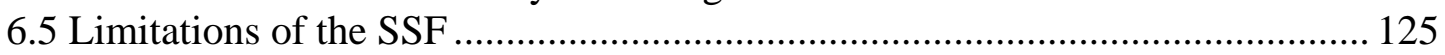

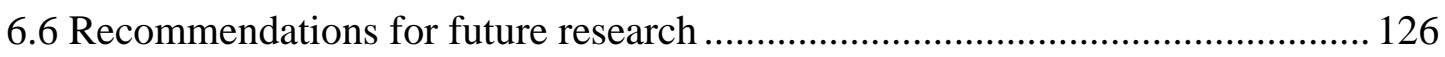

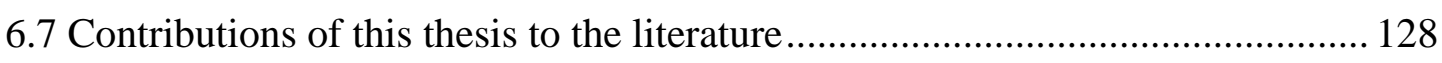

7. References ................................................................................... 130 


\section{Figures}

Figure 1: Ten major forces and CSR Values as potential sources of competitive advantage (Source: Willard, 2005 in Tschopp, 2003) .................................................... 11 Figure 2: From TBL to CSR (Adopted from Ernst \& Young and modified to the needs

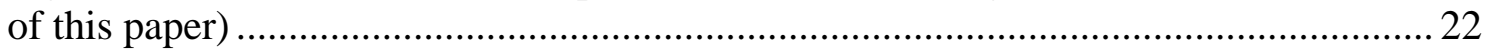

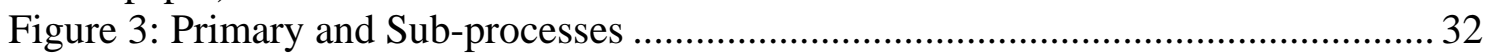

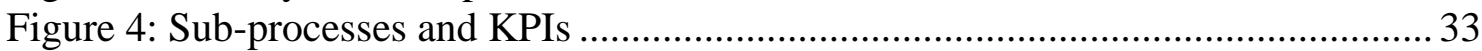

Figure 5: Step-by-step approach to ingrain environmental thinking (Adopted from

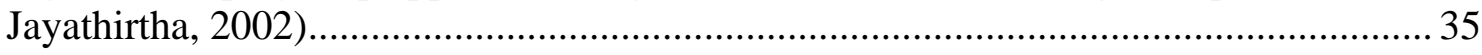

Figure 6: Implementing TQEM (adapted from Jayathirtha, 2002)................................ 37

Figure 7: Balanced Score Card (BSC) (adapted from Kaplan and Norton, 1997) .......... 38

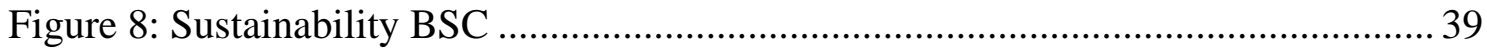

Figure 9: Six dimensions of the BSC (from Parmenter, 2007) ..................................... 41

Figure 10: Strategic Sustainability Framework ......................................................... 42

Figure 11: Germany's Electricity Generation 1991-2004, by Source (Taken from)...... 48

Figure 12: OECD Wind and Solar Electricity Generation Capacity, 2004 ( Taken from)

Figure 13: A Comparison of the Global 100 and the MSCI World (Panda, 2008) ........ 52

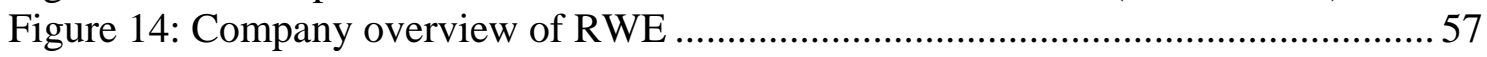

Figure 15: Renewables at E.ON (Taken from E.ON Annual Report 2007) ................... 59

Figure 16: Energy mix at Naturstrom (from www.naturstrom.de ) ................................6 60

Figure 17: FlexStrom advertisement (from www.flexstrom.de ) .................................... 61

Figure 18: New Zealand's five largest power generators (from Ministry of Economic

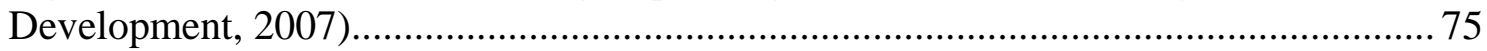

Figure 19: Contact Energy SSF. Blue, good; red, room for improvement. ..................... 89

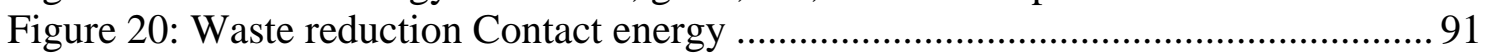

Figure 21: Meridian Energy SSF. Blue, goo; red, room for improvement................... 102

Figure 22: A, Germany's and B, New Zealand's energy consumption by sector, 1999

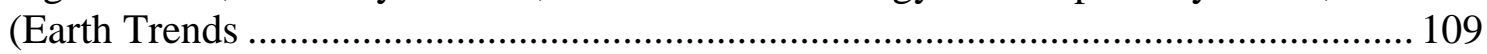

Figure 23: RWE SSF. Blue, good; red, room for improvement. ................................ 113

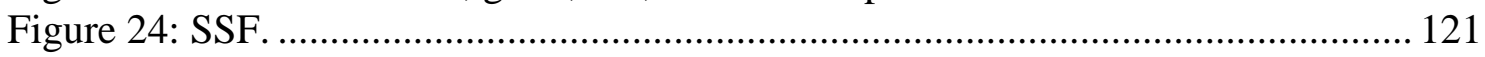

Figure 25: Questions \& Answers (Meridian \& Contact) ............................................ 137

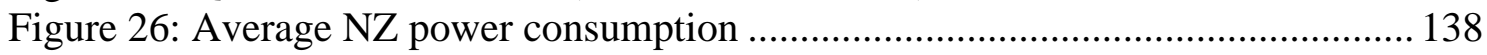




\section{Tables}

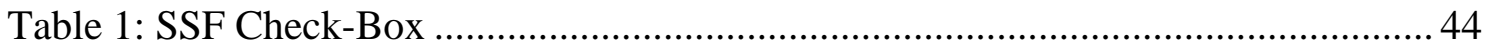

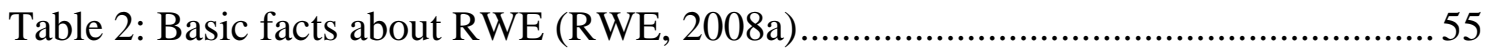

Table 3: Questions and Answers from Interviews with Contact Energy staff................ 85

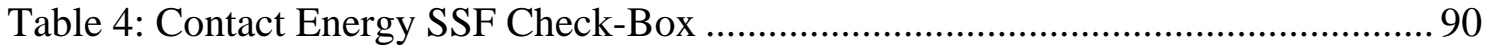

Table 5: Questions and Answers from interviews with Meridian Energy staff.............. 99

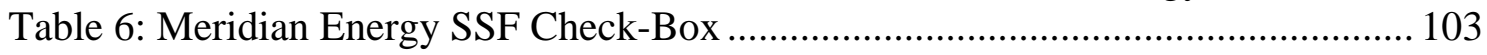

Table 7: Energy indicators and policies in Germany and New Zealand ...................... 106

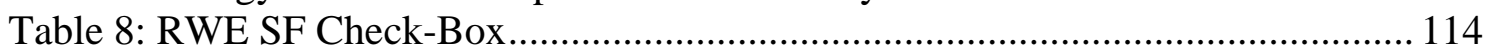




\section{Introduction}

Corporate Sustainability may currently be the 'hottest' topic in management. Whether they choose to make it a core part of their business strategy or not, no business can ignore sustainability. In the past, companies have focused their strategies largely on product or service quality and lean, just-in-time production. However, these things seem more like a foundation each company should see as a matter of course (Langenwalter, 2007). Given this, a particular focus on sustainability is one of the 'newer' practices in business that can be developed to genuinely contribute to a company's competitive edge.

This may be particularly true within a New Zealand context. Because New Zealand is a small geographically isolated market, company size (and 'scope') is a major issue affecting on the global competitiveness of New Zealand companies. The literature suggests that companies can gain a competitive advantage over their bigger competitors by incorporating sustainable practices and principles into their market strategy (Placet et al., 2005; Beloff et al., 2007; Welford et al., 2003)

Public concern about the environment is rising due to perceptions of dwindling resources, climate change and pollution of sea, soil and air. Stakeholders therefore want companies to behave more like a member of the community than just a corporation and to prevent further pollution and help prevent climate change (Henriques and Sadorsky, 1999). As such a member of the community, a company would look after the people and the environment it affects through its business (Quinn, 2002).

Another factor that plays a vital role in the rising stakeholder awareness is the increasing ease with which consumers can access information about a company's practices. Stakeholders can look up increasing amounts of information concerning companies on the internet and any unethical behaviour of companies can become 'fodder' for the media.

Companies may seek to gain a differential advantage by incorporating specific strategic actions in order to diversify their main strategy. This makes it harder for other companies to copy a strategy from a competitor. If, for example, sustainability is 
incorporated into a company's strategy in a way that is unique to that industry, this can give the company a competitive edge due to consumers shifting buying behaviour towards more sustainable products (Porter and Linde, 1995; Hart and Milstein, 2003).

Adding to the emphasis on sustainability, the Dow Jones Sustainability Index, FTSE4Good and Innovest's Global 100 are increasingly used as a performance indicator for prospective and current shareholders (Beloff et al., 2007).

Al Gore, for example, who 'nearly' won the presidential election in the United States in 2000, currently tours the world with his awareness arising movie "An Inconvenient Truth", which urges businesses and politicians alike to take the current climate change and treaties like the Kyoto protocol more seriously. People like him and many others are working hard to raise the issue of sustainability in order to provide a future for following generations.

In summary the opportunity to create sustainable value shareholder wealth that simultaneously drives us toward a more sustainable world is more apparent than it has ever been (Hart and Milstein, 2003, p65) However, evidence as to how this may be achieved is just beginning to emerge.

This thesis seeks to create a framework on how to strategically incorporate sustainability into organisations by examining the different literature streams of corporate sustainability. Furthermore, will this thesis look at challenges organisations might encounter when incorporating sustainable practices as well as highlighting the possible benefits of utilising strategic sustainability.

This research thesis arose from my growing interest in sustainability issues around the world and how businesses in a New Zealand context might take practical steps to incorporating sustainability into their corporate strategies. 


\subsection{Justification}

A sustainable company strategy could fit New Zealand well because it is seen and advertised as a clean, green country in the tourism and primary goods industries (Ministry for the Environment, 2001). Furthermore, a sustainable approach may help secure New Zealand companies futures in an environment of rising demands to reduce carbon footprints and growing consumer awareness of companies' business practices.

While some New Zealand industries have looked into sustainable strategies (wine, tourism and energy), and Carbon Zero has subsequently become the hallmark for wine businesses around New Zealand and is being used to differentiate sustainable wineries from non-sustainable wineries, no substantial research has been done on how to best embrace and ingrain sustainable strategies and practices in the New Zealand business context (Carbon Zero ${ }^{1}$ ).

In order to make sustainable success and benefits measurable to management, this research will introduce Performance Measurements (PMs). PMs reflect the success of sustainable practices within companies as well as quantifying them in order to test weather the sustainable practice is profitable.

Sustainable practices this research will focus on will incorporate Corporate Social Responsibility (CSR) in combination with a resource-based view and the triple bottom line (TBL) approaches. Sustainability, CSR and TBL are very closely linked and triple bottom line reporting is also referred to as corporate sustainability or sustainability reporting (Colbert and Kurucz, 2007; TBL-reporting ${ }^{2}$ ). A resource-based view is important in this context because, depending on resource availability a company might or might not be able to successfully implement environmental practices (GonzálezBenito and González-Benito, 2000). The resource-based view consists of tangible and intangible resources which will be explained in more detail below.

\footnotetext{
${ }^{1}$ The carboNZero programme is an internationally recognised greenhouse gas emissions measurement, reduction and certification scheme offering optional mitigation strategies through the use of credible and verified offsets or carbon credits. Source: http://www.carbonzero.co.nz/about/programme.asp, accessed on the 5th of May 2008.

2 TBL reporting: Is reporting on a company's financial, environmental and social performance to the public and government. Good TBL reporting enables a company to build trust and respect in the community (Ministry for the Environment, 2003)
} 
The triple bottom line is focusing on people (social), the planet (environmental) and profit (performance) (Savitz and Weber, 2006). Corporate Social Responsibility is focusing on the social (people) perspective and therefore is important to mention in this thesis focusing on sustainability, because a social perspective is important to both corporate sustainability and the triple bottom line.

New Zealand would also be ideal for a study such as this in the broader context. Due to its size, and ready access to a wide variety of companies within a limited geographic area, this research might potentially benefit companies within and beyond New Zealand.

This research will look at a small number of New Zealand and German energy companies in order to compare sustainable practices as well as to see what motivates these companies to engage in sustainable practices and what they have gained from those so far. German energy companies were chosen because some authors argue that Germany’s energy policies and energy company practices might be the best in the world and should therefore be used as a benchmark (Blue, 2008; Landler, 2008). The research will be a combination of comparative study, case studies and subsequent theoretical analysis in order to come up with a new framework to aid companies in developing effective sustainable strategies, from both an ecological and a financial perspective.

\subsection{Problem statement}

Sustainability and sustainable practices have become a "hot" topic. However, they are much more than just fashionable phrases and their effects are on the rise; the onus is now on companies as well governments to work towards a better and more sustainable future. Governments can achieve this by implementing environmental and corporate policies; corporations can choose to use renewable resources or produce environmentally friendly products and services. Sustainability, at both government and corporate level, is going to stay an issue for future generations to tackle climate change and our dwindling resources.

Research into the reasons why energy companies in New Zealand have embraced sustainable practices and, more importantly, how they have done so could potentially 
offer insights on how future environmental and sustainability issues might be handled by corporations. Moreover, the focus on government's sustainability and environmental policies can offer methods and insights on how best to tackle climate change and environmental problems on a governmental level.

With this in mind, research on sustainability and sustainable development in the New Zealand energy and government context can provide useful information to academics and practitioners on how sustainability frameworks and theories can best be implemented on both levels. Sustainability and the preservation of our environmental resources are issues that will affect the entire population of our planet as dwindling resources and global warming don not discriminate between individuals.

Existing knowledge in the field of sustainability and sustainable development of corporate practice and government policy implementation will benefit from this research by giving it a more practical approach. Moreover, a comparison between New Zealand's and Germany's sustainable practices will add towards the existing knowledge in the New Zealand context by providing new insights.

This thesis aims to create a framework for the implementation of sustainable practices within corporations in order to make it easier for companies in general to integrate such practices into their companies.

Currently, sustainable practices in corporations are still fairly new and this research might not necessarily create a 'best practice' for sustainable practices within corporations and governments, but it will help to broaden the knowledge of it.

Evidence from multiple sources points towards the need for more sustainable practices in both government and corporate sectors. The New Zealand government points out that a sustainable and green image for New Zealand industries would be desirable in order for New Zealand to be competitive throughout certain industries like tourism and the energy sector (Ministry for the Environment, 2001). Beloff et al. (2007) point out that stakeholders of companies become increasingly more aware of sustainability issues and that the companies therefore need to change their practices in order to satisfy stakeholder demands. Furthermore, companies can gain a strategic advantage over other 
companies that do not practice sustainability (Porter and Linde, 1995; Hart and Milstein, 2003). All this evidence justifies further research in the field of sustainability and sustainable development in order to provide more knowledge in this field of interest.

\section{Literature Review}

This chapter will look at the literature surrounding sustainability and sustainable development including: sustainability, Corporate Social Responsibility, triple bottom line, strategy, measurement, sustainability tools, resources and reporting. Each topic will be looked at in depth from its first occurrence to its importance today. The different topics will be separated by subheadings in order to make it easier for the readers to differentiate the different sections.

\subsection{Sustainability and strategic sustainability}

The word sustainability is widely used these days and various different interpretations exist which can make it a bit confusing as to what sustainability actually means. Originally the word originates from the roman word 'sustinere' which means 'to hold up'; in the English language sustainability means the ability to sustain/maintain (RMIT University, 2001).

The term sustainability or sustainable development became well known through the 1987 Brundtland report, also known as the Our Common future report, published by the UN World Commission on Environment and Development (WCED).

Sustainability or sustainable development is defined by the Brundtland Report as follows: "Sustainable development is development that meets the needs of the present without compromising the ability of future generations to meet their own needs" (sustainable development ${ }^{3}$ ).

3 Source: http://www.ourcommonfuture.org/, accessed on the 16th of May 2008. 
At the Earth Summit in Rio de Janeiro in 1992, sustainability and sustainable development were finally being ingrained into the public policy debate, which heightened awareness of the issue even more (Paul, 2006).

Since then numerous authors have elaborated on sustainability as a strategic advantage, money spinner, differentiation strategy, money saver and many more. The most important articles and authors will be discussed.

Byrch et al. ask what sustainable development means in New Zealand to "thought leaders" and "leaders", which is important to this thesis because it is conducted within New Zealand. The paper found three main views in the New Zealand business community: 1. Participants who generally promote business saw the economic area and economic growth as a path to sustainable development. 2. Participants who promote sustainability emphasised on a focus on the environmental area, the future and a limited supply of our earth resources. 3. Finally, participants who actively promoted sustainable businesses emphasised on a mixed approach of the first two with a focus on government reforms.

Sustainability or sustainable practices can give a company a competitive edge over those companies that do not use sustainable practices. Mahler (2007) supports this statement as follows: "The best companies view sustainability not only as a chance to contribute to social goals, but also as a powerful source of competitive advantage.”(Mahler, 2007).

There has been a lot of evidence lately that those companies outperform those companies that don't use sustainable practices, which can be seen if we compare the Dow Jones Sustainability Index with the Dow Jones Global Index. The Dow Jones Sustainability Index has exceeded the Dow Jones Global Index for many years now (Langenwalter, 2007; Mahler, 2007; Kettinger et al., 1994).

Green productivity was introduced shortly after the 1992 Rio de Janeiro summit and is a strategy to enhance productivity and environmental performance simultaneously in order to gain higher returns by polluting the environment less, creating less waste and improving customer satisfaction (Tuttle and Heap, 2007). 
Tuttle and Heap (2007) point out that the Beijing Consensus supports the view of green productivity. The Beijing consensus is a Chinese thinker's new way of measuring GDP growth, differentiating between 'black growth', 'green growth' and 'clean growth'. 'Black growth' incorporates environmental damage, 'green growth' incorporates corruption and 'clean growth' is measuring the true GDP value. This is how progress should be measured (Tuttle and Heap, 2007).

Hart and Milstein (2003) consider the many dimensions of sustainability and point out that many managers trying to implement sustainable practices only look at one dimension of the issue, which strategically leaves the company in an ill equipped position.

Sisaye et al. (2005) stress the importance of combining Total Quality Management (TQM) with sustainability in order to provide the best quality to consumers. Sustainability focuses here on environmental resource management which makes sure that all stakeholders in and outside the company act in an environmental friendly way to improve quality and sustainability.

Shrivastava (1995) elaborates on the role of corporations in achieving ecological sustainability. Shrivastava links four aspects of ESD (Ecological Sustainable Development) to corporate mechanisms: 1. Population Control - Total quality environmental management; 2. Food security - Ecological sustainable competitive strategies; 3. Ecological resource Management - Technology transfer; 4. Sustainable Economies - Population Impact Control. The paper suggests that companies can mainly contribute to ecological resource management and creating sustainable economies.

Elkington (1999) reviewed sustainable activities around the world up to 1999 and concluded that "successful companies will have little option but to get involved in this rapid emerging area”.

Companies use different terms and tools when incorporating sustainable issues into their strategy. The following points will elaborate on Corporate Social responsibility, the triple bottom line, Stakeholder theory, the resource-based view and measurement 
initiatives to provide a better understanding of the different terms and tools of corporate sustainability.

\subsection{Corporate Social Responsibility}

In a time where resources become scarce, global warming rises and consumers become more aware of companies' business practices, many companies are pressured by shareholders and consumers alike, to act in an ethical and sustainable way. One of the tools companies are using in order to act on that demand is called Corporate Social Responsibility (CSR).

After incidents like Enron the public, shareholders as well as stakeholders demanded companies engage in ethical and long-term growth practices (Enron ${ }^{4}$ ). Furthermore, government leaders called for more "corporate environmental and social responsibility and accountability” in the Johannesburg Declaration and Plan of Implementation of the 2002 World Summit on Sustainable Development (Cetindamar \& Husoy, 2007). From then on companies who have engaged in CSR practices have gained a competitive edge over those companies which continue to do business as usual. Being seen as an ethical and socially responsible company can result in higher sales, better relationships with communities and employees, attracting top talent employees, repositioning of the company in the market and better shareholder/stakeholder relationships (Fox, 2007).

The term corporate social responsibility was first coined by Milton Friedman in 1970, who at that point had a very different view on CSR than most business people have today. The following citation from Friedman (1970) offers a good overview as to how CSR was seen 38 years ago: "The difficulty of exercising 'social responsibility' illustrates, of course, the great virtue of private competitive enterprise -- it forces people to be responsible for their own actions and makes it difficult for them to 'exploit' other people for either selfish or unselfish purposes. They can do good -- but only at their own expense."

\footnotetext{
${ }^{4}$ Compare http://www.enronfraudinfocenter.com/information.php, accessed on the 28th February 2008.
} 
How is CSR defined? Jonker and Witte (2006, p247) conclude that CSR and its implementation are sensible issues and that with respect to this topic Theories and practice are in the midst of a process of discovery. Moreover, the authors explain that multiple attempts exist to explain what CSR is all about among theorists and practitioners. Hence, the meaning of the term “Corporate Social Responsibility” is described in multiple ways in the literature, mainly due to the fact that no clear definition exists and the term CSR admixes with concepts like Sustainability, Corporate Citizenship, and others.

According to Bassen et al. (2005) sustainability was in the beginning based on environmental protection and has been enhanced according to the triple bottom line approach (TBL) discussed below. The authors explain that basically a sustainable development is only possible by considering the three pillars of the TBL in equal measure. In contrast to CSR, sustainability is not only concerned with satisfying stakeholders' needs, but also includes humanity and future generations. CSR also includes Corporate Citizenship, which is basically the engagement in the relationship to local communities (Loew et al., (2004) in Bassen et al. 2005). Corporate Governance aims at controlling the management and its functions in order to avoid malpractice. This is relevant to all stakeholders. Lawrence (2000, p324) describe CG as "the process by which a company is controlled or governed"; where control systems are used in order to protect the stakeholders.

One of the main concepts of CSR is stakeholder management, which basically means that companies should only be held accountable by the stakeholders. Other parties such as customers, employees, suppliers and partners hold the company responsible for their actions instead of regulations by governments (Knox et al., 2005).

CSR can help companies to reduce pollution, energy usage as well as waste reduction along the supply chain by incorporating various CSR tools. Furthermore, CSR engagement projects a positive company image to consumers and stakeholders if used as a marketing tool (Diana, 2006).

The opinions about the necessity of CSR still diverge. According to a survey by SHRM in 2007, which surveyed 431 US companies, 91\% stated that they engage in CSR 
activities. The other 9\% stated that the costs created by CSR lowered profits and economic efficiency, which penalises the shareholders (Fox, 2007).

Figure 1 outlines CSR and its competitive advantage through Willard's 10 market forces (Tschopp, 2003).

Figure 1: Ten major forces and CSR Values as potential sources of competitive advantage (Source: Willard, 2005 in Tschopp, 2003)

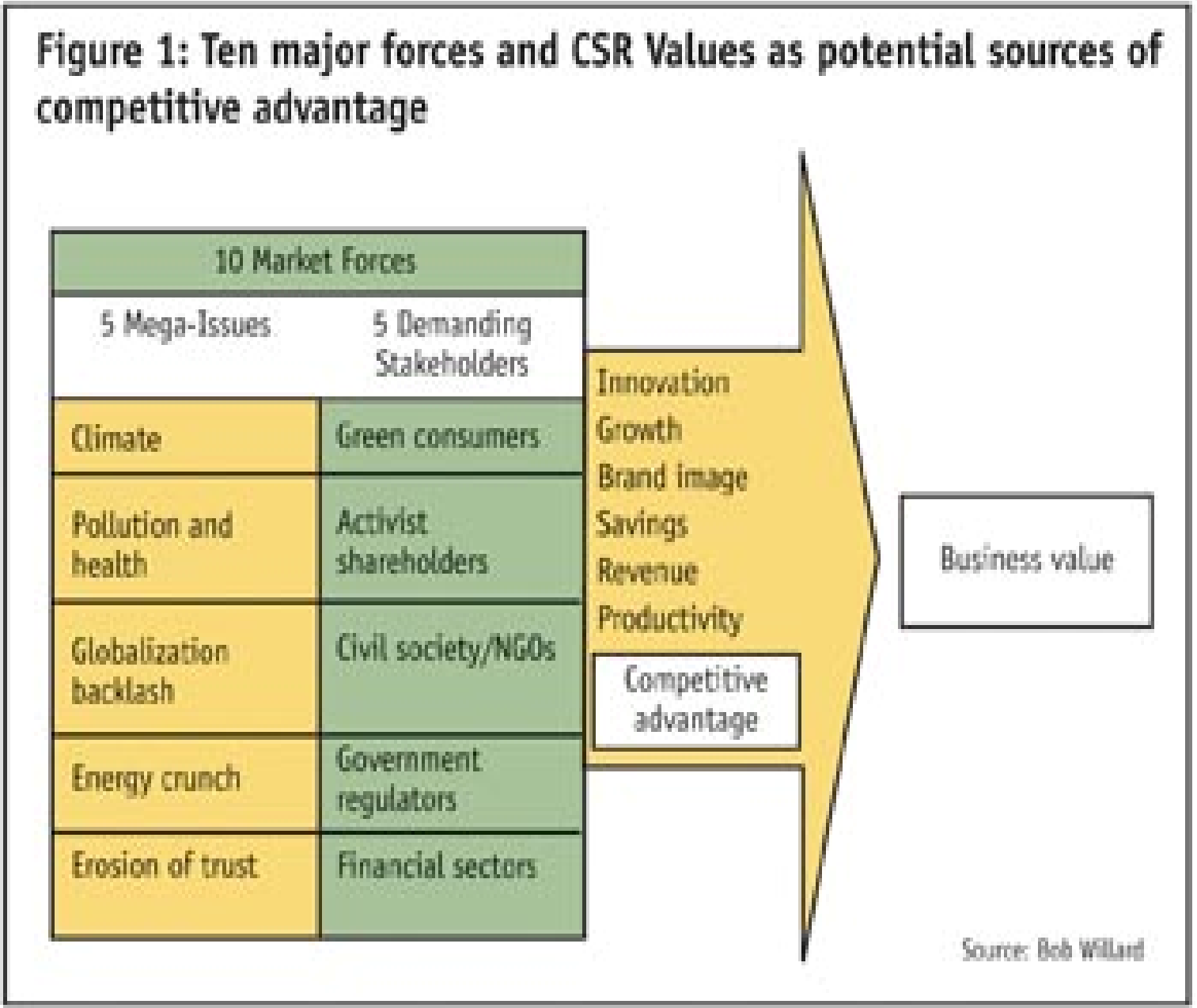

This shows which five issues affect businesses world wide the most, the 5 Mega-Issues. The next issue that highly influences a business is stakeholders, the 5 Demanding Stakeholders. The 5 Mega-Issues and the 5 Demanding Stakeholders form the 10 Market Forces. Those 10 Market Forces affect most businesses around the world; Thus CSR is used as an effective tool to gain a competitive advantage through which business value is created (Willard, 2005). 
Opinions about the necessity for CSR still diverge. According to a survey by McKinsey in 2005, as illustrated by Lawrence et al. (2008, p53), 16\% of 4.238 executives in 116 countries believe that the only responsibility of businesses is making profits, while obeying the laws and regulations. The main arguments against CSR engagement are that the costs created by CSR lower profits and economic efficiency, which penalises the shareholders. Furthermore, the higher costs through CSR engagement can lead to competitive disadvantages relative to competitors, who strictly act according to laws and regulations and therefore avoid additional costs.

It is certainly true that costs cannot be avoided in order to create valuable resources, as investments and working hours are needed to engage in CSR. On the other hand, the survey reveals that $84 \%$ of executives advance the view that CSR engagement offers diverse benefits and advantages. Worth mentioning in this context is that CSR engagement can reduce the demand for government regulations, which leads to more freedom of action for companies and society, which can be seen as a public good. Furthermore, other arguments have been mentioned which can be linked to the fact that intangible resources are created or improved by CSR activities, as will be discussed below.

Long-term profits for companies can be promoted by CSR. In this context the authors (Lawrence et al., 2008) argue, that donations to universities can be a source of attracting talented students, who aim at being employee of such a company. This can lead to better knowledge based understanding in a company, an important and intangible resource. Moreover, the authors (Lawrence et al., 2008) state that CSR engagement leads to increasing trust between a company and its stakeholders and improves the company's reputation, also an intangible resource. Another aspect regarding tangible resources, more precisely financial resources is the engagement in environmentally friendly practices, one pillar of the triple bottom line. In this context Lawrence et al. (2008, p52) explain that companies are often held responsible for environmental pollution that has been caused by its business activities and it is often cheaper to prevent this pollution instead of a subsequent correction. Therefore, costs can be saved in the long-term view by acting in an environmentally friendly way, and more financial resources are available. 
According to Lawrence et al. (2008, p. 103) who describe in the context of utilitarian reasoning, which is often referred to a cost-benefit analysis, that the determination of costs and benefits of ethical behaviour, to which CSR can be related, contains some difficulties. Lawrence et al., (2008) explain that an accurate measurement of costs and benefits is impossible. Even though economic costs and benefits can be expressed in monetary terms, other costs such as social costs or benefits are hardly precisely measurable. This argument can also be brought to the costs and benefits of CSR engagement, and furthermore to the difficulties of measuring intangible resources such as reputation or motivation precisely.

Despite differences in the clear definitions and opinions about CSR in the literature, the theorists mostly agree on certain aspects that are attached to CSR. First of all, engagement in CSR is always a voluntary process of companies. Moreover, engagement in CSR always aims at the satisfaction of the stakeholders' interests and needs. To achieve this objective, the stakeholder theory is a well-known management tool. Furthermore, the triple bottom line approach is a common term in the frame of CSR. These three issues are the focus of this section and will be discussed as they are the basis for the case study.

CSR is seen as a voluntary process of companies. In this context one can argue that the best form of engaging in CSR is the altruistic one, in that companies do not expect anything in return for their activities. Nevertheless the purpose of commercial companies is making profits and hence the management's interest in CSR can be increased by illustrating benefits in financial and non-financial terms that can arise from CSR engagement.

CSR engagement can also result in the attraction of a skilled workforce like highpotential students, increased staff motivation and improvement of staff attitude and loyalty towards the company. Branco \& Rodrigues (2006, p120) clarify that in this context a firm's financial performance is influenced by CSR engagement and mention the aspect of employees' attitude which can be improved through socially responsible employment practices. 
Moreover, diverse expectations of stakeholders put pressure on companies, as explained above, and ignoring those demands can lead to disadvantages. How these demands can be discovered and analysed will be explained in the following.

The importance of companies' resources will be elaborated on, in order to achieve a sustainable competitive advantage.

\subsection{CSR and the resource-based perspective}

In a resource-based context McWilliams et al. (2006, p. 3) as cited in Branco and Rodrigues (2006) argue that through effective control and manipulation of its resources a company is capable of achieving a sustainable competitive advantage. This is also assumed for the engagement in CSR, as has been examined earlier in this paper. It is important to link those topics to CSR literature, and the Resource Based View (RBV), and the influence of CSR engagement on tangible and intangible resources will be illustrated in the following.

Tangible resources can be, among others, assets, machinery and financial resources. Regarding those resources there is no denying that CSR engagement directly involves costs, emerging through investments for environmentally friendly assets, machinery and so on. This is also amplified by the arguments of managers against the engagement in CSR in the study of SHRM, illustrated in earlier on. Furthermore, the reporting and communication of CSR to the stakeholders requires manpower and, therefore, initially influences the financial performance negatively. On the other hand it is obvious that the financial resources, respectively the financial performance can be improved as well.

Branco and Rodrigues (2006) explain that on the one hand operating costs can be reduced by saving water and electricity, producing less waste through recycling and discovering inefficiencies in the company processes. In this context Hart (1995), who related the resource-based perspective to environmental strategies, explains that actions like pollution prevention and the minimisation of environmental consequences through product systems can contribute positively to the environmental and the financial performance. On the other hand the Branco and Rodrigues argue that not only costs for 
irresponsible environmental behaviour can be avoided, the company might also receive monetary grants for CSR initiatives.

Nevertheless, the determination of financial performance caused by CSR engagement is one of the main difficulties, because positive results can occur with a long delay or the benefits are not reliably measurable as is the case with most of the intangible resources.

However, as explained above, tangible and financial resources are not as competitive and less valuable as intangible ones, as they are easily imitable.

Environmentally friendly assets can be bought by any company at any time and, therefore, their value is of minor importance regarding competitive advantages.

In fact the more interesting resources concerning competitiveness are the intangible ones, including capabilities, categorized by Bamberg \& Wrona (1995) as organizational resources. Their creation or improvement is tremendously influenced by CSR engagement. If CSR activities are adjusted to the stakeholders' needs, the intangible resources become relevant for the market and therefore valuable, also in financial terms. Their value is also justified by inimitability and immobility, as becomes obvious in the following. Branco and Rodrigues (2006, p126) explain that relations to external stakeholders through a positive reputation caused by CSR outcomes and their disclosure can be achieved, and that the reputation of a company "... has been identified as one of the most important intangible resources that provide a firm sustainable competitive advantage. Several studies have found a positive relationship between a firm's reputation and its financial performance"

Weaknesses of the resource-based perspective:

The resource-based theory is met with criticism in the corresponding literature. Macharzina (1999, p. 204) points out that the resource-based theory as part of the concept of core competences is hardly convertible, because no concrete instructions for the implementation are given by the theorists. 
Wade \& Hulland (2004) argue that factors surrounding resources are ignored by assuming a simple existence of resources. The specification of concrete benefits resulting from key resources in the resource-based view is evaluated as being unsatisfactory by the authors. Moreover, the development, integration and release of resources are considered as being insufficiently explored in the literature. In this context, Paladino et al. (1996) state that it has not been proven empirically that the RBV leads to a sustainable competitive advantage.

Another aspect of criticism, mentioned by Macharzina (1999, p59), is that the equation of strategy and organizational uniqueness can be misleading, because the uniqueness of resources is not necessarily a guarantor for success. Further investigation in the field of development and maintenance of strategic resources is required.

By paraphrasing Eisenhardt and Martin (2000), Teece et al. (1997) and Volberba (1996), Wade and Hulland (2004, p131) explain the concept of dynamic capabilities, which is underlying a dynamic learning process as follows: “...[The concept of dynamic capabilities is] ...acting as a buffer between core resources and the changing business environment, dynamic resources help a firm adjust its resource mix and thereby maintain the sustainability of the firm's competitive advantage, which otherwise might be quickly eroded."

From this follows that in contrast to the resource-based perspective that puts emphasis on the selection of suitable resources, the concept of dynamic capabilities pursues the development and renewal of resources.

Even though the emphasis is put on the resource-based view in this thesis, this might be an approach of combining the market-based view with the resource-based view in a way that not only internal resources, but also the external environment is emphasised. This is important because resources only become valuable if they are of certain relevance for the market. This leads to the important task for the management to improve the company's resources in order to live up to the market's expectations. As Davies (2005, p37) explains, that a consideration of the RBV and the market-based view, respectively the organisation and the competitive environment is important for an adequate and successful strategy. 
Stakeholder-theory is an important aspect that will be translated to the strategy of CSR engagement in the following section. To relate the market-based view to CSR activities can be achieved by the stakeholder dialogue, as discussed in section above. In the context of CSR the stakeholders can be regarded as the market, whose expectations need to be satisfied. The aspect of the influence of CSR engagement on a company's resources and therefore its performance will be discussed more precisely in the following chapter.

\subsection{Stakeholder Theory}

One of the main concepts of CSR is stakeholder management, which basically means that companies should only be held accountable by the stakeholders. Other parties such as customers, employees, suppliers and partners hold the company responsible for their actions instead of regulations by governments (Knox et al., 2005).

Before introducing the stakeholder theory, it is important to define, what is meant by the term “stakeholder”. Post and Preston (2002), cited in Branco and Rodrigues (2006, p119) define stakeholders as 'individuals and constituencies that contribute, either voluntarily or involuntarily, to its wealth-creating capacity and activities, and who are therefore its potential beneficiaries and/or risk bearers'. Post and Preston (2002) further explain that voluntary stakeholders are those, who create and maintain relationships with a company by contributing to their activities, such as investors, employees, customers or market partners. Those stakeholders expect to improve their situation with this relationship. In contrast to that the involuntary stakeholders demand from the company to be able to maintain their situation in the same manner as if the company did not exist, because their relationship to the company has not been established at free will. Examples are people who suffer from external side effects like pollution due to companies activities. Branco and Rodrigues (2006, p119) further add that stakeholders of a company are "those who supply critical resources, place something of value at risk, and have sufficient power to affect its performance”.

According to Freeman et al., (2004, p7), stakeholder theory asks two main questions:

- What is the purpose of the firm? 
"This encourages managers to articulate the shared sense of the value they create, and what brings its core stakeholders together. This propels the firm forward and allows it to generate outstanding performance, determined both in terms of its purpose and marketplace financial metrics.”

- What responsibility does the management have to stakeholders?

“This pushes managers to articulate how they want to do business - specifically, what kinds of relationships they want and need to create with their stakeholders to deliver on their purpose”. (Freeman et al., 2004, p7)

Comparable with Post and Preston (2002), Lawrence et al. (2008) also classify the stakeholders in two groups, defining them as market stakeholders, consisting of employees, stockholders, creditors, suppliers, customers and distributors and nonmarket stakeholders, such as communities, governments, activist groups, general public, media and business support groups.

Another point of view is expressed by Wilson (2003) who argues that beyond the obvious stakeholders like shareholders and investors, employees, customers, and suppliers, no clear characteristics defining a stakeholder can be found among theorists. Beneath those stakeholders, who are in a relationship with the company as explained above, other authors argue that in principle everyone can be a stakeholder, if the effects of the companies' activities such as those that lead to global warming or changes in culture through marketing activities are taken into consideration. Wilson (2003) further adds that if stakeholders exist, also the term non-stakeholder must be definable, but currently there is still an ongoing discussion regarding this issue among theorists.

Comparable to the statement of Vordank (2007) that stakeholders' interests have to be taken into consideration in order to conduct successful business management, Lawrence et al. (2008, p16) add in the context of stakeholder engagement that research observed a shift in companies over four steps. The first shift is from inactive companies, who ignore stakeholders' interests, to reactive companies that act if forced by law, due to, e.g., environmentally negative incidents, but then in a defensive manner. The next shift was towards proactive companies who attempt to anticipate stakeholder needs. The last step is described as interactive companies who create a relationship with stakeholders, 
containing, trust, openness and respect. The last shift is known as stakeholder engagement, which can be achieved, for instance, with the aid of a stakeholder dialogue. This is important in the context of the stakeholder theory, because it can help to identify the stakeholders' interests.

Wilson (2003) states that in contrast to CSR, which is a philosophical concept, the stakeholder theory is a strategic management concept that was first introduced by Edward Freeman in 1984. The objective is to generate a competitive advantage by continuously improving the relationship to the company's stakeholders. The approach of this theory is identifying the stakeholders and developing a strategy for building a strong relationship that contains, trust, respect and cooperation. As shown earlier, the stakeholder dialogue can be an appropriate tool in this context. The challenge of implementation is the clash of opposed stakeholders' interests. Shareholders focus on high returns for their investments, whereas employees prefer good working conditions and customers aim to buy good quality at low prices and so on. Wilson (2003, p4) adds that "there is a general acknowledgement that the goals of economic stability, environmental protection, and social justice are common across many stakeholder groups.” This statement will be amplified by the triple bottom-line approach, discussed below.

The stakeholder theory provides business arguments for sustainable development of companies, such as that the achievement of a company's business objectives is supported by a strong relationship with stakeholders.

In this context Marcoux (2000) explains that in contrast to the shareholder orientation which was among others shaped by theorists like Milton Friedman, the stakeholder theory can be seen as an advancement of CSR.

The shareholder orientation argues that a company's management is primarily responsible to its investors, the shareholders, and social obligations are regulated by laws, limited to usual moral expectations and play a minor role in contrast to shareholder interests. 
On the other hand, Marcoux (2000) explains in a similar way to Wilson (2003) that the stakeholder theory aims at an improvement of the capitalist enterprise by taking not only shareholders, but all its stakeholders into consideration. This is expressed through an integration of all the stakeholders' needs into the business strategy and its policies on the same level than the shareholders' interests.

A differing point of view is expressed by Wilson (2003) who argues that beyond the obvious stakeholder like shareholders and investors, employees, customers, and suppliers, no clear characteristics defining a stakeholder can be found among theorists. Beneath those stakeholders, who are in a relationship with the company as explained above, other authors argue that in principle everyone can be a stakeholder, if the effects of the companies' activities such as those that lead to global warming or changes in culture through marketing activities are taken into consideration. Wilson (2003) further adds that if stakeholders exist, also the term non-stakeholder must be definable, but currently there is still an ongoing discussion regarding this issue among theorists.

Nevertheless Wilson (2003) adds that problems regarding the stakeholder theory can occur. The most important aspect in this context is that the implementation of this theory might be disadvantageous to shareholders, as the profits of a company are used to satisfy the needs of all other stakeholders as well therefore, holding shares for such a company might entail less profits at same risk. However, a debilitation of this argumentation will be illustrated later on in this thesis, as resources that are created or improved by CSR can result in competitive advantages.

\subsection{Triple Bottom Line}

The idea of the triple bottom line (TBL) emerged at around the same time Corporate Social Responsibility became important and the term was coined by John Elkington in 1994 (Henriques and Sardorsky, 1999). In the past, companies were solely focusing on one line, the financial bottom line. As long as a company was generating enough money to keep the shareholders happy everything seemed fine. These days, however, it becomes more and more important to keep the stakeholders happy, which include vendors, suppliers, the community, employees, environmental organisations and many 
more (Cheney, 2004). Because consumer awareness is on the rise due to the internet and availability of information on company data, many companies invest in CSR or TBL and gain financial benefits by doing so (Colbert et al., 2007).

The Three Pillars of TBL (Savitz and Weber, 2006)

People: Business practices should be fair to the labour community and the region in which the company operates in. Businesses that follow the triple bottom line (TBL) will provide fair wages towards their employees, fair working hours and fair annual leave and holidays. Furthermore, some of the generated profit over the year will be invested back towards their producers. Companies who use TBL are often found to support fair trading practices. TBL companies would, therefore, not use child labour or exploitative labour in third world countries.

Planet: There should be sustainable development, reducing waste and the company's carbon footprint. TBL companies would not produce toxic waste or non-recyclable products but would focus on a sustainable product-life-cycle. Furthermore, the company would try to reduce its carbon footprint by using the least amount of energy possible as well as only using renewable resources. Often those companies enjoy the benefits of their practices through higher sales and secured longer run strategies.

Profit: Consideration should be given to the lasting economic impact of a company on its environment. The company has to be seen as if it would be shared by everybody and is for the higher good of the community. This means that the profit generated by the company benefits the community in which it operates in by boosting the local economy and reinvesting in it. Oil companies in African and south American countries often do not follow TBL practices and therefore often anger the community they operate in because no profits or benefits from the turnover goes back to the community or people .

Figure 2 shows the connection between the three pillars of the TBL and CSR as well as all the affected 'parties' of the three pillars. 
Figure 2: From TBL to CSR (Adopted from Ernst \& Young and modified to the needs of this paper ${ }^{5}$ )

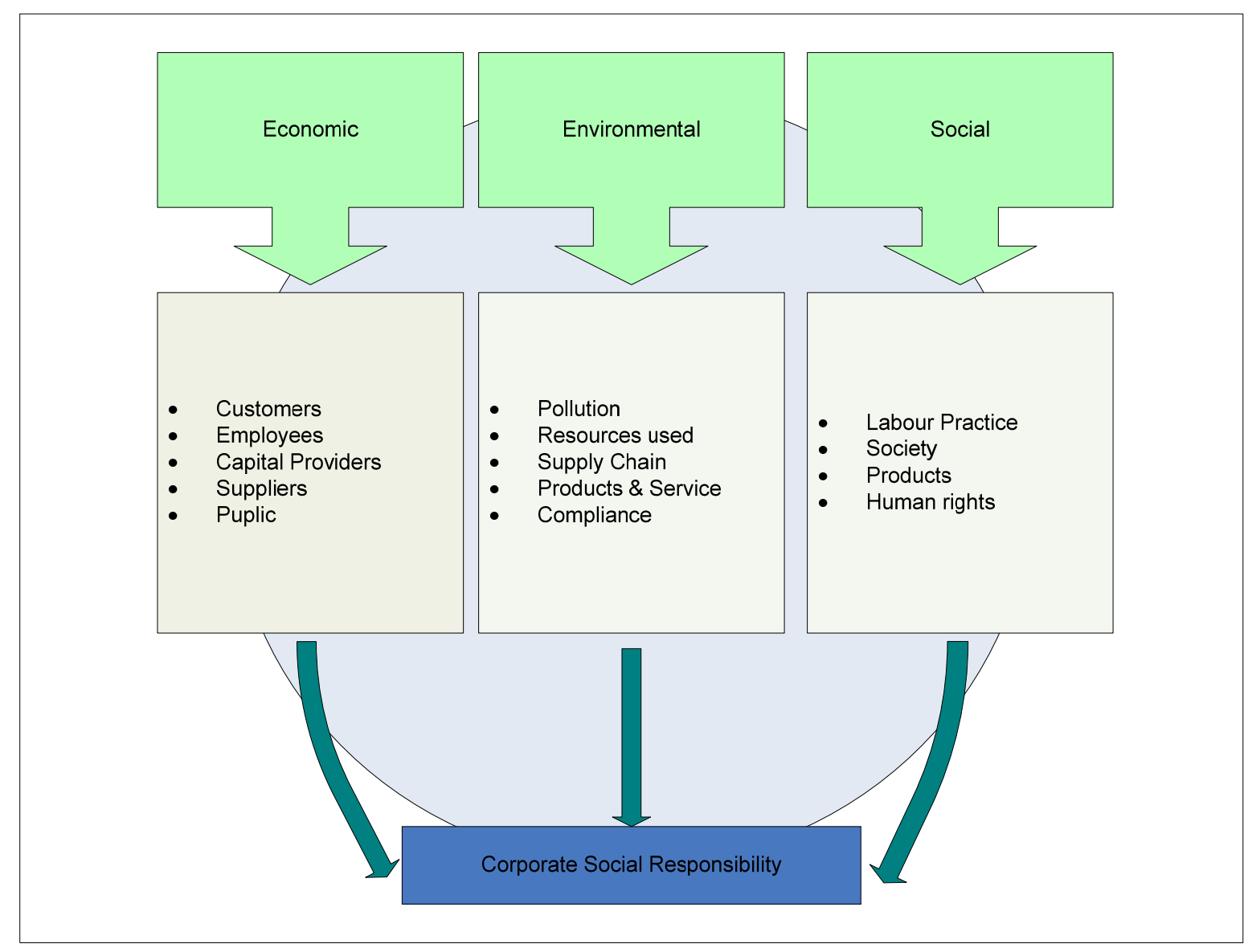

TBL practices are more complex and time demanding than the single-bottom-line (SBL) approach. In time, however, those companies adopting TBL practices will likely generate more profit, as well as gaining a secure long-lasting strategy. That is because those companies will be viewed more positively by consumers due to their good practices, as well as having fewer costs of changing the strategy when the environment starts to demand TBL practices due to dwindling resources and pressure from the public.

John Elkington was interviewed recently by Mother Jones on the topic of triple bottom line, its success rate, and big renowned companies who first tried to implement it (Interview $^{6}$, Mother Jones ${ }^{7}$ ). Elkington mentions most companies, for example, Shell, there is not always a $100 \%$ success rate when comes to sustainability, even if it is a big

\footnotetext{
${ }^{5}$ Source: http://www.ey.com/global/content.nsf/International/Home, accessed on the $10^{\text {th }}$ of May 2008.

${ }^{6}$ Interview: http://www.sustainability.com/aboutsustainability/news_article.asp?id=1595, accessed on the $10^{\text {th }}$ of May 2008.

${ }^{7}$ Mother Jones: http://www.sustainability.com/aboutsustainability/news_article.asp?id=1595, accessed on the $10^{\text {th }}$ of May 2008.
} 
“intelligent" company like Shell. Furthermore, Elkington mentions that many companies around the world, but especially in the US (United States), practice TBL but do not mention it because it has become part of their core value.

\subsection{Triple Bottom Line Reporting}

TBL as well as CSR reporting initiatives are increasing and $68 \%$ of the top 250 companies from the Fortune 500 index have embraced those or similar reporting initiatives (KPMG, 2005). Many of those companies compete against each other in order to get into the Dow Jones Sustainability Index, which rewards companies which are most sustainable in their sectors of the industry (Colbert et al., 2007).

The leading pioneers in environmental reporting, of which TBL reporting is a part, are: Norsk Hydro, BSO/Origin, Danish Steel Works, Monsanto and 3M (Elkington and Rowlands, 1999).

One of the most common definitions of triple bottom line reporting comes from John Elkington who originally coined the term (Elkington, 1999, p16):

I. "At its narrowest, the term triple bottom line is used as a framework for measuring and reporting corporate performance against economic, social and environmental parameters."

II. "At its broadest, the term is used to capture the whole set of values, issues and processes that companies must address in order to minimise any harm resulting from their activities and to create economic, social and environmental value. This involves being clear about the company's purpose and taking into consideration the needs of all the company's stakeholders."

A company's wellbeing is dependent on its stakeholder's perception of the firm and its practices. Therefore, good reporting systems should be put into place to inform stakeholders about the TBL and CSR practices in which the company engages (Deegan, 1999). In order to make sure that suppliers and all other entities affecting the company act in a sustainable, environmental friendly way, meetings should be held between all stakeholders to integrate everyone into the effort of TBL and CSR. 
A critical paper by McDonough and Braungart, (2002); Milne et al., (2003) points out that triple-bottom-line reporting and/or sustainable reporting initiatives are increasing but that they might not be efficient enough. The New Zealand Business Council for Sustainable Development's (NZBCSD) focus on sustainability and sustainable development is firmly rooted in ecological modernisation (environmental protection and resource preservation through means of eco-efficiency and stakeholder commitment). This might not be enough, though, and it might allow companies to continue in their industrial capitalism.

Reporting systems like the Global Reporting Initiative (GRI) release guidelines on the triple bottom line for voluntary use. Many companies have realised that being environmental responsible can add value to the company and can even be used for 'green marketing'. Those companies create reports on the triple bottom line following the GRI guidelines, which are checked by the GRI and released to the stakeholders for information (Colman, 2004).

The GRI has established the world's most accepted sustainability reporting framework and is determent to further improve its guidelines as well as increase its application world wide $\left(\mathrm{GRI}^{8}\right)$. The GRI reporting initiative developed the principals and indicators for companies world wide to report on their economic, environmental, and social performance. Today more than 1500 companies have voluntarily adopted the GRI guidelines and it has become the de facto global standard for reporting.

Some critics argue that the triple-bottom-line reporting and GRI standards will not hold up to their initial purpose due to a wrong focus in their guidelines. The following citation is a concluding remark reviewing sustainable reporting standards: "Yet the GRI with its attendant TBL focus seems unlikely to promote the kind of ecological thinking and literacy, and so change, we see as so necessary. It is not that the GRI (and TBL) does not promote improvements in business reporting and arguably behaviour, especially stakeholder involvement and accountability, it is that such initiatives fail to confront head on that which UNEP/Sustainability recognised over a decade ago,

\footnotetext{
${ }^{8}$ GRI: http://www.globalreporting.org/AboutGRI/WhatWeDo/ , accessed on the $13^{\text {th }}$ of July 2008.
} 
namely: "some products, processes and even entire industries may prove to be unsustainable - even when run efficiently...” (Milne et al., 2003, p9)

\subsection{Triple Bottom Line Reporting in New Zealand}

Triple-bottom-line reporting commenced in 2002 when the Parliamentary Commissioner for the Environment published his report Creating Our Future. Since then, reporting on TBL, Sustainable Development and CSR has improved in private and government sectors.

The New Zealand Business Council for Sustainable Development is one of the main promoters within the country, and has developed a Business Guide to Sustainable Development Reporting. This guide was developed for New Zealand businesses which are interested in starting their TBL reporting (Milne et al., 2003).

The Ministry for the Environment set up two pilot groups in 2002 to see if triple bottom line reporting in New Zealand adds value to the public sector. In addition, workshops were set up for local government departments which were interested in learning more about TBL reporting issues. The study found that triple-bottom-line reporting can add value to the public sector but a more precise business case has to be made in order to see its real value. The study further concluded that there might be three main groups of benefactors from using TBL reporting:

a) the broad stakeholder audience, b) the government and c) the public sector agency itself (Ministry for the Environment, 2006).

Overall, reporting initiatives in New Zealand have improved slightly since 2002, especially in the area of triple-bottom-line reporting, but in comparison with European reporting initiatives it still lags around five years behind (Milne et al., 2001). A greater understanding of the sustainability context and how it relates to business needs to be established in New Zealand (Griffiths, 2006).

Luckman (2006) argues that TBL reporting initiatives/sustainability reporting suffer from uncertainty about the purpose and the content of the reports. Furthermore, Luckman doubts the impact and effectiveness of reporting standards today. Instead, 
Luckman argues in favour of the accreditation system KiwiGrow ${ }^{9}$. KiwiGrow is an accreditation system for management services for sustainable development reporting which is based on a newer universal model of ecosystem well being (Luckman, 2006).

\subsection{Performance Measurement (PM) and Sustainability Performance Indicators (SPI)}

The need to measure performance of strategies has been widely recorded in the literature (Dyson, 2000). The same can be expected for measuring sustainability strategies. In order to make companies and managers aware of the benefits of sustainable strategies measurement tools have to be put into place to measure the benefits of those strategies to make them worth-wile.

Larcker (2003) suggests that performance measurement is used to:

- Help direct the allocation of resources;

- Assess and communicate progress towards strategic objectives; and

- Evaluate managerial performance

Further literature suggests that in order to successfully measure performance a high amount of leadership commitment is needed in order to be successful (Franceschini et al., $2007^{10}$ ).

In order to implement measurement tools in any company, it is of upper-most importance to communicate the 'role' and 'aim' of those indicators to management and staff alike to create a certain amount of understanding within the company (Parmenter ${ }^{11}$, 2007).

\footnotetext{
${ }^{9}$ KiwiGrow: http://www.creativedecisions.co.nz/kiwigrow/understanding.cfm , accessed on the $13^{\text {th }}$ of July 2008.

${ }^{10}$ Franceschini et al., (2007) and Parmenter (2007) have been chosen as key references for this chapter because they both have written important books in the field of measurement. Franceschini has applied measurement systems to various fields and proven that they are applicable for various sectors. Recently paper the measurement system was successfully applied for online diagnostics for mobile phone companies (Franceschini, 2008). The energy sector is obviously different but I am positive that the measurement system can be successfully applied to this industry as well. Parmenter was chosen because he is a renowned expert for KPIs and he has also written papers within the New Zealand context (Parmenter, 2002). Also see http://davidparmenter.com for more information.

${ }^{11}$ See footnote 10
} 
In the following section I will elaborate on the different types of measurement, opportunities, constraints and implementation options for companies in order to measure sustainability.

Another management tool to measure sustainability is the sustainability performance indicators or SPIs.

Sustainability performance indicators ${ }^{12}$ (SPI)

SPIs can help companies to condense their large amount of environmental, economic and social data into a limited amount of key indicators, which makes it easier for them to measure their performance and to plan ahead for the future. SPI indicators cover three areas of information the economic performance, social performance and environmental performance.

SPIs are divided into three main indicators:

- Economic Performance Indicators

- Social Performance Indicators

- Environmental Performance Indicators

The sustainability performance indicators are part of the GRI reporting initiative, and more information on how these indicators work can be found at http://www.globalreporting.org/home .

\subsubsection{Types of PM indicators}

Before discussion of the different types of indicators it is necessary to define what we want to measure and why we want to measure it.

\footnotetext{
${ }^{12}$ Source: http://www.dantes.info/Tools\&Methods/Environmentalinformation/enviro_info_spi.html , accessed on the $15^{\text {th }}$ of July 2008.
} 
1. What we want to measure: In this thesis I want to measure the results of implementing sustainable strategies.

2. Why we want to measure: Measuring the outcome of a new strategy is of utmost priority in order to see if the new strategy was worthwhile. Furthermore, managers will want to see financial numbers in order to be convinced of the importance and value of a new strategic approach.

There are numerous research papers on measurement indicators, of which two recent which three different kinds of indicators are discussed:

1. Initial Indictors focuses on the resources used in a process and are aimed at improving the management of projects; they are also called structure indicators.

2. Intermediate Indicators focus on the condition of a process and whether or not it can be improved; they are also called process indicators.

3. Financial Indicators focus on the project's outcome and indicate whether the targets have been met. Financial indicators are thought of as the most important indicators; they are also called result indicators.

The second is by D. Parmenter (2007) and also elaborates on three different kinds of indicators.

1. Key Result Indicators (KRIs) tell you how you or a certain process has done in certain circumstances. They are more orientated towards the past because they measure over months and quarters. An example could be the change of 'Employee Satisfaction' after the implication of sustainable strategies after six months.

2. Performance Indicators (PIs) more or less tell the company what to do and each PI should be standardised to a certain measurement so that they don not reappear and measure the same process. PIs can measure basically any event either in the past, future or present and they complement KPIs. A PI could be, for example, 'the number of employees participating in courses offered by the company'. 
3. Key Performance Indicators (KPIs) are probably the most important indicators that show you what to do if you want to change a process dramatically. KPIs monitor processes that are most vital to the future success of a company. In comparison to PIs, they are monitored on a daily basis to track any important change.

KPIs are considered the most important indictors. KPIs are described as non-monetary operating figures, an addition to financial business ratios. If implemented correctly the KPIs should be able to show both the long-and short-term opportunities of a business (Jung, 2007).

KPIs possess the following seven attributes (Parmenter, 2007):

- Non-financial measures (not currencies)

- $\quad$ Measured frequently (24/7)

- Acted on by the CEO and senior management team

- Understanding of the measure and the corrective action required by all staff

- Ties responsibility to the individual/team

- Significant effect (affects most critical success factors and more than one Balanced Score Card [BSC] perspective).

- Positive effect on other performance measures

Most companies that use performance measurement tools use a mixture of the above indicators (Parmenter, 2007).

Weaknesses of performance measurement systems in this context

There are two important aspects that performance measures will not show (Franceschini et al., 2007):

- The cause and effect of outcomes are not easily established. Outcomes can be affected by many events outside control. Another conditioning element is time difference between cause and effect.

- Poor results do not necessarily point out poor execution. If the aims of any performance measure are not met, the reason for this is not automatically 
provided. It just becomes obvious that further investigation is required. Possible reasons might be an overestimation about performances that can be reached or an alteration of the priorities.

These measurement systems possess one important weakness, as revealed by Diefenbach and Vordank (2005) and explained by Vordank (2007, p96):

1. Measurement and assessment systems are, at most, able to express correlative connections between particular resources and their influence on economic performance. Causal relations are not yet validly ascertainable.

\subsubsection{Opportunities and constraints of implementing PM indicators}

Indicators normally provide three basic functions: control, communication and improvement. Control is used by managers and employees to measure the performance of their tasks' resources. Moreover, indicators communicate performance to all stakeholders of a firm. Other added indicators support the improvement of performance because they identify the differences between the actual and target state. For evaluation processes and allocating resources, performance indicators are essential in order for those processes to run smoothly therefore, it is vital to select and analyse indicators carefully before use (Franceschini et al., 2007).

Jung (2007) and Franceschini et al. (2007) point out that there can be difficulties regarding the implementation of performance measurement systems in this context. Those implementation mistakes have to be avoided if a firm wants to implement KPIs successfully. Jung (2007) and Franceschini et al. (2007) point out that if certain data are inadequate or too much amassed, data might be ignored or inadequately used.

Furthermore, if the KPIs are compiled in an unstructured way, management can lose interest, and so-called 'data cemeteries' arise. Therefore, it is important that the collected data lead to successful measurement of the firm, correspondingly by the department or service unit. 
Another important point is the frequency of progress measurement. Too many measurements can lead to higher costs, but minimal measurement can create potential problems because the performance cannot be recognized early enough to respond accordingly.

Moreover, it is very important that KPIs are designed with the manager of each department to be measured and that the reasons for measurement are communicated to the employees of those departments. This is crucial because otherwise the acceptance of measurement from the department might be lacking, and important information to create the KPIs might not be taken into account. Furthermore, the importance of sufficiently balancing the performances to be measured will be explained below with the help of the Balanced Score Card.

\subsubsection{Developing and implementing KPIs}

According to Jung (2007) the implementation of KPIs is a very sensitive undertaking. First of all the right business has to be chosen which indicates the right 'drivers' of their business. The next step is to gather useful performance data with respect to the objectives of the company. In order to implement KPIs successfully, a systematic approach is recommended. As mentioned earlier on, it is of utmost importance to have insider knowledge of each department for which KPIs are developed. In order to gain that knowledge KPIs should be developed in partnership with the managers and experts of each department.

Franceschini et al. (2007) mention every structured organisation consists of several subunits or sub-processes, which influence a company's target through different means. This statement is consistent with Jung. (2007) who argue that in the context of KPI development it is useful to apply a practically approved procedure for internal service units, which is in agreement with the demand of a structured, systematic and cooperative advancement of controllers and internal experts. This is called the threestage approach.

Firstly, primary and sub-processes should be identified. In the first stage the help of an internal expert is very important because expert knowledge of the affected unit is very 
important. Each process should be combined with the name of the person responsible in order to trace back all outcomes of the measurement (Figure 3). For example: 'A CEO can call a member of staff to ask why a certain process is late or done in a certain way'.

\section{Figure 3: Primary and Sub-processes}

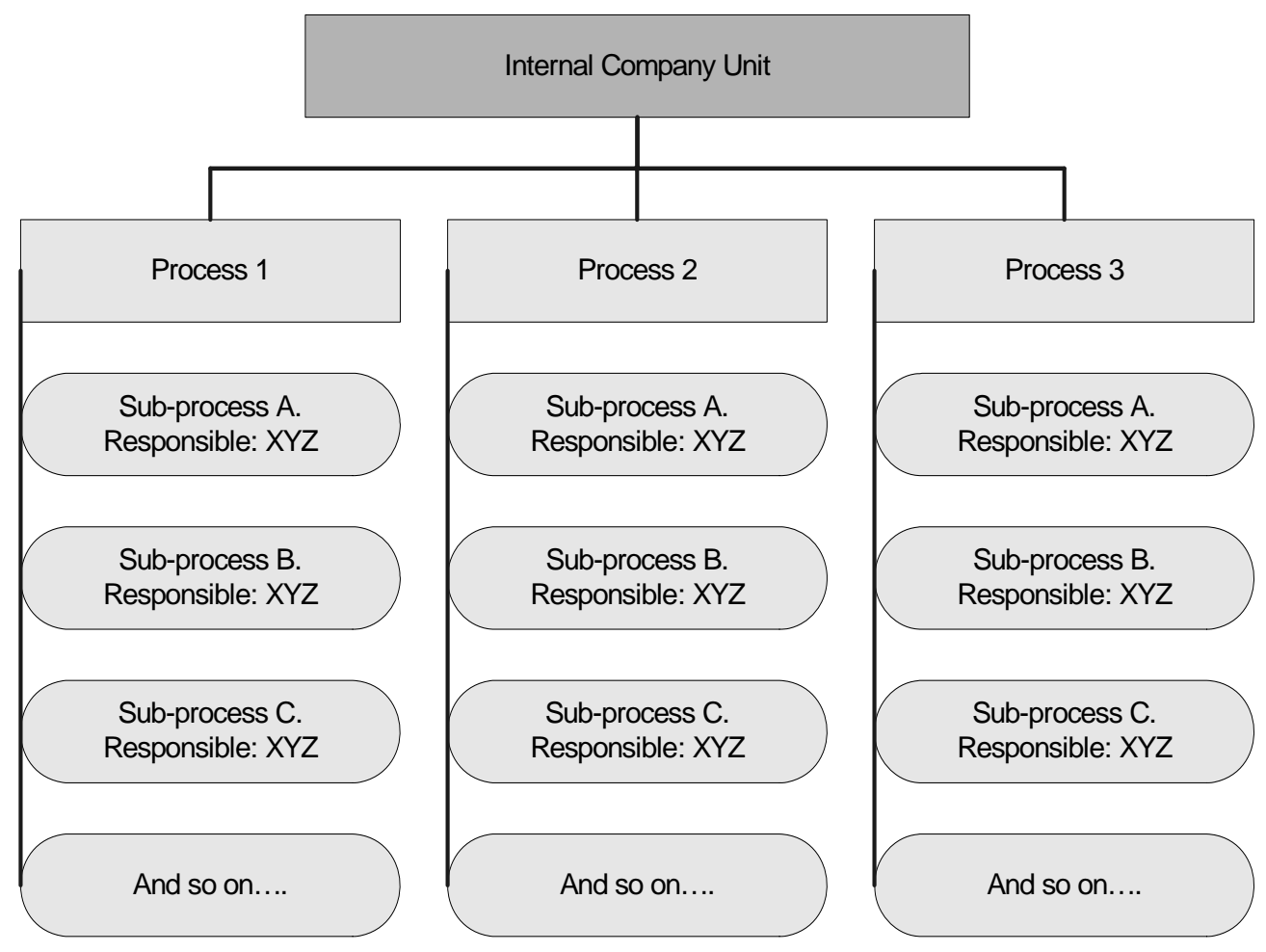

The second step consists of developing the essential success drivers for each subprocess. It is very important that the important leverages are illustrated and causally connected with the sub-processes.

The third step involves developing the most important KPI leverages. Franceschini et al., (2007) state that the KPIs central criterion for quality is their ability to measure the success or failure in a sub-process.

At the same time the KPIs have to be set up with respect to their efficiency. There might be figures that represent a more appropriate description of an activity, but they can only be collected with disproportionally more effort and are not available quickly enough. It is important to preserve equilibrium of effort and benefit, which is possible through the 
inclusion of already existing or easily ascertainable figures besides newly implemented figures in the KPI concept.

Figure 4: Sub-processes and KPIs

\begin{tabular}{|l|l|l|}
\hline Responsibilities & Sub-process & KPI's \\
\hline Service unit X & $>$ Sub-process A & $>$ KPI 1 \\
& $>\mathrm{KPI} \mathrm{2}$ \\
\cline { 2 - 3 } & $>$ Sub-process B & $>\mathrm{KPI} 1$ \\
\hline Service unit Y & $>$ Sub-process A & $>\mathrm{KPI} 1$ \\
& $>\mathrm{KPI} 2$ \\
& $>\mathrm{KPI} \mathrm{3}$ \\
& & $>\mathrm{KPI} 4$ \\
\cline { 2 - 3 } & $>$ Sub-process B & $>\mathrm{KPI} 1$ \\
& $>\mathrm{KPI} 2$ \\
\hline Service unit Z & $>$ Sub-process A & $>\mathrm{KPI} 1$ \\
& & $>\mathrm{KPI} 2$ \\
\cline { 2 - 3 } & $>$ Sub-process B & $>\mathrm{KPI} 1$ \\
\cline { 2 - 3 } & $>$ Sub-process C & $>\mathrm{KPI} 1$ \\
\hline
\end{tabular}

Following the selection of KPIs and their adjustment with the help of management, the KPIs have to be implemented into the controlling processes, especially into the reporting system (Figure 4). Every affected department should receive records about their responsibilities. Furthermore, management should receive an overview through a selection of the most successful and most important KPIs.

Paramenter (2002) listed in getting started with a winning set of KPIs:

1. Call in an external expert who helps to gather information and who has access to a performance indicator database.

2. Report on late projects.

3. Deliver a presentation to your CEO and management team in order to get highlevel support for the project.

4. Develop your Business Score Card (BSC) with at least five to six result indicators. 


\subsection{Sustainability tools}

Here I will take a closer look at a number of sustainability tools (ST) which could be used as a means to embrace corporate sustainability. I will focus on three sustainability tools only and will give reasons as to why each tool was chosen; I acknowledge that there are many more tools which could be used to measure sustainability. Borri and Boccaletti (1996, p1,3) point out that being equipped with the necessary tools is of utter importance: 'When an industry voluntarily decides to pursue a continuous improvement programme with regard to its environmental issues, it must at the same time equip itself with the necessary tools to manage the complexity of the matter'.

\subsubsection{ISO 14001, Environmental Management System (EMS)}

Since ISO 14001 was established in 1996 it has been recognized world wide as one of the best environmental management systems (Berthelot and Coulmont, 2004).

ISO 14001 was established in 1996 by the International Organisation for Standardisation in order to provide a standard and tool for companies to incorporate environmental management systems (Hemenway and Hale, 1996).

Any company can implement ISO 14001 into their company regardless of size or industry. Surveys have shown that generally larger corporations use the ISO 14001 standard, which could be due to the paperwork and effort involved to fulfil the standard (Berthelot \& Coulmont, 2004).

ISO 14001 consists of five principles (Jayathirtha, 2001):

1. Commitment and Policy: A company should focus on what needs to be done and focus or create environmental management systems. Once implemented, the systems should be defined and stated in a policy.

2. Planning: A plan should be defined and put into action to guarantee the company's 'best' commitment to the new policy. 
3. Implementation: In order for the new policy to be integrated in the best possible manner, support mechanisms and capabilities should be developed.

4. Measurement and evaluation: The environmental performance of a company should be measured and evaluated.

5. Review and Improvement: A company's environmental performance should be constantly improved in order to improve the overall environmental performance.

Committing to the ISO 14001 standard has to be sincere, because it requires a lot of paperwork because to it is monitored, and reports have to be written explaining each step of implementing and ‘sticking with’ the ISO 14001.

Many companies have moved beyond ISO 14001 towards Total Quality Environmental Management (TQEM). Many companies use the ISO 14001 standard as a baseline and move to embrace TQEM as the next 'natural' step (Hemenway and Hale, 1996). The following step-by-step approach by Jayathirtha offers a possible approach to environmental thinking.

Figure 5: Step-by-step approach to ingrain environmental thinking (Adopted from Jayathirtha, 2002)

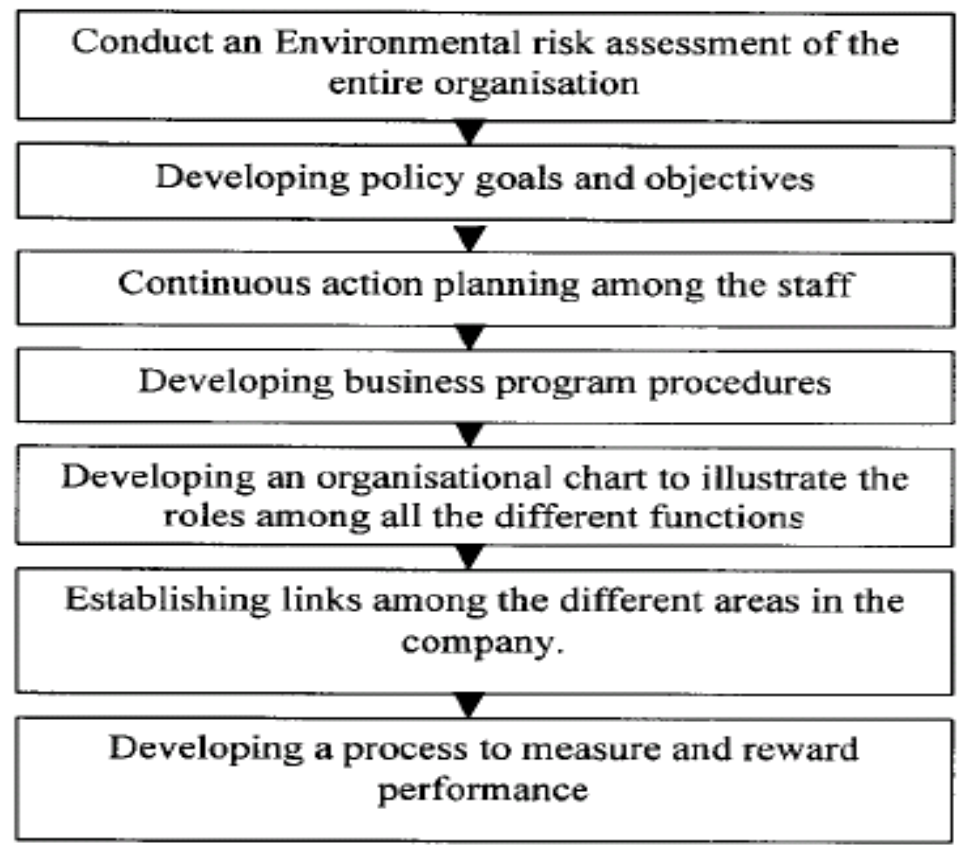




\subsubsection{Total Quality Environmental Management (TQEM)}

TQEM was chosen as the second sustainability tool because the Global Environmental Management Initiative (GEMI ${ }^{13}$ ) has embraced TQEM as one of the most efficient and successful sustainability tools (Kirschner, 1992).

TQEM is very similar to Total Quality Management $\left(\mathrm{TQM}^{14}\right)$, but focuses on environmental problems. Like TQM, it tries to optimise the ecological performance of the whole company from a total systems approach. A life-cycle-analysis $\left(\mathrm{LCA}^{15}\right)$ is used in order to understand the links between the organisation and its environment. This enables the organisation to understand the ecological costs of its inputs, outputs and throughputs of their products.

TQEM encourages the company to use renewable energy, to produce ecologically 'friendly' products by redesigning and to take recycling issues into account. It aims to use ecologically sensitive purchasing methods, such as fair trade in order to help their producers. TQEM generally tries to minimize waste, reduce costs, eliminate emissions and accidents.

Jayathirtha (2001) listed the aims of TQEM as:

1. Reduce waste production

2. Reduce resource depletion

3. Reduce environmental pollution and destruction

4. Product redesigning, to use renewable resources and produce the least amount of waste

5. Minimise impact on the environment with new product development

6. Promote environmental awareness within the company and community.

\footnotetext{
${ }^{13}$ GEMI: for more information about GEMI please see http://www.gemi.org/AboutGEMI.aspx , accessed on the 20th of July 2008.

14 “Total Quality Management (TQM) is a comprehensive and structured approach to organizational management that seeks to improve the quality of products and services through ongoing refinements in response to continuous feedback". Source: http://searchcio.techtarget.com/sDefinition/0, sid182_gci799434,00.html, accessed on the $20^{\text {th }}$ of July 2008.

${ }^{15}$ LCA: "Life cycle assessment determines the environmental impacts of products, processes or services, through production, usage, and disposal”. Source: http://www.gdrc.org/uem/lca/lca-define.html , accessed on the 21st of Ju;y 2008.
} 
Figure 7 is a step-by-step approach to implementation of TQEM, adopted from Jayathirtha (2001).

Figure 6: Implementing TQEM (adapted from Jayathirtha, 2002)

\begin{tabular}{|c|}
\hline Commit to Environmental Management \\
\hline$\nabla$ \\
\hline Establish an Environmental Management policy \\
\hline $\boldsymbol{\nabla}$ \\
\hline Provide Environmental Management Leadership \\
\hline $\boldsymbol{\nabla}$ \\
\hline Train people in the area of Waste / Kaizen / 7 QC / SGA \\
\hline$\nabla$ \\
\hline Adopt ISO 14000 series of standards \\
\hline$\nabla$ \\
\hline $\begin{array}{l}\text { Empower the Environmental Management Team } \\
\text { (Continuous Process Improvement, Benchmarking) }\end{array}$ \\
\hline $\boldsymbol{\gamma}$ \\
\hline $\begin{array}{l}\text { Develop and implement environmental management procedures } \\
\text { and instructions }\end{array}$ \\
\hline$\nabla$ \\
\hline $\begin{array}{l}\text { Control Environmental management processes, practices and } \\
\text { documents }\end{array}$ \\
\hline$\nabla$ \\
\hline Maintain Environmental Management Information and records \\
\hline $\boldsymbol{\gamma}$ \\
\hline $\begin{array}{l}\text { Measure Monitor and Audit the Environmental Management } \\
\text { Svstem }\end{array}$ \\
\hline $\boldsymbol{\gamma}$ \\
\hline Review and improve Environmental Management Systems \\
\hline $\boldsymbol{\nabla}$ \\
\hline Communicate with all stakeholders \\
\hline $\boldsymbol{\gamma}$ \\
\hline Practice sustainable development \\
\hline
\end{tabular}




\subsubsection{Sustainability Balanced Scorecard (SBSC)}

I chose the SBSC as the third important sustainability tool because of the world-wide acceptance and usage of the Balanced Score Card. Furthermore, according to Figge et al., (2002), the Balanced Score Card helps to overcomes shortcoming of conventional environmental and social management systems (Figge et al., 2002).

The Balanced Score Card (BSC) was first created in 1992 by Kaplan and Norton (1992). The original BSC was later further developed in 1997 and 2001 in order to incorporate the complex market of today with multinational companies and the Internet. The new BSC incorporates four main perspectives (Figure 8; Kaplan and Norton, 1997):

- The financial perspective, which looks at improving the financial perspective of a company.

- The customer perspective, which looks at the target segment of customers in which it competes.

- The internal process perspective, which looks at the internal business processes and how they could be improved.

- The learning and growth perspective, which looks at the infrastructure which is needed in order to full fill the company's target goals.

Figure 7: Balanced Score Card (BSC) (adapted from Kaplan and Norton, 1997)

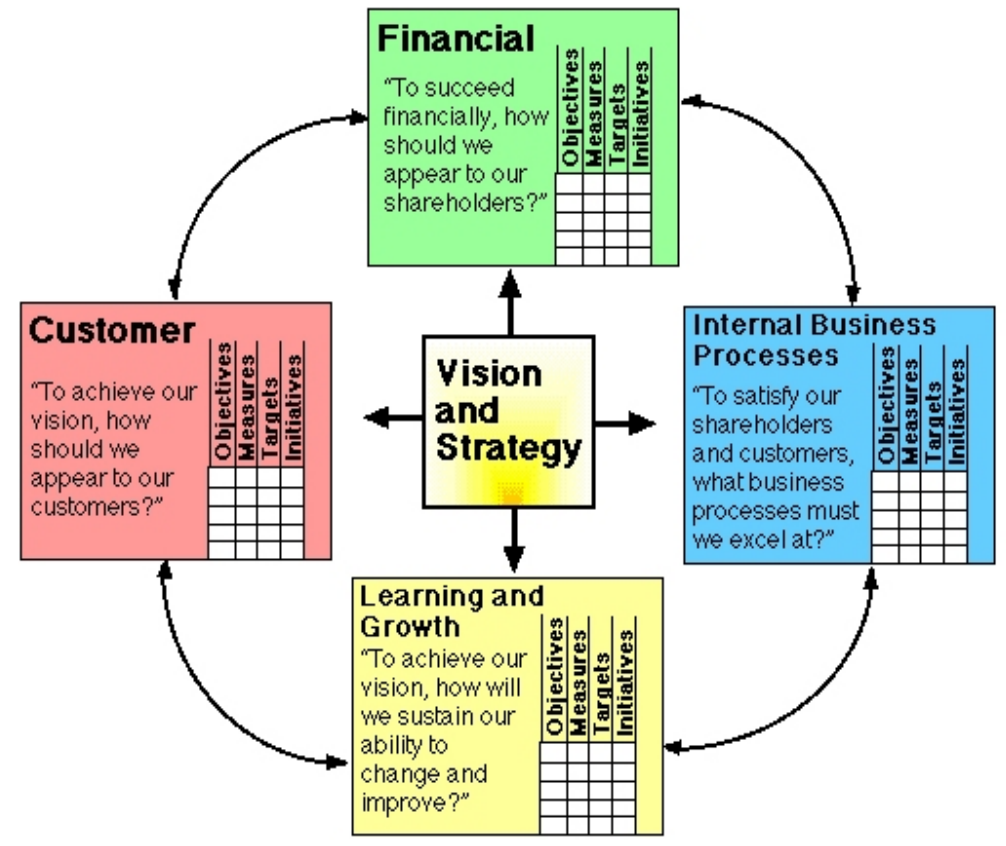


Because the BSC looks at all aspects of a company, it is well suited to ingrain sustainability into any given company. The SBSC (Sustainable Balanced Score Card) aims to simultaneously improve the three dimensions of sustainability: ecological, social and economic goals. To do so, the three dimensions can be applied to the four perspectives, until all four perspectives are analysed. Now steps can be taken in order to improve the four main perspectives of a company in order to become more sustainable (Figure 9; Figge et al., 2002).

\section{Figure 8: Sustainability BSC}

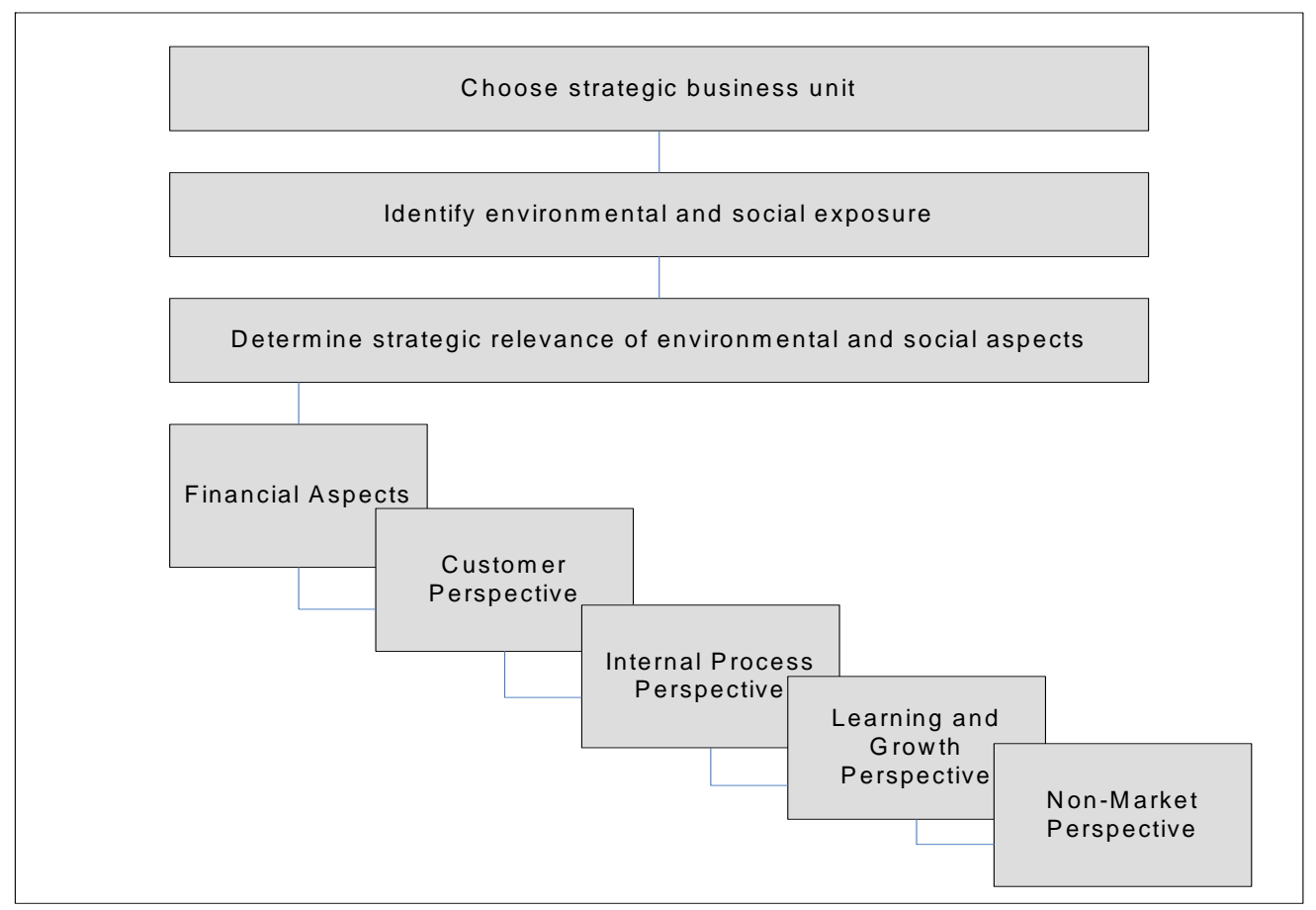

Due to the hierarchical structure of the BSC, all business activities are linked together in order to successfully implement a new business strategy. In the case of sustainability as a 'new' strategy, this means that all three dimensions of sustainability (the three dimensions of TBL), ecological, social and economic can be successfully combined into one sustainability tool, the SBSC (Figge et al., 2002).

Combining those three dimensions into the BSC offers three advantages (Figge et al., 2002):

1. If sustainability is properly incorporated and backed up by management, it is not endangered by an economic crisis, because sustainability will become part of the 
company's core strategy which will not abandoned in times of financial misfortune. In most businesses, strategies which are not directly tied to the financial success of a company will be cut off. Economically sound management of sustainability, on the other hand, will maintain to their commitment of sustainability at all times.

2. Companies which practice sustainable strategies use their engagement often as a marketing tool which will send a positive message out to consumers and other companies, making it more likely that they, too, take sustainable practices more seriously. Thus companies which first and successfully embrace sustainable practices, serve as a 'role-models' for the rest of the industry, which gets more companies to embrace similar strategies.

3. If BSC is implemented correctly, businesses incorporate all three aspects of sustainability into their strategy. Including all three dimensions (economic, social and economic) is of primary importance because these three dimensions have a complementary relationship to each other. Therefore, it makes sense to implement all three dimensions of sustainability simultaneously to get the best possible result out of the effort.

Sustainability can either be incorporated into the four existing dimensions of the BSC, or another two dimensions can be added as proposed by Parmenter (2007). If the existing BSC is used, management has to only integrate a sustainable dimension into each dimension of the BSC. Parmenter (2007), on the other hand, proposes to add two more dimensions to the BSC which then would include all three pillars of the triple bottom line. Furthermore, Parmenter (2007) states that the additional two dimensions were underestimated by Kaplan and Norton (1997). For example the dimension "staff satisfaction" has been underestimated. As has been mentioned before, employee satisfaction can create or improve important intangible resources. As far as the environment/community perspective is concerned, Parmenter (2007) explains that a greater customer satisfaction, more positive customer perceptions and even increased sales can be the result of such an engagement. It helps the company becoming an employer of choice. 
Figure 9: Six dimensions of the BSC (from Parmenter, 2007)

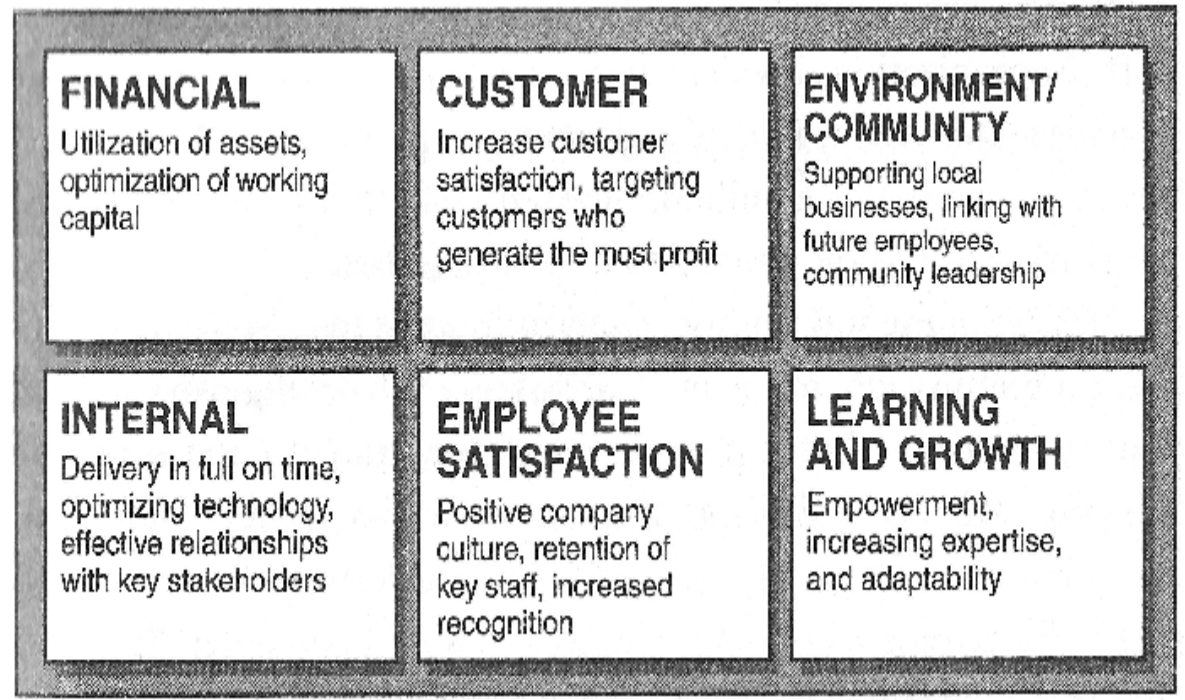

The enlarged BSC by Parmenter (2007) has two added dimensions, Environment/Community and Learning and Growth (Figure 10). Those two dimensions can simply be added to the existing BSC in any business to integrate sustainability issues into company. The BSC is the ideal tool for it because it can also measure nonmonetary factors, the so-called soft factors. Soft factors are, for example, intellectual capital, knowledge creation, customer orientation and learning perspectives. Many sustainable factors fall into this category and are therefore best managed and monitored by a BSC/SBSC (Figge et al., 2002).

\subsection{Strategic Sustainability Framework (SSF)}

This framework is the result of the literature review of this thesis as well as the problem statement of implementing sustainability into organisations (Figure 18). Each important component of every chapter is incorporated in this framework, leading towards a successful implementation of sustainable practices within organisations. Each step of the framework links back to the literature reviewed previously. 


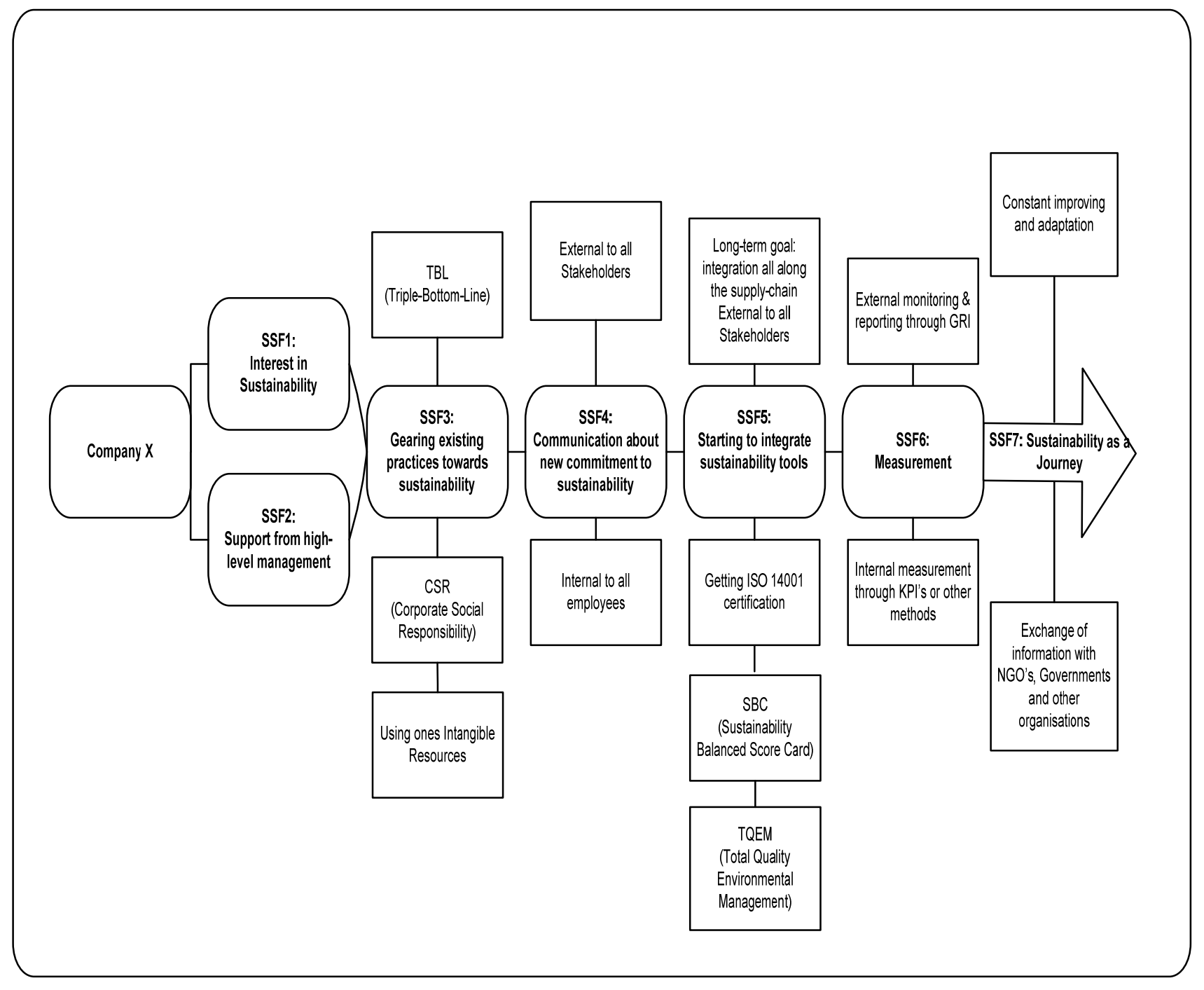

Step-by-Step explanation of the Framework:

Company $\mathrm{X}$ has to be chosen.

SSF1: Company $\mathrm{X}$ has to be genuinely interested in integrating sustainability into their core business. (Links to overall sustainability literature; without genuine interest a successful implementation might fail)

SSF2: The company needs high level management support for the integration of sustainability. This is very important in order for the integration to be successful. Integrating sustainability into the core business of an organisation calls for strong 
support from top level management due to costs and to make sure that it will be taken seriously. (Links to PM literature (Franceschini et al., 2007))

SSF3: Gearing existing practices towards sustainability. In order to make the integration of sustainability easier, existing practices like CSR, TBL and intangible resources can be used to make the integration easier. Especially CSR and TBL are fairly easy geared towards sustainability because they have a very holistic view of the business environment. (Links Sustainability tools)

SSF4: Communication about new commitment to sustainability. This is another very important step because the whole company has to work together in the attempt to integrate sustainability. Every manager of every department as well as every employee and stakeholder should be involved. At the start of the integration a meeting of all people involved would be advisable in order to let everyone know about the new commitment to sustainability and why this approach was decided on. (Parmenter, 2007)

SSF5: Starting to integrate sustainability tools. After having geared existing practises towards sustainability and having communicated the new commitment to sustainability throughout the company it is time to integrate some sustainability tools. The following three tools seem to be the most suited to help integrate sustainability: The ISO 14001 certification, the Sustainability Balanced Score Card and Total Quality Environmental Management (explained in more detail in the literature review). The long-term goal of integrating sustainability tools is to have integrated sustainable processes and thinking all along the supply chain.

SSF6: Measurement. This step is of major importance because we have to measure whether the integration of sustainable practices was worth-while. Internally KPIs or similar measurement tools should be used in order to measure sustainability. Externally the GRI guide provides good monitoring and reporting standards.

SSF7: Sustainability journey. Sustainability will have to be constantly improved and adapted due to a changing environment and new rising technologies. Sustainability should not be seen as just another tool to make money but as a core value/intangible 
resource that becomes part of the thinking process of the company. (Links to sustainability debate about core values and why companies adopt it)

A check-box can be used together with the framework to ascertain areas in which a company performs well or where it needs improving (Table2).

Table 1: SSF Check-Box

\begin{tabular}{|c|c|}
\hline \multicolumn{2}{|c|}{ SSF Check-Box } \\
\hline Company & Company $\mathrm{x}$ \\
\hline 1. Interest in Sustainability & $\sqrt{ }$ \\
\hline 2. Support from high level Mgmt & $\sqrt{ }$ \\
\hline $\begin{array}{l}\text { 3. Gearing existing practices towards } \\
\text { Sustainability }\end{array}$ & $\sqrt{ }$ \\
\hline 3a. CSR & $\sqrt{ }$ \\
\hline 3b. TBL & $\sqrt{ }$ \\
\hline $\begin{array}{l}\text { 4. Communication about new } \\
\text { commitment to sustainability }\end{array}$ & $\mathrm{x}$ \\
\hline 4a. Internal & $\sqrt{ }$ \\
\hline 4b. External & $\sqrt{ }$ \\
\hline $\begin{array}{l}\text { 5. Starting to integrate sustainability } \\
\text { tools }\end{array}$ & $\mathrm{x}$ \\
\hline 6. Measurement & $\sqrt{ }$ \\
\hline 6a. Internal & $\mathrm{x}$ \\
\hline 6b. External & $\sqrt{ }$ \\
\hline 7. Sustainability Journey & $\sqrt{ }$ \\
\hline
\end{tabular}

\subsection{Summary}

This literature review has covered corporate sustainability and its related topics, such as: Corporate Social Responsibility (CSR), the Resource Based Perspective, the Triple Bottom Line (TBL), Stakeholder Theory, Performance Measurement (KPIs), Germany's energy sector and various tools which can help to integrate corporate sustainability into company practice. Furthermore, a sustainability framework (SSF) has been created by using the vital, key aspects of the literature review. The SSF framework 
will be applied to three case studies in order to establish how they have approached corporate sustainability and how they can improve it.

Many authors have elaborated on CSR, TBL and performance measurement but corporate sustainability is still a fairly new field to researchers. The word sustainability was first coined by the Brundtland Report in 1987, but even today sustainability still remains a mystery to many businesses. Even today many businesses have not adopted or even approached sustainability in their practices.

This literature review described in detail why corporate sustainability as well as CSR and TBL should be integrated into businesses and how it would benefit them. For many companies CSR and TBL are common business practice but corporate sustainability is for many still a buzz-word. In order for those businesses to be successful in the longterm, integrating corporate sustainability into their company should be the next step. Corporate sustainability is not integrated easily though and it will have to be embraced throughout the whole company, from top management down to all employees, throughout the supply chain and stakeholders.

The questions used in the research interviews have a direct link to the literature review. The questions will aim to uncover what sustainability means to the companies participating in this study, what sustainable business practices they use, how they measure sustainability internally and externally, how they guarantee a return to their stakeholders by following a sustainable strategy and the information on which they based their future strategy.

Following, Germany's energy related policies and practices will be examined in order to compare those to the New Zealand energy market; which might help to improve New Zealand's policies and practices in the energy market. 


\section{Best Practice Germany? A review of Germany's energy sector and policies}

Here I examine Germany's policies towards sustainability with a particular focus on a number of German power companies. Some publications suggest that Germany's sustainability practices and policies should be a benchmark for other countries (Blue, 2008; Landler, 2008). In addition, this section will analyse those power companies' policies towards sustainability and what they are currently doing to stop climate change. Finally, I will compare Germany's and New Zealand's policies towards sustainability as well as their power companies' incentives to move towards sustainability, and explore where Germany and New Zealand might learn from one another's practices towards sustainability.

\subsection{Introduction}

Sustainability has been an important part of German education as far back as 1970 and has been deeply ingrained into German society ever since. In 2003 Germany became the world's leading exporter of environmental protection goods with over $18.8 \%$ of the world market, followed by the United States with $18.4 \%$ and Japan with

10.15\%. In 2004 Germany produced goods to protect the environment and climate worth $€ 55$ billion and in 2003 a total of 3.3\% of Germany’s overall R\&D expenditure was in the field of environmental protection (Federal Ministry of Education, 2005).

The German Ministry of Education and Research (BMBF) established a 'Research for Sustainability framework' in order to help to fulfil Germany's ambitious goals regarding sustainability. The programme involves societal actors in project design and implementation at the very early stages. By linking technological progresses with societal progresses, Germany reached a high degree of acceptance from the public as well as the introduction of sustainability concepts into the education system. This approach guarantees a high degree of public education on sustainability issues which in turn increases the growth of this area rapidly.

Another reason for the success of the Research for Sustainability framework is that around $70 \%$ of the partners involved in this project are commercial companies which 
are highly active in the field of 'key innovations'. The reason why the BMBF is so successful is clarified by its objective:" The objective of the BMBF is to promote sustainable economic systems and lifestyles in a comprehensible and scientifically sound manner and to gain the support of the society in this endeavour" (Federal Ministry of Education, 2005, p7).

This suggests that Germany might be more advanced in sustainability issues than other countries, and in the following section I will examine Germany's sustainability practices in the energy sector.

\subsection{The German energy sector}

\section{Introduction}

Germany’s energy sector has a fairly long history compared with New Zealand, which is mainly due to its manufacturing industry which was the worlds, second largest as far back as in 1913. Consequently, Germany’s demand for power was always fairly high (Helio, 2000).

The German energy market was a monopolist market till 1998 when it was liberalised by European legislation. Towards the end of the 1970s the focus of the energy sector slowly turned away from nuclear energy and fossil fuels towards renewable energy source. Since then the German energy market has undergone tremendous change (Holzer, 2005).

Today the German energy market is made up of:

- 3 mayor power suppliers:

o E.ON: www.eon.com/

o RWE: www.rwe.com/generator.aspx/language=en/id=450/home.html

o Vattenfall Europe: www.vattenfall.com/

- 50 other 'pure' energy producers

- 60 regional suppliers

- 25 bigger 'Stadtwerke’ (i.e., public services)

- 700 smaller and middle 'Stadtwerke' 
- 100 smaller and private suppliers

- 150 energy traders and producers of ‘Oekostrom’ (renewable energy)

Statistics in 2004 showed that the power suppliers alone employed over 200,000 people. Furthermore, more than 200 additional power suppliers have entered the German energy market since 1998 of which many are from foreign countries.

Figure 11: Germany’s Electricity Generation 1991-2004, by Source (Taken from ${ }^{16}$ )

\section{Germany's Electricity Generation, by Source}

\section{Conventional Thermal $\mathbf{H}$ Hdroelectric Nuclear $\mathbf{0}$ Other Renewables}

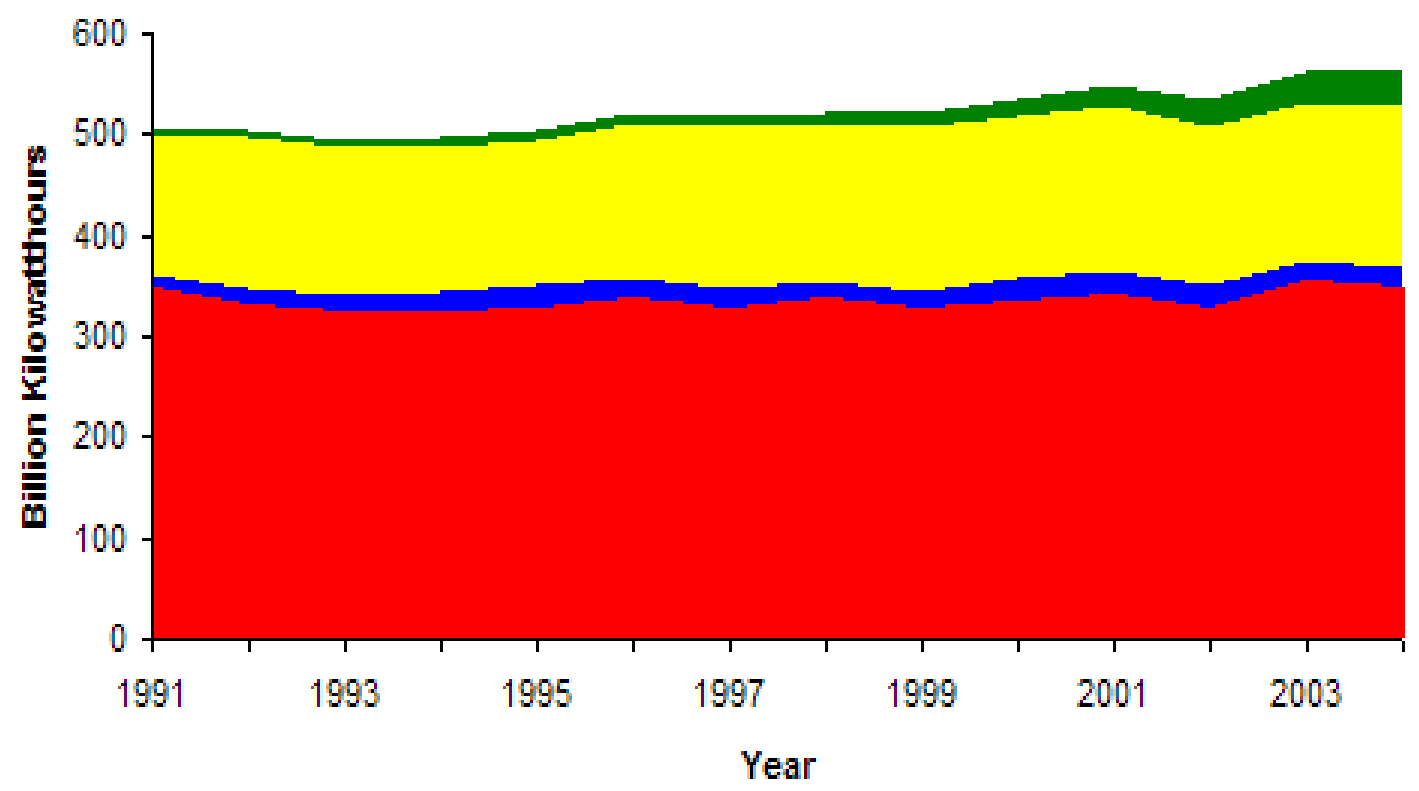

Source: ElA International Energy Annual 2004

1

\subsection{The German Renewable Energy Act (EEG)}

In March 2000 the Renewable Energy Act was introduced, which followed the 'Stromeinsparungsgesetz' from 1990, in order to promote the supply of energy from renewable energy resources. In 2003 an amendment was proposed by the German Government in order to change minimum feed-in tariffs for renewable resources, which now had a higher priority.

\footnotetext{
${ }^{16}$ Source: http://www.eia.doe.gov/emeu/cabs/Germany/Electricity.html , accessed on the $23^{\text {rd }}$ of July 2008.
} 
The objective of the EEG is to create a sustainable power supply and increase the use of renewable resources dramatically. The goal of the German government is to increase the use of renewable resources to $12.5 \%$ of the total energy source by 2010 . The German government's main motivation behind this is climate and environmental protection by introducing new technologies. A long-term goal of the German government is to increase overall renewable energy use up to $20 \%$.

In order to reach their targets Germany is using strategic industrial incentives to promote the use and innovation of renewable energy technologies. Germany is doing this by offering the industry favourable regulations such as tax incentives. The overall objective is to create a national industry of renewable energy plant producers for the domestic market and for export.

The EEG is based on guaranteed feed-in prices to encourage the production of renewable energies. Furthermore, the local grid operator is obliged to buy power from renewable energy sources, which are defined by law. A minimum price for each technology is set by the government, for hydro power, for example the price is 6.65 Euro cent $/ \mathrm{kWh}$ and for photovoltaic power it is 50.62 Euro cent $/ \mathrm{kWh}$. The average feed-in tariff in 2001 was 8.64 Euro cent/kWh.

The four main transmission grid operators in Germany are obliged by law to compensate local operators for power promoted by the EEG. The power supply industries which provide the power to the consumers are obliged to take EEG power and compensate for it at an average rate. This in turn leads to increasing consumer prices (which are kept in check through a competitive energy market) and the government has set no limit on obligatory payments for renewable energy (Holzer, 2005).

Figure 12 on the next page shows how much Wind and Solar energy Germany is generating in comparison to the rest of the Organisation for economic co-operation and development (OECD) which counts 30 countries as their members. 
Figure 12: OECD Wind and Solar Electricity Generation Capacity, 2004 ( Taken from $^{17}$ )

\section{OECD Wind and Solar Electricity Generation Capacity, 2004}

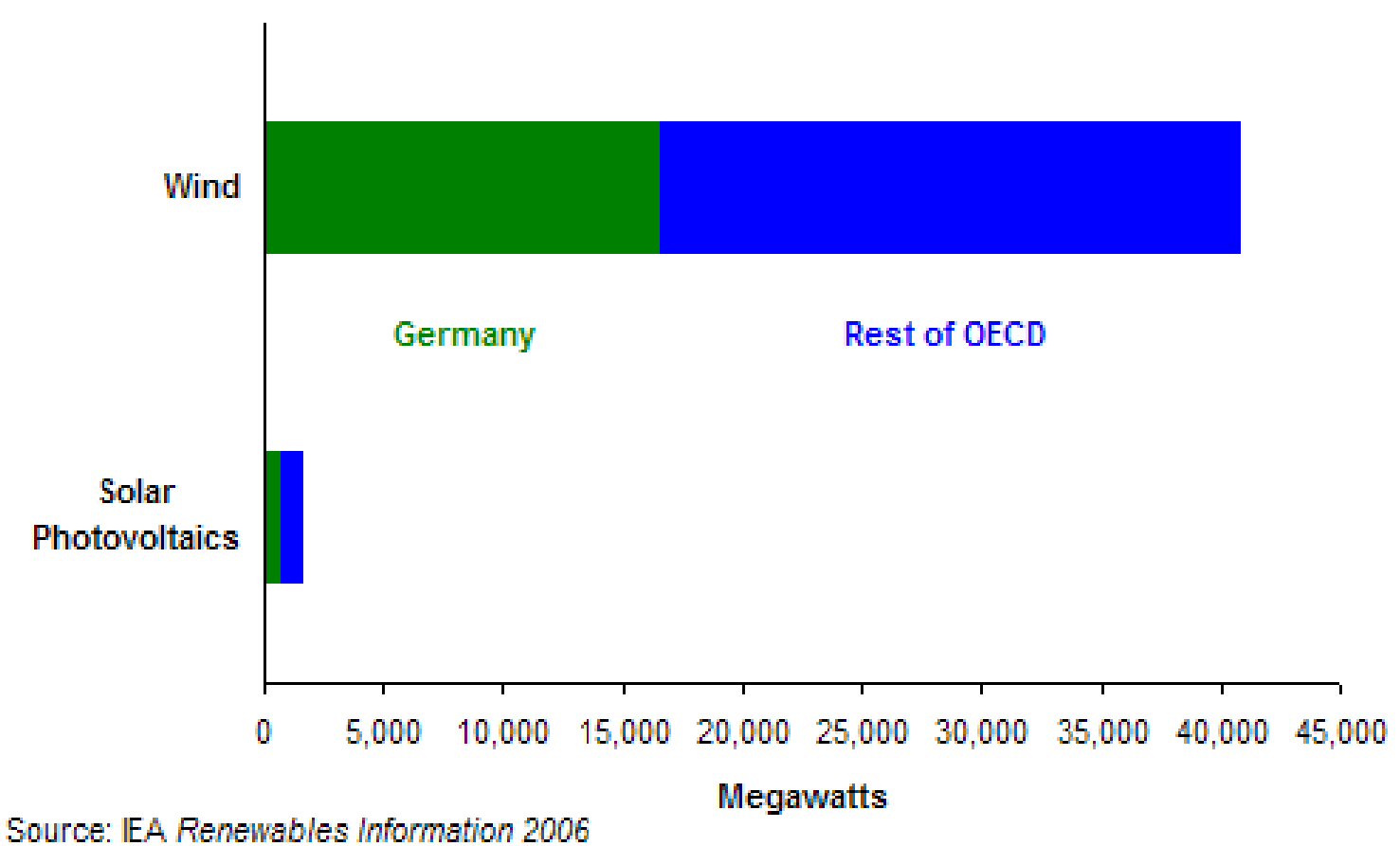

Source: IEA Renewables Information 2006

\subsection{European Emission Trading Scheme (EETS/EU ETS)}

The EETS is Europe's attempt to reduce CO2 emissions in a time of global warming and was established on 25 December 2003. This European approach is an answer to the Kyoto protocol. The EETS allows the tradability of so called 'carbon credits', which are emission allowances a company can sell if they do not reach their maximum allowance (i.e., if a company has a certain emission allowance and stays under its maximum allowance it can sell the rest as 'carbon credits' the same principle is valid for ‘offsetting projects' like wind farms for example).

The aim of the EETS in Europe is to fulfil the EU's obligations under the Kyoto Protocol, with an overall target of reducing the EU's emissions by 8\% between 2008 and 2012.

\footnotetext{
${ }^{17}$ Source: http://www.iea.org/textbase/papers/2005/variability.pdf , accessed on the $24^{\text {th }}$ of July 2008.
} 
Within the EU each member state has to fulfil their own objective due to the 'interEuropean burden-sharing'. Germany's contribution is about 21\%. Certain countries such as Portugal are allowed to increase their emissions, which is an exception because most countries will have to lower their emissions (Holzer, 2005).

Further information about the European Emission Trading Scheme is available at: http://ec.europa.eu/environment/climat/emission.htm

\section{Facts and Figures}

- Germany is the world leader in renewable resources through its Renewable Energy Source Act (or EEG in German) (Henkel, 2008).

- Germany produced 20.7 GW of energy from wind sources in 2006 (Henkel, 2008).

- Installations for geothermal energy since 2006 more than doubled (Henkel, 2008).

- The world's leading renewable companies (Q-Cells, Vestas, General Electric and First Solar) have made major investments in Germany due to its infrastructure and potential for renewable energy sources.

- Germany has five companies (Adidas, BASF, Fresenius, Henkel and SAP) in the Global 100 Index which is an index for the most sustainable companies in the world (Panda, 2008).

- Germany has 3.8 GWp (Gigawatt peak) of installed photovoltaic capacity, which is nearly half the world's solar energy market (PR Newswire, 2008).

- Between 1990 and 2005 Germany’s greenhouse gas emissions went down 18\% (in comparison the US went up 16\%) (Blue, 2008).

- Eco-tax on fuel to discourage petroleum use.

- Producers must pay to deal with recycling the packaging they produce.

- Germany is trying to build offshore wind parks which will generate $1500 \mathrm{MW}$ by the end of 2011 (Johnstone, 2008). 
Figure 13 is comparing two indexes and their performance in relation to each other. The Global 100, which is a sustainability index, is outperforming the MSCI World, which is not focused on sustainability practices. This might indicate that companies using sustainable practices outperform companies that do not use those practices.

Figure 13: A Comparison of the Global 100 and the MSCI World (Panda, 2008)

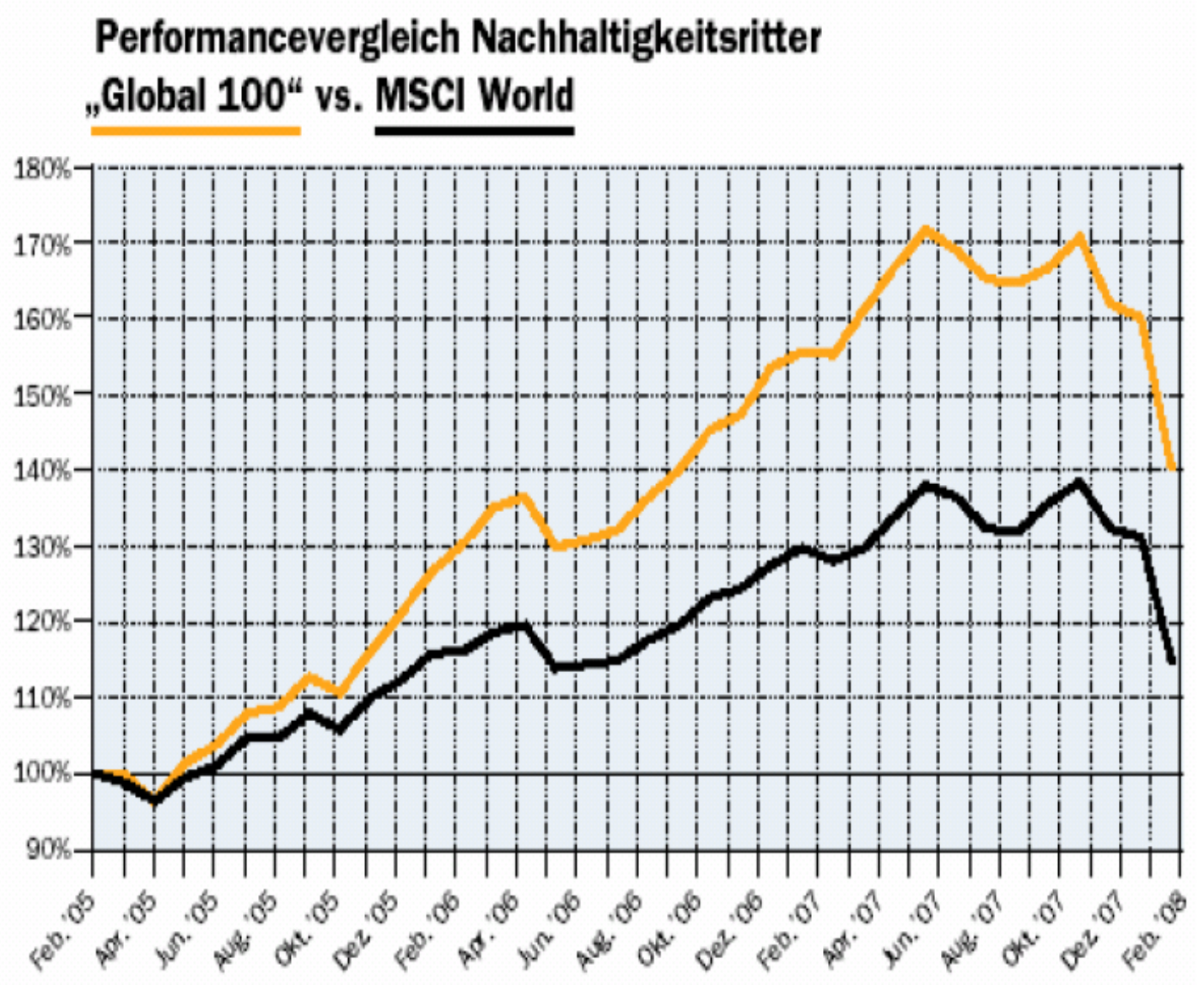




\subsection{Market-forces and government incentives}

This section examines the market differences and government policies which might affect the implementation of sustainable practices within energy companies in both New Zealand and Germany.

Germany's energy market has around 82 million customers in Germany alone, which is about 20 times the size of the New Zealand market. This fact alone indicates that the German energy market experiences a lot more competition between energy companies, which in turn might lead to more market driven incentives towards sustainability. As stated above Germany has three major energy producers and hundreds of other energy distributors as well niche-energy companies which focus on renewable energy sources only.

The EEG, Renewable Energy Act, one of Germany's main government policies promoting renewable energies, is probably the biggest incentive in Germany promoting renewable energies. Due to the EEG Germany has become an investor heaven for renewable energies, guaranteeing investors a certain feed-in tariff on which they can rely. Furthermore, the German Chancellor Angela Merkel is putting a lot of pressure on the energy industry to become more efficient, to reduce pollution and to become more sustainable.

The New Zealand energy market is a lot smaller than the German market and therefore does not allow for as much competition. Furthermore, the New Zealand energy market has only one privatised energy company, where in Germany most companies are privately owned, which allows for more market driven incentives for change.

New Zealand has the ideal resources to become a green and clean country which could use only renewable energy sources in order to provide energy security. The country is definitely moving in the right direction and is currently generating around $70 \%$ from renewable energy sources. The New Zealand government's main policy/legislation is the New Zealand Energy Efficiency and Conservation Act, which focuses on the promotion of renewable energy sources and energy security. If the New Zealand government came up with a similar incentive to the German EEG, it could very quickly 
become one of the most sustainable countries in the world. Companies would have more incentive to integrate sustainable practices and would be assured of getting the same money from renewable energy as out of non-renewable energy resources.

New Zealand energy companies seem as advanced when it comes to sustainability as German companies, the only differences being more government and market driven incentives which currently make Germany one of the most sustainable countries in the world.

\subsection{Case examples}

As case examples I have chosen Germany's two biggest power companies in order to show their sustainability practices and commitment. I have chosen those companies as case examples because they are Germany's biggest players in the energy market and often those companies set an example for the rest of the industry. Therefore I found it very important to introduce those two companies in this research. More than two companies could obviously have been chosen but the main case study in this research focused on two power companies in New Zealand so this section focuses on two German companies only.

\section{A) RWE Energy}

RWE Energy is based in Dortmund (Germany) and is the second biggest energy company in Germany. RWE employs over 28,233 people in countries like Germany, Austria, Czech Republic, Hungary, Slovakia, Poland and the Netherlands. RWE Group has over 17 subsidiaries around Central Europe and supplies around 23 million customers with water, gas and electricity (Table 1).

As mentioned above RWE is Germany's number two energy supplier with over 168.3 billion kilowatt-hours of electricity annually, is Germanys number one water supplier with over 107 million cbm annually and gas supplies of 258.0 billion kilowatt-hours annually (RWE, 2008a). 
Table 2: Basic facts about RWE (RWE, 2008a)

Revenue

Workforce

Final Customers

- electricity customers

- gas customers

Electricity sales

Gas sales
$28.5 €$ bn

28,323

23.1 million

15.5 million

7.6 million

168.3 bn kWh

258.0 bn kWh

\section{Current sustainability practices ${ }^{18}$ :}

RWE started very early on to care for its environment and in early 1979 the first environmental protection department was created. One year later in 1980 environmental protection units were established throughout the operating divisions.

In 1983 RWE started to introduce emission control programmes for flue gas generated from their power plants and furnaces. Two years later the first central environmental officer was appointed who oversaw all environmental issues. A short time later environmental officers were appointed for every major sub-division.

In 1986, emissions from all major power plants were reduced by installing vapour recovery systems, especially in refineries and tank farms. This happened all around Germany, due to new government laws which required emission reductions from the industry. In early 1998 RWE introduced the environmental management system pursuant to DIN EN ISO 14001 to all their mayor power plants.

The first group-wide environmental reporting system was introduced in 1999. Furthermore, RWE is actively sponsoring projects with the International Energy Agency (IEA) in order to explore technologies designed to reduce the greenhouse effect.

\footnotetext{
${ }^{18}$ Source: http://www.rwe.com/web/cms/en/108460/search/?q=sustainability, accessed on the $1^{\text {st }}$ of August 2008.
} 
RWE is also a partner of the Global Change ${ }^{19}$ project with the Massachusetts Institute of Technology (MIT) and is developing low-energy buildings for sport halls and buildings with reduced energy consumption.

Together with Avanza Eco Power, RWE offers a product exclusively produced by solar, hydroelectric and wind power plants. By doing so RWE is filling a niche-market for environmentally aware customers who choose not to buy energy generated from fossil fuels (RWE, 2008b).

Lastly, RWE is included in the Dow Jones Sustainability Index and belongs to the silver class of sustainability leaders 2007/2008. Belonging to the silver class of sustainability leaders requires commitment to sustainability throughout the organisation. Having achieved such a high sustainability standard shows how committed RWE is to sustainability (RWE, 2008b).

\footnotetext{
${ }^{19}$ Global Change: Is a programme that aims to bring together science and policies in order to stop climate change. For more information see: http://globalchange.mit.edu/cover/climate-challenge.html , accessed on the $1^{\text {st }}$ of August 2008.
} 
Figure 14: Company overview of $\mathrm{RWE}^{20}$

ENVIRONMENTAL MANAGEMENT WITHIN THE RWE GROUP

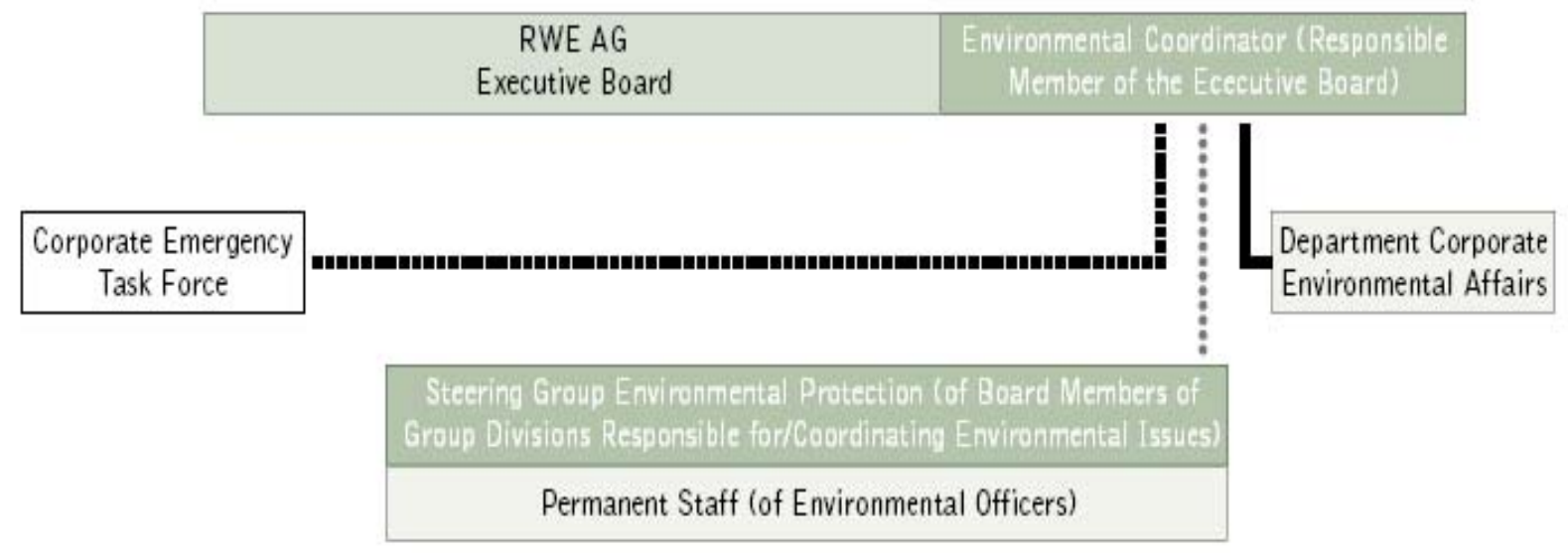

Board Members of Group Divisions Responsible for/Coordinating Environmental Issues

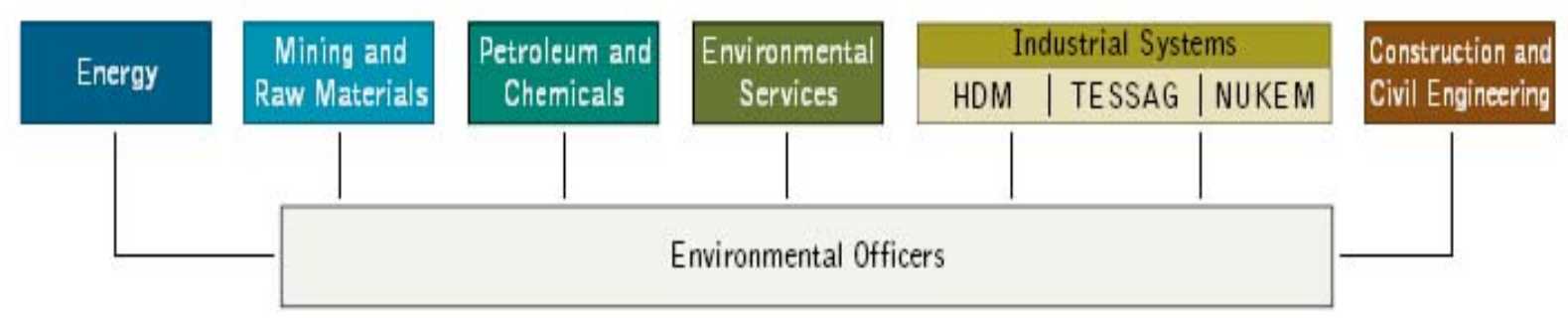

subordination muna co-operation ..... charing

\section{B) $\mathrm{E} . \mathrm{ON}$}

E.ON was formed in 2000 through a merger between VEBA and VIAG which were two of Germany's biggest industrial groups. VEBA and VIAG used to be holding companies for state-owned industrial enterprises in the 1920s and were listed in the DAX (stock index of Germany’s top 30 'blue chips’) in the 1980s.

Today E.ON is the world's largest investor-owned power company and has over 88,000 employees in Europe, Russia and North America. E.ON is dealing in electricity, gas and renewable energies with which they generated over $€ 69$ billion in 2007. Furthermore,

${ }^{20}$ Source: All information was taken from: http://www.rwe.com/web/cms/en/100400/about-us/, accessed on the $1^{\text {st }}$ of August 2008. 
E.ON is a vertically integrated business which allows them to manage all activities along their value chain, from gas and electricity production to distribution and customer service (E.ON Energy, 2007).

E.ON is actively working to reduce its impact on the environment and is aiming to reduce its $\mathrm{CO} 2$ emissions by $50 \%$ in the next 20 years. E.ON has also defined its own ‘Climate Protection Strategy’ (E.ON Energy, 2007).

\section{Current sustainability practices}

E.ON is currently actively expanding their renewable energy capacity and is enhancing the thermal efficiency of their current generation fleet, and has increased their investment in research and development of environmental technologies.

By the end of 2012 E.ON will have invested $€ 10$ billion in order to increase the thermal efficiency of their renewables and R\&D. Currently the company is investing substantial amounts of money into environmental projects and new technologies like tidal and wave energy, which might have a big effect in reducing climate change once they are viable. E.ON is also a member of 3C (Combat Climate Change) a group of companies which either produce or consume high quantities of power and are trying to reduce climate change (E.ON Energy, 2007).

E.ON might not yet be as sustainable as RWE, for example, but the company is actively working towards a more sustainable future. Currently the company is involved in projects with the World Council for Sustainable Development in order to become more sustainable. E.ONs sustainability commitment is: “At the start of 2008, we centralize all our European trading activities in power, gas, coal, oil and CO2 emission allowances. We also combined our renewable operations (with exception of hydroelectricity) and our climate-protection operations and plan to expand this business globally" (E.ON Energy, 2007).

E.ON created E.ON Energy Trading which is responsible for emission trading. Germany's partner company E.ON UK is currently planning on building the world's largest offshore wind farms, the London Array. Finally, E.ON is actively working 
together with all its customers to reduce energy usage in family homes in order for them to save money as well as to reduce CO2 emissions (E.ON Energy, 2007).

Figure 15: Renewables at E.ON ${ }^{21}$ (Taken from E.ON Annual Report 2007)
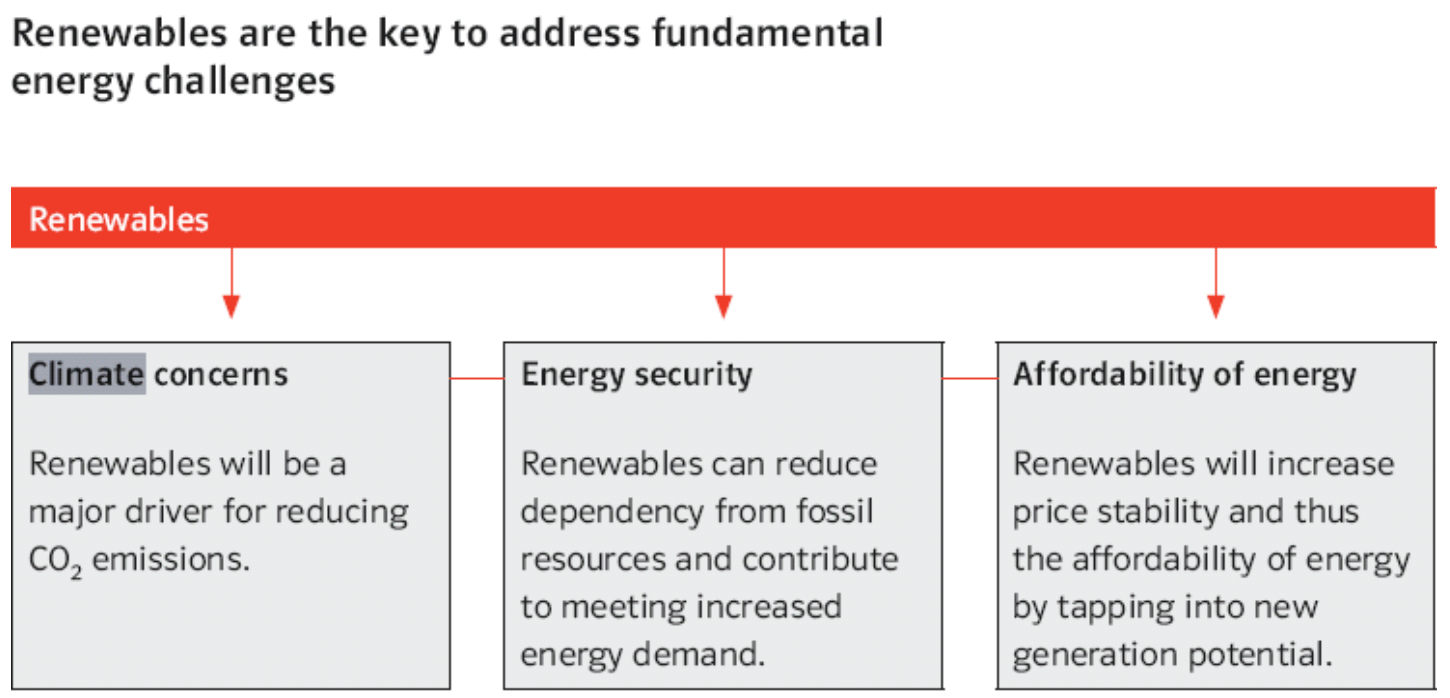

I will now examine some of the unique market aspects as well as niches and government policies that make Germany best practice in the field of sustainability.

One of the factors that make Germany an example of 'best practice' in the field of sustainability today is the long influence of the Green Party on government politics. The Green party won just under 7\% of the national vote in 1998 and entered into a coalition with the Social Democratic party (Blue, 2008). The Green Party's leader, Joschka Fischer, even became foreign minister. Due to the Green Party's influence on politics from late 1990, politics since then has had a 'green touch' to it.

One of the Green Party's first actions was to introduce an eco-tax on fuel to discourage the use of fossil fuels in the industry and families homes (Blue, 2008). This is just one reason why Germany started very early, in comparison to other countries, to investigate the possibilities of renewable energy sources. Furthermore, the German government

\footnotetext{
${ }^{21}$ Source: www.eon.com , accessed on the $1^{\text {st }}$ of July 2008.
} 
passed a law that reduces waste from packaging and recycling; the government simply forced producers to pay to deal with the packaging they create.

The German Renewable Energy Act (EEG) encourages the research and production of renewable energies. Moreover, Germany's market offers power companies the ideal environment to fill niches. Due to Germany's educational system, most people are very aware of climate change and pollution issues. Power companies that realised this offer their customers energy packages from 100\% renewables, where the customer can even choose the percentage of each renewable energy source.

Naturstrom is one of Germany's renewable energy producers. Figure 16 shows the percentage of each renewable energy source and is an example of the choice its consumers have.

Figure 16: Energy mix at Naturstrom (from www.naturstrom.de )

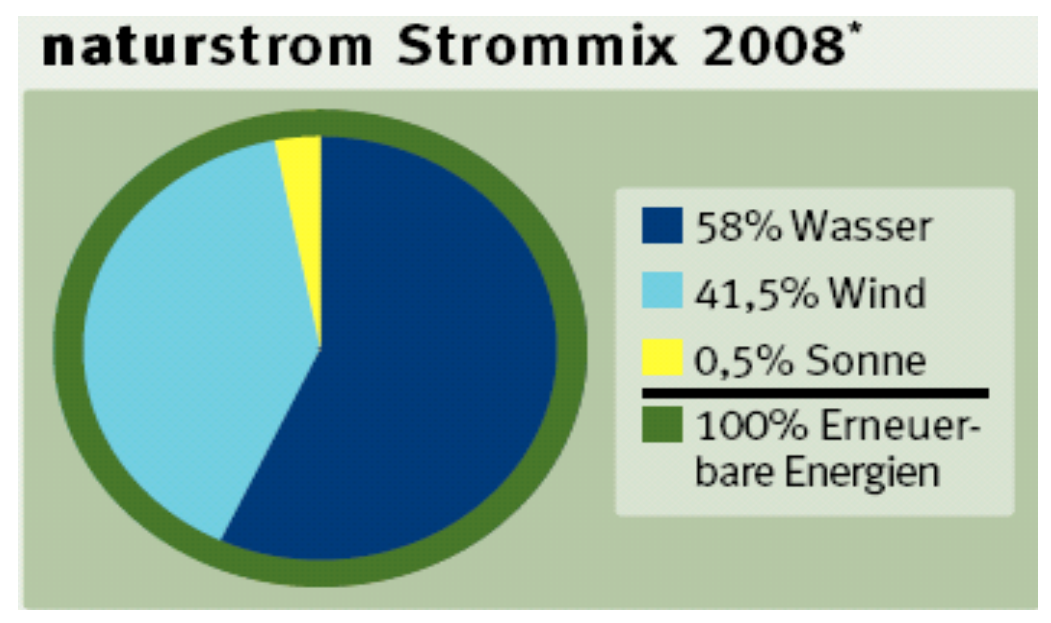

$($ Wasser $=$ Water $/$ Wind $=$ Wind $/$ Sonne $=$ Sun $)$

FlexStrom offers a similar package of renewable energy sources. Here the customer can choose which renewables they want and part of their energy bill at the end of the month goes towards saving Costa Rica’s rainforest (Figure 17). 
Figure 17: FlexStrom advertisement (from www.flexstrom.de )

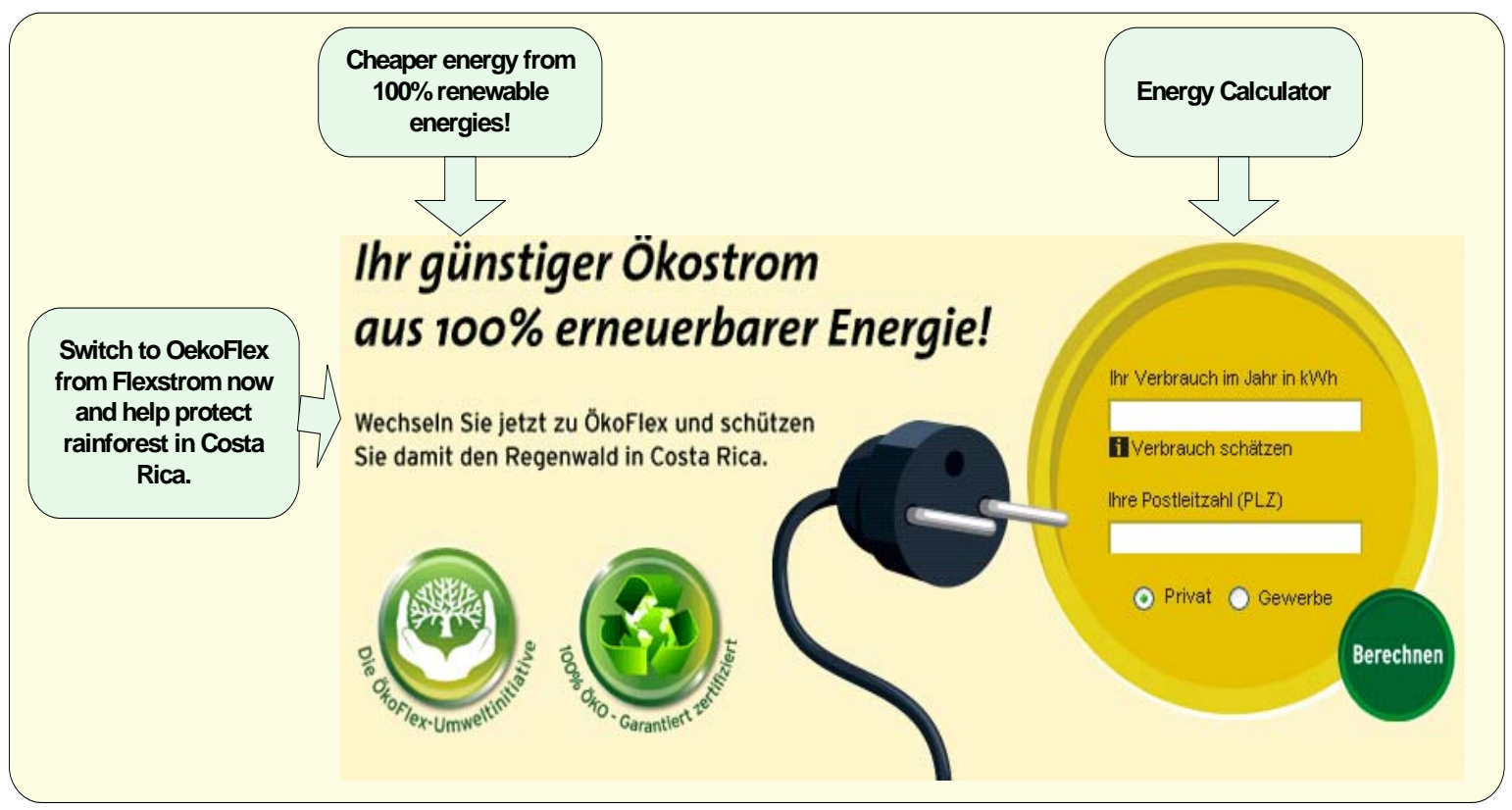

The two examples above are good indicators as of German energy companies have adapted to different demands from their customers. Due its larger market (over 85 million customers) there is a lot of competition in the energy market which keeps the price for the end-consumer low and encourages new approaches to win over customers.

German chancellor Angela Merkel announced in 2007 that Germany will cut greenhouse emissions by $40 \%$ by 2020 , which will heavily affect the energy sector, a strong lobby in Germany. Furthermore, she rules out any changes in the government's policy that all nuclear facilities will phased out in the next 14 years. This policy forces energy companies to invest in new technologies and, because fossil fuels are expected to become even more expensive, those new technologies will very likely be renewable options. As if that wouldn't be enough strain on the energy sector, Merkel is demanding from energy producers a 3\% percent increase in production and improved conservation each year (Dempsey, 2007).

This makes Germany currently best practitioner in the sector of renewable energies and sustainability. This success story is not unique and could be in many countries, if their policies changed towards renewable energies and they created encouraging laws like the EEG. Some of the examples above might give energy companies and governments alike options to change some of their policies and current practices. 
For example New Zealand's former prime minister Helen Clark played a big role in New Zealand to prepare for a more sustainable way in the future: "That is why I have issued a challenge to New Zealand - that we could become the world's first truly sustainable nation, and that we could even aspire to be a carbon neutral nation" (German Sustainability Council, 2007).

The concept of sustainable development has been integrated into New Zealand legislation for some years but especially so since the passage of the Resource Management Act. In 2002 part of this Act was rewritten in order for local government to take a sustainable development approach towards social, economic and environmental issues (German Sustainability Council, 2007). New Zealand's sustainable energy practices and policies towards a cleaner and greener New Zealand will be discussed in more detail below in Chapter 6 .

Germany might still be one of the world's leaders in sustainability and renewable energies, but New Zealand is equally determined to become more sustainable and has taken many actions already to become a more sustainable country. 


\section{Research Methods}

\subsection{Overview}

The previous chapter of this thesis reviewed the literature on corporate sustainability, as well as its potential benefits and drawbacks. This section of this thesis will look at how this research is going to be done, what methods will be used, procedures which will be undertaken and what techniques will be applied.

\subsection{Research objective}

The research objectives of this paper are as follows:

- To contribute to building knowledge and theory for the area of corporate sustainability in the New Zealand energy sector, by developing a strategic sustainability framework

- To understand what benefits a company can expect by embracing corporate sustainability

- To find out what challenges companies come across when implementing corporate sustainability

\subsection{Research design/methodology}

This research will use a multiple-case study approach in order to find out how two businesses in the New Zealand energy sector have applied sustainable practices within their company and whether or not those implementations were successful. Furthermore, this research will also look at two German energy companies and compare those findings with the two New Zealand cases in order to see if there are any differences and whether or not they could learn from each other. Finally, both New Zealand's and Germany's energy-related government policies will be analysed and differences between the two approaches will be highlighted to see if both countries could possibly learn from one another. 
By taking a case study approach I want to find out sets of decisions which have led to the implementation of sustainable practices. According to Schramm (1971) in Yin (2008), wanting to find out how and why a set of decisions was formed requires a case study approach. By taking a case study approach I will be able to find out why certain decisions were made, how they were implemented and what resulted from those actions.

By using a case study approach this research will embrace a mainly qualitative design (Creswell, 2003), but will also integrate a quantitative section to the research in order to compare New Zealand's and Germany's country profiles. According to Yin (2008) case studies can be based on both quantitative and qualitative data. This form of research is ideal for this study, because it enables the researcher to explore certain activities and processes of a company in depth (Stake, 1995).

\subsubsection{Why case studies?}

In order to understand the motivation behind incorporating sustainable practices for businesses it is necessary to analyse a couple in cases of the industry. Obviously questionnaires could be send out to a broader sample of companies in order to generate greater data, but that would not give the researcher the chance to understand what motivated managers to integrate those strategies in the first place. A case study on the other hand enables the researcher to look at a couple of cases, interview managers faceto-face about their beliefs, values and reasons behind implementing certain strategies (Marshall and Rossman, 2006).

In this research questions like 'how' and 'why' will be dominant in order to find out how and why each company has integrated sustainability and how they have done it. How and why questions are more explanatory and likely to lead to the use of case studies, because “...such questions deal with operational links needing to be traced over time, rather than mere frequencies or incidence”. (Yin, 2003, p6)

The strength of a case study is the unique ability to deal with a wide variety of evidence which might be documents, artefacts, interviews and observations (Yin, 2003; Eisenhardt, 1989). This is very important for this research because I will look at a wide 
variety of data ranging from secondary data on the internet, interviews and company profiles.

\subsubsection{Critique}

Case studies in the past have been criticised for having insufficient precision and rigor and many researchers view it as the most circumspect of studies for various reasons (Gerring, 2007; Yin, 2003). One reason for this is that focusing on a 'mere' single case can not produce valuable data for a broader number of organisations. This being a multiple-case-study where more than one case will be looked at, changes that 'fault' into strength to gain valuable data for the New Zealand energy sector. By looking at least at two cases of the New Zealand and German energy sector different approaches to integrate corporate sustainability might emerge, which can than be used to create a new and better way for New Zealand energy companies to incorporate sustainability.

Another concern about case studies is that they provide little basis for scientific generalisation. Critics may ask 'how can you generalize from one single case study?' The same applies for experiments though. Experiments are barely ever based on a single experiment but on many experiments (Yin, 2003). The same applies to this research by using not one single case study but a multiple-case study with two companies in New Zealand and two companies in Germany. Yin (2003, p10) clearly confirms this: "In this sense, the case study, like the experiment, does not represent a "sample", and in doing a case study, your goal will be to expand and generalize theories (analytic generalization) and not to enumerate frequencies (statistical generalisation)”.

Organisations which were selected for this research have had at least two or more years of experience in the field of sustainability. This will make sure that the companies have had enough time to monitor the effects of their sustainable strategy as well as a chance to improve them. 


\subsection{Data Collection}

\subsubsection{Interviews}

In order to collect information from the two chosen case studies, this research uses interviews as a means to gather data. In-depth interviews are the main tool qualitative researchers use to generate data (Marshall and Rossman, 2006; Yin, 2003). Through interviews the researcher aims to uncover the participants view on certain topics, which is the foundation of qualitative research.

Why use interviews?

Personal face-to-face interviews are a very good way to ask people open-ended questions in order to find out the motives and values behind integrating sustainable practices. Through open-ended interviews rich data can be obtained which would be hard to come by with questionnaires, for example. In questionnaires you can usually indicate: I agree, do not agree, high, low, yes or no, numbers between one and five etc. Interviews are a better approach in this case study because they generate richer data which allows the researcher to see how the participants see their surrounding and world views. Furthermore, questions can be clarified while interviewing and new questions may arise during interviews. Another reason for interviews to be used in this case study was that with interviews a response rate of nearly 100\% could be obtained (Marshall and Rossman, 2006; Yin, 2003).

Another reason why I chose interviews is that they are the most important source of case study data. By using open ended questions the researcher can guide the interviews more like conversation, rather than a structured inquiry (Yin, 2003).

Obviously there are also some disadvantages to using interviews. It takes considerably more time to do one-on-one interviews, and some respondents might be worried about the confidentiality of the interview. In this case participants will be given information sheets prior to the interviews with information regarding the interviews and a clause which assures them about confidentiality. Furthermore, the researcher has to be well 
informed about various interviewing techniques in order to get the best results, which can take up a considerable amount of time (Marshal and Rossman, 2006).

\subsubsection{Secondary data}

Interviews only form a small part of this research and the largest dataset to be analysed comes from secondary sources like the internet, or brochures and annual reports from the companies which were interviewed. Before the interviews were conducted, each of the two companies was thoroughly analysed as to what their current practices are, and their policies towards sustainability and communities. Those data were then used to create suitable questions for the interview. The interviews aimed to close knowledge 'gaps' which might not have been answered through secondary data. The secondary data which will be used in this case study can also be called an unobtrusive measure which basically means that the researcher requires no cooperation from the subjects or is actually invisible to them. Data collection of this kind looks at documents and archival records like annual reports etc. (Marshall and Rossman, 2006; Yin, 2003).

Why secondary data?

Why use secondary data? The information is easy to obtain through the internet, media or libraries and provides good background data to make an analysis of any given company (Marshall and Rossman, 2006; Yin, 2003). This analysis then provides valuable information needed to conduct a successful interview in which specific questions can be asked in areas where more data are needed.

\subsubsection{Comparative study}

As part of this research a comparative study between New Zealand and German energy policies as well as companies was done in order to show both strengths and weaknesses in the area of sustainability practices and policies in the energy sector. This comparative study is very important because it is always very helpful to 'benchmark' ones own practices with those of someone else. In this case Germany was chosen as a 
'benchmark' because it currently is one of the world's leaders in sustainability and I a very good understanding of the German Industry due to being German.

The comparing of two or more cases is part of searching for cross-case patterns where the researcher can compare the findings of multiple cases. The researcher can then list similarities and differences between the cases (here between the two German and New Zealand cases) to help analyse the data (Eisenhardt, 1989).

Why a comparative study?

A comparative study was chosen because New Zealand's government as well as both participating energy companies can learn valuable information about how sustainability is approached in other countries like Germany. Furthermore, this approach might indicate what future government and corporate policies regarding sustainability might be worthwhile.

\subsubsection{Data analysis}

The main strategy for this research is to follow the theoretical proposition which led to this thesis in the first place. This method/strategy is one of three general strategies of which the other two are rival explanations and pattern matching. The use of theoretical propositions is helpful when the researcher is looking at casual relations, in this case 'how' and 'why' questions about the use of sustainability and its outcomes (Yin, 2003).

Having defined the strategy approach abroad this research is using cross-case synthesis as the main analytical technique. Cross-case synthesis is especially useful for multiple case-studies, in this case the research looks at four (two New Zealand and two German) cases. This technique allows the researcher to treat each case as a single case and to highlight the differences or similarities between them (Yin, 2003).

The data analysis was conducted using mainly qualitative and some quantitative research methods. Two interviews were conducted, one with Meridian Energy and one with Contact Energy. Each interview was with the person in charge of the sustainability 
department. The interview with Contact Energy was done via teleconference due to a busy period at Contact. The interview with Contact Energy took around half an hour and produced very good data. In addition to the two interviews the researcher met with members of Starfish ${ }^{22}$ consultancy which at that time were working on sustainability issues for a New Zealand based Energy Company. The discussions held with the consultancy members provided good additional information for the researcher as well as confirming some of theories used in this research.

Victoria University of Wellington provided another and final important contact for me, Stephen Ward, who at that time was part of the MBA programme. Stephen Ward used to work in the energy sector and provided good background information on the New Zealand energy sector as well as valuable advice as to where source important information might be found. Stephen Ward was actively involved to write the report 'The environmental performance of the Electricity Commission' from 2006. Including the discussions with Stephen Ward this research used a wide array of information, interviews (Meridian Energy and Contact Energy), discussions with experts in the field of study (Starfish consulting and Stephen Ward) as well as secondary data for both New Zealand cases and especially for the two German cases. No interviews were conducted with the German companies because it proved to difficult to contact them with the existing time difference between the two countries, but both German energy companies referred me to their annual reports and secondary data on their internet homepages.

The use of multiple sources of evidence and information is in making sure that a wide range of information was used, which is of utmost importance for case study research. The use of multiple sources of evidence is also known as data triangulation, which is of high importance for every case-study researcher (Yin, 2003).

The interview with Meridian Energy took place at the new Meridian Energy building at the waterfront and lasted about the same time as the one with Contact Energy. This interview produced very good data as well and filled all the knowledge 'gaps' after analysing their secondary data first.

\footnotetext{
${ }^{22}$ Starfish: www.starfishconsulting.co.nz , accessed on the $2^{\text {nd }}$ August 2008.
} 
Prior to the interviews, both companies were contacted through a letter which introduced my study, possible outcomes and the request for participants for my interviews. Both companies were immediately interested and arranged interviewees for me who had a lot of knowledge in the field of sustainability. Dates were set to meet people from Meridian and Contact Energy to discuss my research with them. After the first initial meeting, dates were set to conduct the interviews.

This data analysis will use a process described by O'Leary (2004) which uncovers and discovers themes that run through the raw data. Those themes will then be interpreted by the researcher which will lead to the findings and recommendations of this research.

In addition to the interviews, secondary data for both case studies were analysed and studied prior to the interviews in order for the interviews to fill the knowledge 'gaps' from the secondary data analyses. Secondary data is also known as an unobtrusive measure, meaning that the researcher does not intervene with the subjects he/she studies (Marshall and Rossman, 2006; Yin, 2003). Sources of secondary data used in this research were the homepages of the four energy companies, including annual reports and company profiles as well as news reports about those companies.

\subsubsection{Limitations}

This study is limited to the New Zealand energy sector mainly because only two case studies in the energy sector have been conducted. Furthermore, the New Zealand energy sector is structured differently than in most other countries, which might make it more difficult to reproduce the data the exactly same way as done in this research. Further limitations of this research might be connected to the three major weaknesses of case studies. The main three Key weaknesses of case study approaches will be examined at as well as what I did to try and mitigate those weaknesses. The three main key weaknesses I draw on here were described by Yin (2003). 


\section{Lack of rigour:}

One problem often associated with case studies is the lack of rigour, and many people believe that looking at a mere single case does not produce valuable enough data (Gerring, 2007; Yin, 2003).

In order to mitigate that problem, I have chosen a multiple case-study approach, looking at four cases. Looking at multiple cases makes sure that the researcher comes up with more valuable data as well as being able to compare results from the four different cases which might lead to new insights into the field of study.

2. Little basis for generalisation:

The second problem often associated with case study research is that with single cases there is little basis for generalisation (Yin, 2003)

As mentioned before, by looking at multiple cases the weakness of generalisation is mitigated by having more than one case. If certain behaviours in the energy industry emerge simultaneously the researcher has a better 'case' to make generalisations for the industry.

3. They take too long and result in huge masses of documents:

The third problem often associated with case study research is that it often results in huge masses of documents and that it takes too much time (Yin, 2003). I mitigated those problems by planning the case-study well by using Microsoft Project Management, where strict deadlines were set and companies were approached very early on. Furthermore, all data gathered during the research were carefully labelled and stored in a case-study database, so that it could be found quickly at any time. Prior preparation before site visits was also undertaken, which included preparing all secondary data for the interviews. This preparation allowed me to ask specific questions about company documents which needed more information in order to be valuable. 


\subsection{Research issues}

\subsubsection{Ethical issues}

This study is involving human subjects for data collection, therefore extra care had to be taken in order to respect their contribution. In order for any student to collect data from human subjects, a Human Ethics Approval form has to be filled out which then has to be approved by the Human Ethic Committee at the University. This process makes sure that all ethical issues the researcher might encounter in her/his research have been carefully considered by the researcher and a third party. Participants in this research were provided with information about the research as well as a consent form, which they agreed to sign, before any interviewing took place. Every participant was given the option to receive a transcript of the interview, to allow him/her to double check the data before it was included in the research. Furthermore, the participants were entitled to confidentiality clauses as well as the choice to withdraw from participating in the research.

\subsubsection{Confidentiality issues}

Most companies in the New Zealand energy sector are state owned, which makes it fairly easy to gain information about those companies on the internet. Due to this fact there is no need for confidentiality concerning public data. Furthermore, the New Zealand energy sector is small in comparison with other countries, and companies might be fairly easy to identify. None-the-less, participating organisations were given they choice to hide the organisations name as well as individual interviewee names. 


\section{The Case of New Zealand's Energy Sector}

All information about the history of New Zealand's energy sector was taken from the 'Chronology of the New Zealand Electricity reform' by the Electricity Group of New Zealand from 2008 (Electricity Group, 2008); unless indicated otherwise.

The New Zealand energy sector was controlled by the government in the mid 1980s and electricity generation and transmission was the task of the Ministry of Energy. During that time local distribution and supply was the responsibility of around 61 electricity supply authorities, ESAs. Customer choice at that time was very limited and security of supply often a problem.

In 1986 the New Zealand government announced that they would change the generation and transmission of the electricity sector. One year later in 1987 the Electricity Corporation of New Zealand Ltd (ECNZ) was set up in order to take over all activities formerly run by the Ministry of Energy. The New Zealand government hoped that ECNZ, a State Owned Enterprise (SOE), would run the energy business more effectively and efficiently.

In 1988 the Electricity Amendment Act came into force which removed the need for the Minister of Energy to approve of all new hydro-related matters. In the same year Transpower was set up, which from then on ran the transmission network as a subsidiary of ECNZ.

From the late 1980's to the late 1990's, the New Zealand government introduced many more acts and energy related policies such as the Electricity Power Boards Amendment Act 1990, the Energy Companies Act from 1992 and the Electricity Industry Reform Act 1998.

In 1996 Contact Energy was established and started operations as a SOE in direct competition with ECNZ. Contact took over a number of power stations which were formerly run by ECNZ, which totalled around 22\% of the country's power generation. 
The biggest change in the New Zealand energy sector happened in 1998, and 1999. In 1998 40\% of Contact Energy was sold to Edison Mission Energy which is US-based; the remaining shares of Contact Energy were sold to more than 225,000 investors (mainly New Zealanders) for \$NZ 3.10 a share. Contact Energy is the only privately owned energy generator in New Zealand to date.

In 1999 the New Zealand government split its state-owned enterprise ECNZ into three competing state-owned generators. Those companies were: Genesis Power Ltd which owns the Huntly and Tongariro power stations as well as the electricity retailer First Electric; Meridian Energy Ltd which owns the South Island's Waitaki and Manapouri power stations and Mighty River Power Ltd which owns the Waikato Hydro systems.

Since 1999, the New Zealand energy market has gone through a number of reforms and acts to finally shape the New Zealand energy market to what it is today. As part of those reforms and acts were sustainability issues, renewable energy debates and a proposal on a carbon emission trading scheme.

Today the New Zealand energy market is made up of five major power companies (Figure 19)

5 major power companies

- Contact Energy Ltd : www.contactenergy.co.nz

- Genesis Power Ltd : www.genesisenergy.co.nz

- Meridian Energy Ltd : www.meridianenergy.co.nz

- Mighty River Power Ltd : www.mightyriverpower.co.nz

- $\quad$ Trust Power Ltd : www.trustpower.co.nz 
Figure 18: New Zealand's five largest power generators (from Ministry of Economic Development, 2007)

Top 5 generators-capacity and type

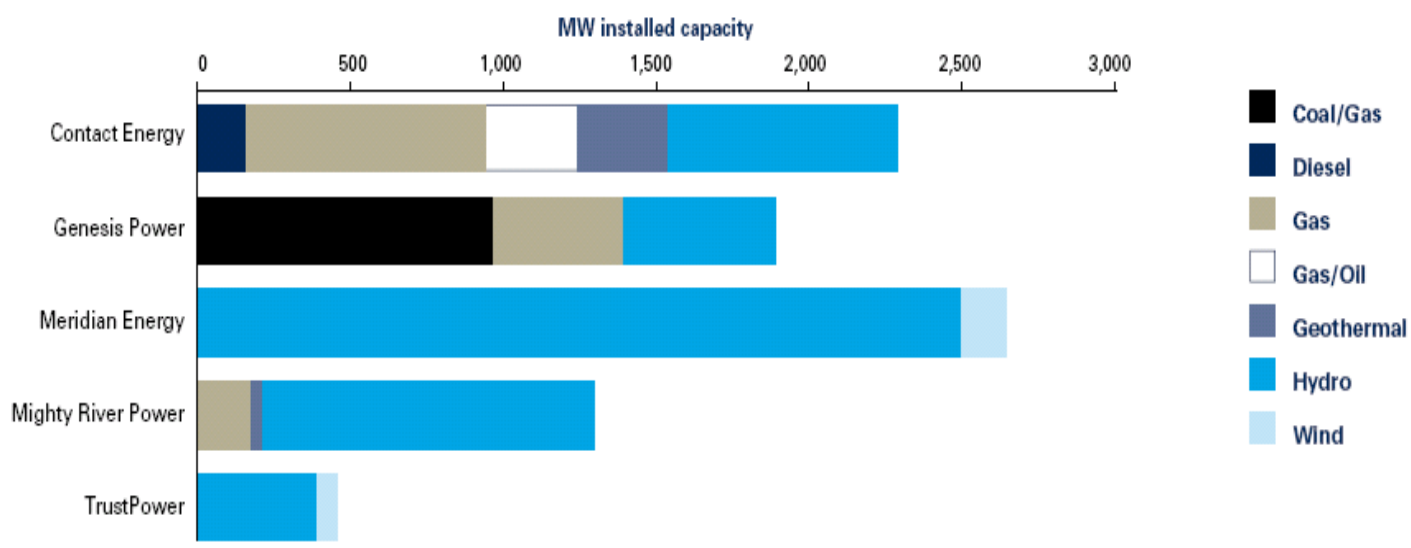

Source: Ministry of Economic Development, Energy Data File, 2007

New Zealand's electricity is generated mainly from hydro, gas, coal and geothermal energy. Electricity from those sources is generated at around 40 major electricity generation sites which then feed the electricity into the main grid. Transpower is the owner of New Zealand's national grid and is responsible for bringing electricity from remote generation sites all the way to the customer.

The distribution $^{23}$ of electricity is done through around 28 lines companies which own local distribution networks throughout New Zealand. Those distributors then sell their distributing services to retailers who are responsible for establishing contracts with the end users. Retailers normally buy electricity from the generator companies and sell it for a fixed price to the end user.

Currently there are nine retailers:

- Contact Energy Ltd

- Empower Ltd

- Energy Online

- Genesis Power Ltd

- Meridian Energy Ltd

\footnotetext{
${ }^{23}$ Source: http://www.electricitycommission.govt.nz/industry, accessed on the $4^{\text {th }}$ of August 2008.
} 
- Mercury Energy Ltd

- Bay of Plenty Electricity

- King Country Energy

- $\quad$ Trust Power Ltd

I will now introduce New Zealand's current energy legislation as well as policies related to renewable energies and sustainability. The first act to be introduced will be the New Zealand Energy Efficiency and Conservation Act, followed by the New Zealand Energy Efficiency and Conservation Strategy (NZEECS), the Climate Change Response Act and the Emissions Trading Scheme.

\section{New Zealand Energy Efficiency and Conservation Act}

The New Zealand Energy Efficiency and Conservation Act (2000) is the government's legislative basis in New Zealand to promote energy efficiency, renewable energy and energy conservation. The Energy Efficiency Act established the Energy Efficiency and Conservation Authority (EECA) which is responsible for promoting renewable energies, energy conservation and energy efficiency across all sectors of the industry as well as the government departments and local households.

This Act aims to support:

- Promoting public awareness of energy issues

- Ensuring there is a national strategy on energy conservation

- Promoting efficient renewable energies

- Monitoring energy efficiency and energy conservation

- Publishing relevant information and research

- Policy development

For more information see:

http://www.legislation.govt.nz/act/public/2000/0014/latest/DLM54948.html?search=ts_all\%40act\%40bill\%40regulati on_Energy+Conservation\&sr=1

2. New Zealand Energy Efficiency and Conservation Strategy (NZEECS) 
The NZEECS is part of the Energy Efficiency and Conservation Act and replaces the National Energy Efficiency and Conservation Strategy from 2001. This strategy aims at using energy more efficiently and conservative in order use energy 'smartly'. Furthermore, the Government of New Zealand has invested in research showing that renewable energies (at least for electricity) will be cheaper over the next 20 years than fossil fuels, especially now with rising fuel prices (EECA, 2007).

Targets of this strategy are:

- Better insulated homes

- Businesses that embrace energy efficiency

- Vineyards and tourism industry that embrace sustainability

- Businesses going carbon neutral

- Creating a more efficient transport fleet (hybrid cars, bio-diesel)

- Better public transport

- More focus on renewable energy sources

- Energy security

For more information see:

http://www.eeca.govt.nz/eeca-library/eeca-reports/neecs/report/nzeecs-07.pdf

\section{Climate Change Response Act}

The Climate Change Response Act (2002) is New Zealand's legal framework to meet its obligations to the Kyoto Protocol and cut carbon emissions. Furthermore, the Act builds the foundation for $\mathrm{CO}_{2}$ credits on a global scale. In charge of selling C02 credits is the Finance Minister of New Zealand. The Act also enables New Zealand to monitor and record important information regarding greenhouse gasses in accordance with international requirements.

Targets of the Act are:

- To allow New Zealand businesses and private individuals to trade in emission units

- "provide for the accounting of two new types of emission units (created by international decisions at a Conference of the Parties to the United Nations 
Framework Convention on Climate Change) which will cater for forest sink projects under the Kyoto Protocol's Clean Development Mechanismopo”.

For more information see:

http://www.legislation.govt.nz/act/public/2002/0040/latest/viewpdf.aspx?search=ts act Climate+Change+Response+ $\underline{\text { Act }}$

\section{Emissions Trading Scheme}

New Zealand's emission trading scheme is being phased in between 2008 and 2013 and is one of the world's first emission schemes which covers all areas of gasses (Sustainability Council Conference, 2007). Each sector of New Zealand is to be phased in at a different time as follows:

- Forestry Sector $\rightarrow 1^{\text {st }}$ of January 2008

- $\quad$ Transport Sector $\rightarrow 1^{\text {st }}$ of January 2009

- Energy Sector and Industrial processes $\rightarrow 1^{\text {st }}$ January 2010

- Agriculture and Waste Sector $\rightarrow 1^{\text {st }}$ of January 2013

(Sustainability Council Conference, 2007)

The emission trading scheme is supported by two main strategies, the New Zealand Energy Strategy and the Energy Efficiency and Conservation Strategy. (Sustainability Council Conference, 2007)

This chapter has given a good overview of the New Zealand energy market and some related acts and policies. In comparison with the German energy market, the New Zealand market is a lot smaller due to New Zealand's size and the fact that it is not land-locked (can not import nor export electricity). Due to this fact there are a lot fewer power companies in New Zealand which results in less competition over market shares, which in turn might lead to higher energy prices and less innovative practices.

As we can see, New Zealand seems very committed to integrate sustainability into every part of their legislation and industry, and maybe the only difference between Germany and New Zealand is that Germany is historically a lot older and therefore started to integrate sustainability a lot earlier. There seem to be a lot of similarities to 
sustainability commitment from both countries, and by studying the German example of sustainability commitment New Zealand might be able to integrate the sustainability agenda a lot quicker.

The following three citations taken from the German Sustainability Conference highlight that an exchange of knowledge in the area of sustainability is already happening; this supports this thesis’s proposal for knowledge exchange.

- “Increasingly, New Zealand's relationships with Germany and with Europe in general have a sustainability dimension”. (Sustainability Council Conference, 2007)

- "Our largest city, Auckland, has entered into a strategic alliance with Hamburg, with a particular focus on co-operating and learning from each other's experiences in sustainable city development”. (Sustainability Council Conference, 2007)

- "In recent years considerable collaborative research between German and New Zealand scientists has been in the area of climate change and ozone depletion. And in February this year our respective science ministers concluded a review of the 30-year old Science and Technology Co-operation Agreement, paving the way for even greater levels of co-operation”. (Sustainability Council Conference, 2007)

Two case studies from the New Zealand energy sector will now be presented. The first company which will be introduced is Contact Energy, followed by Meridian Energy. Contact Energy was chosen because it is New Zealand's only privately owned company as well as having the most diverse energy source mix. Also, Contact Energy has started to invest heavily into renewables and sustainability has been on their main agenda since 2007.

Meridian is the only New Zealand Carbon Zero certified company which makes it a very interesting company to study because it could be seen as the ideal benchmark in 
the energy sector. Meridian Energy has integrated sustainability into their core business from the very foundation of the company.

Contact Energy and Meridian Energy are the biggest energy generators in New Zealand, which is another reason why they have been chosen for this study.

\subsection{Case Study A}

Case Study A has been conducted with and for Contact Energy. The aim of this case study is to analyse Contact Energy's current sustainability practices, which entails what sustainability tools are being used, how is sustainability measured, what future sustainability strategies might be implemented and how current practices might be improved. The following section will introduce Contact Energy and its current sustainability practices.

\subsubsection{Introduction of Contact Energy ${ }^{24}$}

Contact Energy was part of the Electricity Corporation of New Zealand (ECNZ) till 1996 when ECNZ was split into Contact Energy and then further in 1999 into Meridian Energy, Genesis Energy and Mighty River Power. Contact Energy was privatised in the same year and the other three energy companies remain State-owned Enterprises till today (Electricity Group, 2008).

Contact Energy is one of New Zealand leading electricity generators and retailers as well as one of New Zealand's biggest listed companies. Contact Energy currently employs over 1.000 people all over New Zealand and is the only company that can sell both electricity and gas across the whole country.

\footnotetext{
${ }^{24}$ Source: http://www.contactenergy.co.nz/web/view?page=/contentiw/pages/aboutus/aboutus\&vert=au , accessed on the $5^{\text {th }}$ of August 2008.
} 
Contact runs nine power stations in New Zealand and produces an estimate of $25 \%$ of the country's electricity. Contact is New Zealand's leading generator of renewable geothermal electricity and is leading New Zealand towards a cleaner and more climatefriendly electricity generation sector. This is going to be achieved through a $\$ 2$ billion investment programme in renewable wind and geothermal generation projects.

Contact Energy is striving for sustainable and energy efficient use of natural resources and actively encouraging efficiency improvements in energy production and energy supply. Furthermore, Contact will promote and support practical energy conservation measures among its customers.

The major shareholder of Contact Energy is the Australian based company Origin Energy which owns an estimated $51.4 \%$ of the company. The remaining shares are owned by around 85,000 'mostly' New Zealand-based investors (Electricity Group, 2008).

\subsubsection{Current sustainability practices}

All information about Contact Energy's sustainability practices have been taken form their 2007 Sustainability Report (Contact Energy, 2007); unless indicated otherwise.

Contact Energy established a dedicated Environment and land group in 2003, which reports directly to the General Manager. This enables Contact Energy to work closely together with communities as well as being able to react more quickly to environmental issues

Contact Energy launched a Positive Energy campaign in 2004 throughout New Zealand including nation wide TV, newspaper and websites (www.positive-energy.co.nz). This campaign tried to establish a good discussion between all customers and stakeholders of Contact Energy about New Zealand's electricity future. This included the effects on the environment and communities.

In addition Contact Energy gained the internationally recognized ISO 14001 environmental performance management system certification in 2004. Today, all its energy producing facilities are certificated ISO 14001. 
Contact Energy achieved carbon neutral status through the Land-care Research carbonNZero programme for all of Contact Energy's offices and electricity generation sites across the country.

Contact is also designing a new waste system for their offices to reduce the impact on the environment; this resulted in a waste reduction of $58 \%$ over one year time. Moreover, the 40\% challenge was introduced, which challenges the New Zealand energy sector to cut emissions by up to 40\% by 2012 .

Contact is promoting 'Energy Savings in a Box'. This scheme offers customers a voucher for an energy efficiency check-up in their homes plus energy efficient light bulbs plus a voucher for Mitre 10 when purchasing energy efficient products.

All of Contact's offices are sustainable and only use recycled paper supplies. On top of that they also introduced a new fleet of seven Toyota Hybrid cars that have been purchased for employee transportation, which reduces the use of fossil fuels.

Finally, Contact introduced the Contact Energy Carbon Calculator in 2007 to help customers measure their effect on the environment. Contact is also investing in various projects for the community and the environment (Contact Energy, 2007).

Contact Energy's Environmental Policy:

Environmental Legislation - complying with environmental legislation and resource consents.

Energy Efficiency - striving for sustainable and energy-efficient use of natural resources and actively encouraging efficiency improvements in energy generation and energy supply. In addition, Contact will promote and support practical energy conservation measures amongst its customers.

The community - striving for sustainable and energy-efficient use of natural resources and actively encouraging efficiency improvements in energy generation and energy supply. In addition, Contact will promote and support practical energy conservation measures amongst its customers. 
Staff - training staff in the efficient and safe use of all plant and equipment.

Environment improvement - monitoring the effects of its operations on the environment and using the results to develop smart, practical measures aimed at reducing the environmental effects of its operations.

Environmental reporting - undertaking annual environmental compliance audits and publishing an annual environmental report that will be widely available to members of the community. (Contact Energy, 2004)

"If a company is to genuinely embrace sustainability, it must first be on a sustainable financial footing. More New Zealanders choose to invest their wealth in Contact than any other company with its primary listing in New Zealand, and Contact has strong obligations to deliver value and create wealth for our approximately 85,000 shareholders.” (Contact Energy, 2007, p36)

\subsubsection{Case findings}

In this section we will discuss the findings of both the secondary data analysis and the interview data gathered at Contact Energy. To start off with the secondary data will be looked at.

In the last two years Contact Energy has invested heavily in sustainability and renewable energies. Sustainable thinking has been integrated efficiently into Contact Energies core values and everyone seems to be involved in sustainable practices.

Through the establishment of the Environment and land group in 2003, Contact Energy made sure that it works closely together with all the communities affected by their power generation. This way all problems encountered by the communities were dealt with by Contact Energy in a quick an efficient way which produced favourable results for both sides (Contact Energy, 2004).

Contact Energy also started a very important nation wide discussion about New Zealand's energy future which had a big impact on how people thought and used energy. 
Introducing a new transportation fleet was a smart move in order to produce fewer emissions and also save fossil fuels in a now fossil fuel and carbon emission restricted environment.

How deeply integrated sustainable thinking is at Contact Energy showed when all employees went through the effort of sorting rubbish and creating a new, better recycling system which reduced waste by over 58\% (Contact Energy, 2004).

All of Contact's generation sites are ISO 14001 certified and all office space is certified carboNZero, which shows how environmentally friendly Contact Energy is today.

Data gathered from the interviews are summarised in Table 3 and discussed in detail below. 
Table 3: Questions and Answers from Interviews with Contact Energy staff

\begin{tabular}{|c|c|c|}
\hline Questions & Contact Energy & Links to Literature \\
\hline $\begin{array}{l}\text { 1. What does } \\
\text { sustainability mean to } \\
\text { Meridian/Contact? }\end{array}$ & $\begin{array}{l}\text { - Its more than just the environment } \\
\text { - Ensuring resources for future generations } \\
\text { - Expanding sustainability with (shareholders, } \\
\text { customers, employees etc.) }\end{array}$ & $\begin{array}{l}\text { - Links back to the } \\
\text { sustainability } \\
\text { literature. How is } \\
\text { sustainability } \\
\text { interpreted? }\end{array}$ \\
\hline $\begin{array}{l}\text { 2. What sustainable } \\
\text { business practices does } \\
\text { Meridian/Contact } \\
\text { employ? }\end{array}$ & $\begin{array}{l}\text { - CSR/Sustainability } \\
\text { - 50\% Renewable from Hydro Geothermal } \\
\text { - 50\% - 65\% renewables in the next 5-6 years }\end{array}$ & $\begin{array}{l}\text { - Links back to CSR, } \\
\text { TBL and reporting } \\
\text { literature. }\end{array}$ \\
\hline $\begin{array}{l}\text { 3. When did } \\
\text { Meridian/Contact start to } \\
\text { consider and employ } \\
\text { sustainable business } \\
\text { practices? }\end{array}$ & $\begin{array}{l}\text { - from } 1996 \text { (Increased focus on renewables) } \\
\text { (Feb 2007) }\end{array}$ & $\begin{array}{l}\text { - Links to } \\
\text { sustainability } \\
\text { timeline in order to } \\
\text { see when } \\
\text { implementation took } \\
\text { place. }\end{array}$ \\
\hline $\begin{array}{l}\text { 4. Why did } \\
\text { Meridian/Contact begin } \\
\text { to investigate sustainable } \\
\text { business practices? }\end{array}$ & $\begin{array}{l}\text { - Viable for the future } \\
\text { - Delivering good 'economics' to the } \\
\text { shareholders } \\
\text { - High fuel prices; they will continue to rise } \\
\text { - Strong obligation to shareholders, renewables } \\
\text { are the future (Carbon emissions will cost) } \\
\text { - Delivering value }\end{array}$ & $\begin{array}{l}\text { - Links to } \\
\text { sustainability debate } \\
\text { to see why they } \\
\text { implemented } \\
\text { sustainability. Value } \\
\text { based or monetary } \\
\text { based decision? }\end{array}$ \\
\hline $\begin{array}{l}\text { 5. What resources does } \\
\text { Meridian/Contact invest } \\
\text { in sustainable business } \\
\text { practices? }\end{array}$ & $\begin{array}{l}\text { - Capital expenditure plan (2billion NZ\$ just } \\
\text { recently) } \\
\text { - New renewable energy projects }\end{array}$ & $\begin{array}{l}\text { - Links to framework } \\
\text { in order to see how } \\
\text { committed the } \\
\text { companies are. }\end{array}$ \\
\hline $\begin{array}{l}\text { 6. Is Meridian/Contact } \\
\text { using any external } \\
\text { reporting standards? }\end{array}$ & $\begin{array}{l}\text { - GRI } \\
\text { - ISO } 14001 \text { (All generation sites) } \\
\text { - Investigation to take that ISO accreditation to } \\
\text { the next level }\end{array}$ & $\begin{array}{l}\text { - Links to TBL } \\
\text { reporting literature as } \\
\text { well as reporting } \\
\text { standards and tools }\end{array}$ \\
\hline $\begin{array}{l}\text { 7. Does Meridian/Contact } \\
\text { use any internal } \\
\text { measurement systems in } \\
\text { order to measure the costs } \\
\text { and benefits of using } \\
\text { sustainable practices? }\end{array}$ & $\begin{array}{l}\text { - Internal programmes (NO KPIs) } \\
\text { - Rubbish initiatives which are measured } \\
\text { - Paper and Compost recycling system which are } \\
\text { measured as to their impact. } \\
\text { - Reduced landfill from office waste by 50\% } \\
\text { - } 2008 \text { report will be way more focused on } \\
\text { measurement }\end{array}$ & $\begin{array}{l}\text { - Links back to PM } \\
\text { literature and internal } \\
\text { measurement }\end{array}$ \\
\hline $\begin{array}{l}\text { 8. How does } \\
\text { Meridian/Contact balance } \\
\text { the costs of sustainable } \\
\text { business practice with } \\
\text { ensuring returning an } \\
\text { investment to } \\
\text { shareholders? }\end{array}$ & $\begin{array}{l}\text { - By investing into sustainability we guarantee } \\
\text { return for shareholders }\end{array}$ & $\begin{array}{l}\text { - Links back to the } \\
\text { stakeholder literature }\end{array}$ \\
\hline $\begin{array}{l}\text { 9. What is } \\
\text { Meridian/Contacts' future } \\
\text { strategy regarding } \\
\text { sustainability? }\end{array}$ & $\begin{array}{l}\text { - Focus is on renewable } \\
\text { - Investing into Wind Energy }\end{array}$ & $\begin{array}{l}\text { - Links back to } \\
\text { framework } \\
\text { (sustainability } \\
\text { journey) }\end{array}$ \\
\hline
\end{tabular}




\begin{tabular}{|l|l|l|}
\hline $\begin{array}{l}\text { 10. What kind of strategic } \\
\text { or market analysis is the } \\
\text { future strategy based on? }\end{array}$ & $\begin{array}{l}\text { - } 1 \text { billion NZ\$ in wind energy } \\
\text { - Where do we see carbon and Fuel prices going } \\
\text { etc. }\end{array}$ & $\begin{array}{l}\text { - General question to } \\
\text { see what their future } \\
\text { strategy is based on }\end{array}$ \\
& $\begin{array}{l}\text { - Geothermal is the best option } \\
\text { - What is the electricity demand is going to be? } \\
\text { - Carbon constraint environment, time of coal } \\
\text { fired power stations are over. }\end{array}$ & \\
\hline
\end{tabular}

1. What does sustainability mean to Contact?

Sustainability means more than just the environment for Contact Energy; it is also about the communities, employees, shareholders and stakeholders. By incorporating sustainability into their business Contact is ensuring that valuable resources are available for future generations. Furthermore, Contact is actively working together with their shareholders, customers and employees to expand sustainability efforts within the company and its environment.

In comparison to other companies Contact Energy started fairly late to incorporate sustainability into their business, but as stated in their sustainability report it is very important to stand on an economically sustainable footing before embracing sustainability into all aspects of the business. From a strategic point of view, therefore, it made sense for Contact Energy to wait a bit longer than some of their competitors to embrace corporate sustainability (Peel, 2005).

\section{What sustainable business practices does Contact employ?}

Contact energy is actively involved in CSR and has embraced sustainability as one of their core values within the company. Currently 50\% of Contact energy is coming from renewable resources, which is hoped to be expanded to up to $65 \%$ in the next five to six years.

3. When did Contact start to consider and employ sustainable business practices?

Contact energy started to embrace sustainability more recently, in 1996 to be exact. The next big milestone towards sustainability was the sustainability report which was 
published in February 2007. The report and Contact's new commitment to sustainability and renewable energy resources was applauded by both shareholders and stakeholders. That day Contact's shares went up by an estimated 3\%.

The fact that Contact's shares went up by 3\% the day they announced they would commit to renewable energies and sustainable practices confirms the findings of Placet et al., (2005) and Beloff et al., (2007).

4. Why did Contact begin to investigate sustainable business practices?

Contact energy started investigating sustainable energy solutions after intensive market analysis of fuel prices and future carbon taxes indicated that fossil fuel powered electricity generation is no longer viable. In order for the company to grow and to deliver good economics to the shareholders, Contact's focus was now on sustainable energy solutions. Contact energy realised that renewable energy solutions are the future and therefore it would not make sense to reinvest in fossil fuel powered energy generators.

Yeoman et al. (2006) stated that new technologies will emerge to replace oil as an energy source when oil prices become too expensive. Rising oil prices therefore help businesses to realize that better, less polluting energy sources need to be developed. Dwindling resources like oil, for example, are reasons some energy companies invest more heavily into renewable energies. Contact Energy pointed out in the interview that they have to provide 'good economics' to shareholders, and with current and forecast oil prices that would not be possible. 'Peak oil', therefore, is one of the reasons Contact Energy invests so heavily in renewable energies.

\section{What resources does Contact invest in sustainable business practices?}

Contact has a major capital expenditure plan and just recently invested NZ\$ 2 billion in a sustainability project. Furthermore, many new renewable energy projects are on the way, with investments close to NZ\$1billion. Contact's employees are also heavily involved with sustainable practices around their workplace (recycling, energy saving etc.), which makes Contact the sustainable energy company they are today (Contact Energy, 2007). 
6. Is Contact using any external reporting standards?

Contact Energy is using the GRI guide for external reporting as well as ISO 14001. All electricity generation sites are ISO 14001 accredited. Furthermore, Contact is investigating taking their ISO accreditation to the next level.

7. Does Contact use any internal measurement systems in order to measure the costs and benefits of using sustainable practices?

Contact is using internal programmes to measure the success of their sustainability programmes and initiatives like the waste reduction programme. Furthermore, Contact measures the effect of their paper and compost recycling systems. Contact Energy is aiming to focus more on internal measurement for their next sustainability report in 2008. Key Performance Indicators (KPIs) might be one approach to tackle the internal measurement at Contact Energy.

8. How does Contact balance the costs of sustainable business practice with ensuring returning an investment to shareholders?

Contact energy is ensuring a return on investment to shareholders by investing in sustainable practices and renewable energies, because by not investing in fossil fuels they will secure long-term success and avoid high costs of fossil fuels, which will only get more expensive.

9. What is Contacts' future strategy regarding sustainability?

Contact Energy is going to focus on renewable energies for electricity production as well as heavily investing in wind energy over the coming years.

10. What kind of strategic or market analysis is the future strategy based on?

Contact Energy's future strategy is based on a market analysis which showed that carbon and fuel prices will only go up in the future and this decided them to focus on 
renewable energies. Furthermore, the geothermal capacities of Contact Energy are to be expanded because they are currently one of the best renewable options. Contact just recently invested NZ\$1 billion into wind energy due to the fact that we live in a carbon constrained environment and the time of coal-fired power stations is over.

The Sustainability framework can be applied in order to see where Contact Energy has its strength and where it could improve parts of its organisation (Figure 21).

Figure 19: Contact Energy SSF. Blue, good; red, room for improvement.

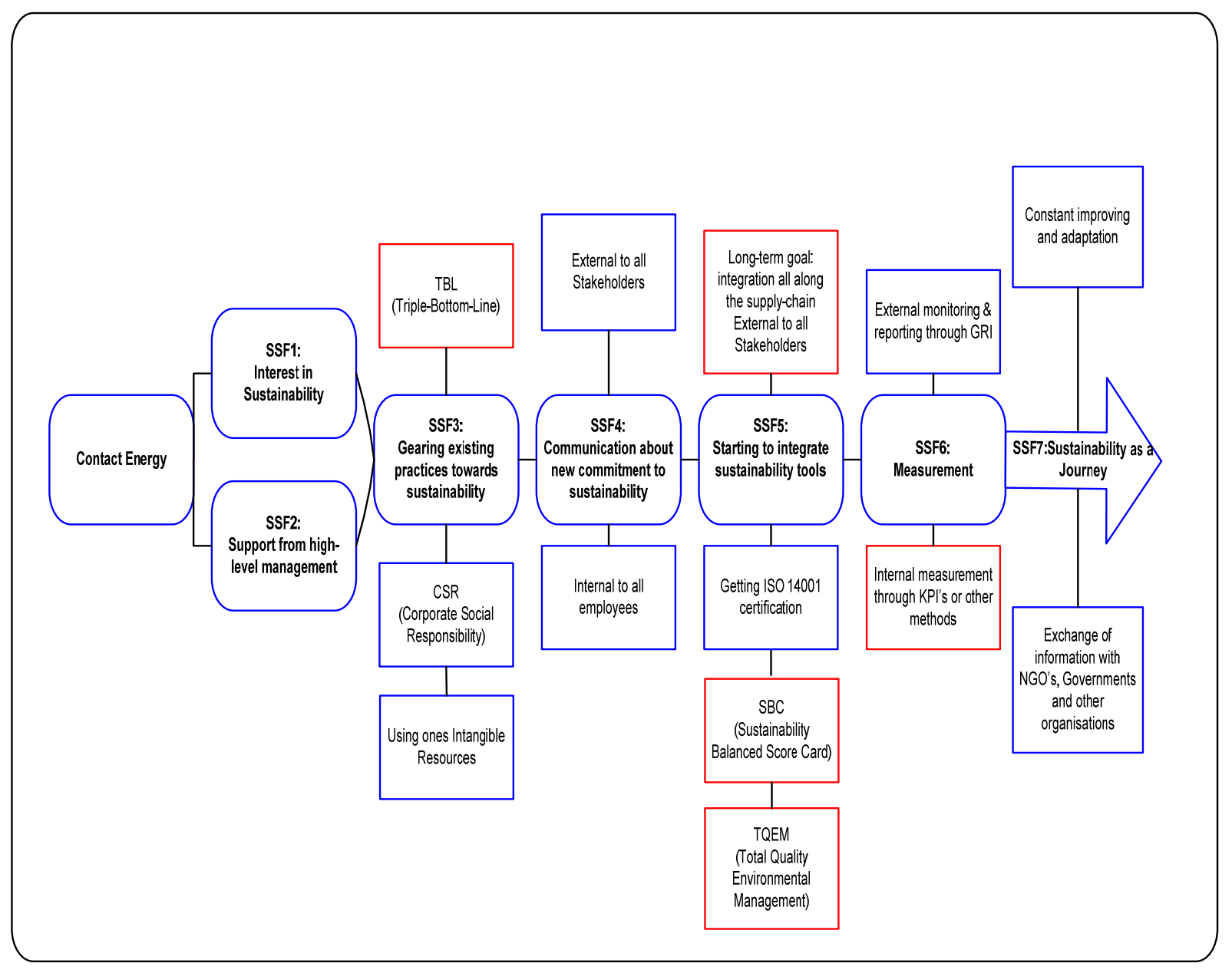

Contact Energy has integrated sustainability very well into their business since early 2007, when it was decided that sustainability was the way to go forward. Areas for improvements indicated in Figure 21 will be discussed below using the Check Box (Table 4). 
Table 4: Contact Energy SSF Check-Box

\begin{tabular}{|l|l|}
\hline \multicolumn{2}{|c|}{ SSF Check-Box } \\
\hline Company & Contact Energy \\
\hline 1. Interest in Sustainability & $\sqrt{ }$ \\
\hline 2. Support from high level Mgmt & $\sqrt{ }$ \\
\hline $\begin{array}{l}\text { 3. Gearing existing practices towards } \\
\text { Sustainability }\end{array}$ & $\sqrt{ }$ \\
\hline 3a. CSR & $\sqrt{ }$ \\
\hline 3b. TBL & $\mathrm{x}$ \\
\hline $\begin{array}{l}\text { 4. Communication about new } \\
\text { commitment to sustainability }\end{array}$ & $\sqrt{ }$ \\
\hline 4a. Internal & $\sqrt{ }$ \\
\hline 4b. External & $\sqrt{ }$ \\
\hline $\begin{array}{l}\text { 5. Starting to integrate sustainability } \\
\text { tools }\end{array}$ & $\sqrt{ } \mathrm{x}$ \\
\hline 6. Measurement & $\sqrt{ }$ \\
\hline 6a. Internal & $\mathrm{x} \sqrt{ }$ \\
\hline 6b. External & $\sqrt{ }$ \\
\hline 7. Sustainability Journey & $\sqrt{ }$ \\
\hline
\end{tabular}

\section{Interest in Sustainability}

Contact Energy is highly interested in sustainability and is currently focusing on only investing in renewable energy sources in the future. Currently over $50 \%$ of Contact's energy is produced from renewable energy sources. $\boldsymbol{J}$

\section{Support from high level Mgmt}

In early 2007 Contact's top management team decided after careful investigations that the future belongs to renewable energy sources, and plans to become more sustainable were made. Contact Energy does have the back-up of the top-level management for their sustainable practices. $\checkmark$ 


\section{Gearing existing practices towards Sustainability}

\section{3a. CSR}

Contact Energy is actively using CSR to manage the company's social responsibilities towards the affected communities and their environment. Corporate Social Responsibility helped Contact Energy to integrate sustainability into their business. $\mathbf{J}$

3b. TBL

Triple-Bottom-Line activities are non-existent at Contact Energy. $\mathbf{x}$

\section{Communication about new commitment to sustainability}

\section{4a. Internal}

Internally the new commitment to sustainability has been communicated very well and everyone is doing their part to save energy and to produce less waste. $\mathbf{J}$

Figure 20: Waste reduction Contact energy

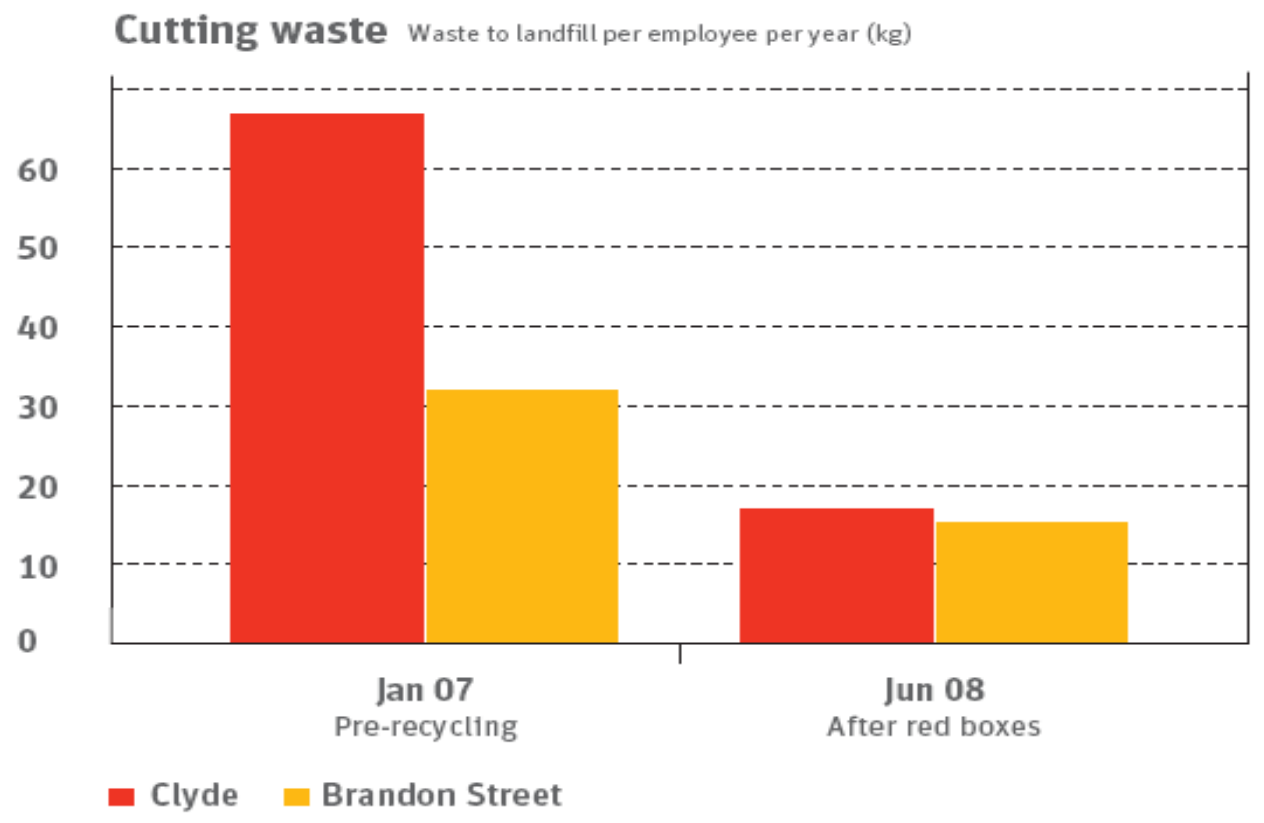

(Energy, 2008)

\section{4b. External}

Externally the commitment has been communicated well to most stakeholders of Contact Energy. As a next step, integrating sustainability all along the supply chain 
would be advisable. In their 2007/2008 sustainability report most external stakeholders are addressed but suppliers are currently not mentioned. Would it be advisable to integrate sustainability along the supply chain as for example, is done by Meridian Energy (Contact Energy, 2007; Contact Energy, 2008). J

\section{Starting to integrate sustainability tools}

ISO 14001 is actively used by Contact Energy and all their production sites are ISO 14001 accredited. The SBSC and TQEM should be considered for future use. $\sqrt{ } \mathbf{x}$

\section{Measurement}

\section{6a. Internal Measurement}

Internally Contact Energy is currently not measuring the exact effect of their sustainable practices but is measuring waste reduction and cost savings related to that. Contact Energy stated that they are working on creating more defined measures measure the effect of their sustainable practices in the near future. KPIs could become part of the internal measurement system. $\mathbf{x} \boldsymbol{J}$

\section{6b. External Measurement}

For external measurement Contact is following the GRI guidelines and ISO 14001, which are internationally accepted reporting standards. $J$

\section{7: Sustainability Journey}

Contact Energy is committed to their new sustainability approach and will constantly improve and adapt their practices to the changing environment.

\subsubsection{Conclusion:}

Contact Energy has gone through tremendous effort since deciding on committing to sustainable principles and renewable energy sources. The framework of this thesis showed that Contact's approach to integrating sustainability was nearly exactly what this thesis is recommending as an integration process. Areas on which Contact Energy should focus more in the near future are internal measurement of their sustainability 
efforts as well as integrating sustainable principles all along their supply chain in order to make every product they purchase as clean as possible. Furthermore, Contact energy could implement some more sustainability tools within the company in order to help integrating it even more. Overall, Contact Energy has done a good job of implementing sustainability into their business since early 2007.

In contradiction to the findings of the Contact Energy case, Contact Energy is ranked in the Greenpeace 'Clean Energy Guide’ as less sustainable than in this research. The Greenpeace 'Clean Energy Guide’ ranks Contact Energy near the lower end of the scale of clean energy companies in 2005. The independent survey for Greenpeace looked at all New Zealand energy companies and ranked them according to their current energy practices as well as their future plans on renewable energies. This research looked at Contact Energy's current and fairly recent energy and sustainable practices and, therefore, the findings of this research in comparison to the 2005 report might be slightly better. Contact energy only just committed to a greener and more sustainable future in early 2007 and the efforts towards sustainability might therefore not be reflected in the 'Clean Energy Guide ${ }^{25}$, from 2005.

\subsection{Case Study B}

Case Study B has been conducted with and for Meridian Energy. The aim of this case study is to analyse Meridian Energy's current sustainability practices, which entails what sustainability tools are being used, how is sustainability measured, what future sustainability strategies might be implemented and how current practices might be improved. The following section will introduce Meridian Energy and its current sustainability practices.

25 Source : http://www.cleanenergyguide.org.nz/ceg/info.asp , accessed on the $4^{\text {th }}$ of August 2008. 


\subsubsection{Introduction of Meridian Energy}

Meridian Energy is New Zealand's largest state-owned electricity generator as well as the only electricity company in New Zealand which is labelled carbon zero. Carbon zero in this context means that Meridian Energy is providing energy to the customer which is carbon neutral, i.e., the process of generating energy is not producing greenhouse gasses. Any other greenhouse gasses which might be produced at Meridian Energy are 'offset' with carbon credits ${ }^{26}$.

Meridian is generating most of its energy from hydro dams, wind farms and other renewable resources that do not produce greenhouse gas emissions. Currently Meridian operates nine hydro power stations in the South Island as well as New Zealand biggest wind farm, Te Apiti (Electricity Group, 2008).

The following statement by Meridian Energy points out that New Zealand has the means for sustainable energy production: "New Zealand is blessed with excellent wind and hydro resources that have provided the nation with a competitive advantage for more than a century and they hold significant further potential. As well as being a more environmentally sustainable option, renewable energy is cost competitive, it addresses carbon emission issues, and it is what New Zealanders want." (Hydro Energy Fact Sheet; Meridian Energy, 2006, p1)

Meridian Energy sets the new bar for 'green buildings'

The Head Office of Meridian Energy was recently moved into a new building which is designed to meet ecological and sustainable standards of The New Zealand Green Building Council (NZGBC). The NZGBC has awarded the new Meridian Energy building with five stars which is the highest rating, and will be setting the bar for future green buildings.

${ }^{26}$ Source:

http://www.meridianenergy.co.nz/AboutUs/News/Meridian+Energy+first+NZ+energy+company+to+have+certified+ carbon+neutral+electricity+.htm , accessed on the $4^{\text {th }}$ of August 2008. 
Features of and in the new Meridian building are:

- Chilled beams for efficient heating or cooling of office space.

- Double-skin facades on two external walls for efficient ventilation and temperature control.

- Thermal mass in the concrete structure which can absorb heat during the day which then can be used the next day to heat office space.

- Lights with motion-sensors in order to guarantee that energy for lighting is only used when needed.

- Waterless urinals and water efficient toilets to minimize water use as well as the use of rainwater for flushing toilets.

- The concrete in the building consists of $65 \%$ of recycled concrete which reduces the carbon footprint of the building.

- Low energy photocopiers and printers.

- A central stairwell in order to discourage the use of lifts as well as to circulate air within the building.

- The building has a waste management system in place to reduce waste and landfill.

- Low energy screens in offices.

- Maximum use of natural light.

- Solar-powered hot water heaters in their kitchens.

Overall the Meridian Energy building will use about 70\% less water than the average office building and 60\% less power. The huge amount of water and energy saved clearly shows the benefits of a sustainable green building. Over the years Meridian Energy will be able to achieve significant cost saving for energy and water which can be used to further improve Meridian’s sustainability strategy. 


\subsubsection{Current sustainability practices}

All information on Meridian Energy’s sustainability practices are taken from their 2001 sustainability report (Meridian Energy, 2001); unless indicated otherwise.

Meridian Energy's sustainability policy

Meridian is committed to take account of their commitment to the goal of sustainability in their business decisions and activities.

Meridian proactively meets their commitments under current legislation and agreements. Furthermore, Meridian is ensuring robust environmental outcomes by involving stakeholders where appropriate in their decision-making process.

Meridian is committed to recognise cultural diversity and to respect the views and values of indigenous people where they are affected by their activities. Moreover, Meridian promotes awareness of environmental issues amongst their employees and suppliers and involves them in projects where appropriate.

Meridian is also committed to promote the efficient use of energy to their customers and recently started to introduce smart-meters which measure the actual energy consumption in households.

Meridian will continue to refine and develop their environmental management systems as well as set targets for environmental improvement. Finally, Meridian will measure, report and review their performance in meeting these commitments.

Meridian also works closely with communities and the Department of Conservation (DOC) which helps to make sure that all policies and activities take the environment and wild life into account and protects it as good as possible.

Meridian helped to restore culturally and environmentally significant wetlands in the Jericho Valley in corporation with the Ngai Tahu and Te Waiau Mahika Kai Trust. 
In 2005 Meridian provided free energy-efficient products for about 1000 customers around New Zealand as part of the Energy Saver Vans scheme (Meridian Energy, 2007).

Meridian took extra care to minimize their environmental impact on the White Hill Wind Farm through various means which preserved as much as possible of the native plant and wildlife (Meridian Energy, 2007).

Meridian is actively sponsoring the project River Recovery in cooperation with the Department of Conservation, which aims to maintain indigenous vegetation by removing problem weeds and enhancing wetland areas. Large-scale predator control is also looked into in order to help native wildlife to recover (Meridian Energy, 2007).

Currently Meridian is working actively on creating a Sustainability Supply Chain which focuses on making sure that all suppliers of Meridian Energy employ environmental friendly practices and products. Meridian is using a Sustainability Chain management guideline based on the United Nations Global Compact which is widely accepted in the business community. This guideline helps Meridian to make sure that sustainable factors are taken into the process of selecting new suppliers (Meridian Energy, 2007).

Meridian Energy is also giving advice to consumers on how to best save energy in their households. The tips and tricks on how to save energy are very useful and manifold; most tips on how to conserve energy are cost free. See Appendix for image.

\subsubsection{Case findings}

In this section we discuss the findings of both the secondary data analysis and the interview data gathered at Meridian Energy.

To start with we will look at the secondary data. Meridian Energy seems to work very closely together with their customers and provides very good advice on how to save energy cost. Furthermore have they recently introduced smart-meters which measure the 
actual power consumption per household, which helps householders to know in which areas power can be saved.

Meridian's commitment to sustainability is probably the hallmark in its industry. Due to its early commitment to sustainability (1999) and only renewable energy sources Meridian Energy managed to become the first New Zealand energy company to be labelled carbon zero.

Meridian is also working very closely with their stakeholders and all affected communities which helps to find the best sustainable outcome for all parties involved.

Meridian stated in their 2007 Annual Report that they now focus on a sustainable supply chain, where current suppliers are motivated to embrace sustainable values and new suppliers are chosen that follow sustainable standards (Meridian Energy, 2007). After having deeply ingrained corporate sustainability into their business, integrating sustainability into the supply chain makes good sense.

Overall Meridian Energy seems to have embraced corporate sustainability to the fullest and now aims to expand their sustainability commitment throughout all their stakeholders.

Data gathered from the interviews are summarized in Table 5 and discussed in detail on the next page. 
Table 5: Questions and Answers from interviews with Meridian Energy staff.

\begin{tabular}{|c|c|c|}
\hline Questions & Meridian Energy & Links to Literature \\
\hline $\begin{array}{l}\text { 1. What does sustainability mean } \\
\text { to Meridian/Contact? }\end{array}$ & $\begin{array}{l}\text { - Core values } \\
\text { - Chief executives values were high on sustainability } \\
\text { - "Part of the DNA" }\end{array}$ & $\begin{array}{l}\text { - Links back to the } \\
\text { sustainability literature. How is } \\
\text { sustainability interpreted? }\end{array}$ \\
\hline $\begin{array}{l}\text { 2. What sustainable business } \\
\text { practices does Meridian/Contact } \\
\text { employ? }\end{array}$ & $\begin{array}{l}\text { - Climate Change Team } \\
\text { - "Is something everyone lives and does” } \\
\text { - Selling carbon credits through their wind-farms } \\
\text { - GRI }\end{array}$ & $\begin{array}{l}\text { - Links back to CSR, TBL and } \\
\text { reporting literature. }\end{array}$ \\
\hline $\begin{array}{l}\text { 3. When did Meridian/Contact } \\
\text { start to consider and employ } \\
\text { sustainable business practices? }\end{array}$ & - From the very beginning (1999) & $\begin{array}{l}\text { - Links to sustainability } \\
\text { timeline in order to see when } \\
\text { implementation took place. }\end{array}$ \\
\hline $\begin{array}{l}\text { 4. Why did Meridian/Contact } \\
\text { begin to investigate sustainable } \\
\text { business practices? }\end{array}$ & $\begin{array}{l}\text { - Inheritance of renewable assets and a sustainable vision for } \\
\text { the future from the start } \\
\text { - Values }\end{array}$ & $\begin{array}{l}\text { - Links to sustainability debate } \\
\text { to see why they implemented } \\
\text { sustainability. Value-based or } \\
\text { monetary- based decision? }\end{array}$ \\
\hline $\begin{array}{l}\text { 5. What resources does } \\
\text { Meridian/Contact invest in } \\
\text { sustainable business practices? }\end{array}$ & $\begin{array}{l}\text { - Sustainability Integration Specialist } \\
\text { - Many more people are involved with sustainability issues }\end{array}$ & $\begin{array}{l}\text { - Links to framework in order } \\
\text { to see how committed the } \\
\text { companies are. }\end{array}$ \\
\hline $\begin{array}{l}\text { 6. Is Meridian/Contact using any } \\
\text { external reporting standards? }\end{array}$ & $\begin{array}{l}\text { - GRI/ Carbon Zero Programmes } \\
\text { - ISO } 14064\end{array}$ & $\begin{array}{l}\text { - Links to TBL reporting } \\
\text { literature as well as reporting } \\
\text { standards and tools }\end{array}$ \\
\hline $\begin{array}{l}\text { 7. Does Meridian/Contact use any } \\
\text { internal measurement systems in } \\
\text { order to measure the costs and } \\
\text { benefits of using sustainable } \\
\text { practices? }\end{array}$ & $\begin{array}{l}\text { - Robust Business Case } \\
\text { - Emission reduction plan for Carbon Zero, pointed out } 11 \text { areas } \\
\text { which had to be measured } \\
\text { - Is aiming to be "the global reference company in the area of } \\
\text { sustainability" }\end{array}$ & $\begin{array}{l}\text { - Links back to PM literature } \\
\text { and internal measurement }\end{array}$ \\
\hline $\begin{array}{l}\text { 8. How does Meridian/Contact } \\
\text { balance the costs of sustainable } \\
\text { business practice with ensuring } \\
\text { returning an investment to } \\
\text { shareholders? }\end{array}$ & $\begin{array}{l}\text { - Any project that gets approved, has to have a very sound } \\
\text { bases (strong business case) } \\
\text { - Shareholders themselves are very interested to further develop } \\
\text { sustainability }\end{array}$ & $\begin{array}{l}\text { - Links back to the stakeholder } \\
\text { literature }\end{array}$ \\
\hline $\begin{array}{l}\text { 9. What is Meridian/Contacts' } \\
\text { future strategy regarding } \\
\text { sustainability? }\end{array}$ & $\begin{array}{l}\text { - To continue the sustainability ‘journey’ } \\
\text { - Further development of sustainable policies } \\
\text { - Sustainable Development Policy }\end{array}$ & $\begin{array}{l}\text { - Links back to framework } \\
\text { (sustainability journey) }\end{array}$ \\
\hline $\begin{array}{l}\text { 10. What kind of strategic or } \\
\text { market analysis is the future } \\
\text { strategy based on? }\end{array}$ & $\begin{array}{l}\text { - Renewables only ' after intensive research in 2004' } \\
\text { - Relying on imports would not be good (Oil, LED), therefore } \\
\text { renewables only }\end{array}$ & $\begin{array}{l}\text { - General question to see what } \\
\text { their future strategy is based on }\end{array}$ \\
\hline
\end{tabular}

\section{What does sustainability mean to Meridian?}

Meridian Energy was established in 1999 and inherited only renewable energy sources from the government. The Chief Executive of that time valued sustainability and made sustainability one of the core values of Meridian. Thus sustainability is an inherent part of Meridian. Furthermore, sustainability is seen as a journey which is ongoing and ever improving. Sustainable thinking is something that everyone lives and does at Meridian Energy.

Meridian Energy, in comparison to other energy companies, was in a prime position to embrace sustainability. Not only did they only inherit (by in 'inherit' I mean that only renewable energy sources were handed to them by government when the energy sector 
was restructured (Electricity Group, 2008)) renewable energy resources, they also had high commitment from top management towards sustainability.

2. What sustainable business practices does Meridian employ?

Meridian energy does not actively follow CSR or TBL principles but combines those and other principles in their sustainability efforts. CSR activities will be embraced in the near future due to growing government interest. Meridian is using GRI guidelines which are an international standard in sustainability. Moreover, Meridian is selling carbon credits through their wind-farms on the international market as well as investing resources into their climate change team.

\section{When did Meridian start to consider and employ sustainable business practices?}

Meridian energy started to embrace sustainability the very day of its foundation (1999) due to the resources they inherited as well as the vision of the former chief executive.

\section{Why did Meridian begin to investigate sustainable business practices?}

Meridian started to investigate sustainability because of their Chief Executive's values and vision as well as their unique position of having inherited only renewable assets.

5. What resources does Meridian invest in sustainable business practices?

Due to Meridian's commitment to renewable energies and their policies towards sustainability, one could say that most resources at Meridian are geared towards sustainability. No exact figures exist which could be linked with sustainability practices, but Meridian is employing a sustainability integration specialist, which can be seen as a resource. Furthermore, every person involved with sustainability issues is a resource committed to sustainability.

\section{Is Meridian using any external reporting standards?}

Meridian Energy is using the GRI guide as its external reporting standard and is following those guidelines for their business reports and publications. Furthermore, 
Meridian Energy is using the ISO 14064 which is the international standard for greenhouse emissions inventories and verification.

7. Does Meridian use any internal measurement systems in order to measure the costs and benefits of using sustainable practices?

Meridian Energy is currently not using any specific internal measurement systems in order to measure the costs and benefits of using sustainable practices. This might be due to the fact that sustainability is so deeply ingrained in the company that it becomes hard to measure. When Meridian went through their emission reduction plan in order to qualify for Carbon Zero, 11 areas were found which had to be measured in order to qualify for Carbon Zero.

Internal measurement such as KPIs or similar indicators would be useful to integrate in the near future for both (success) measurement and statistics.

8. How does Meridian balance the costs of sustainable business practice with ensuring returning an investment to shareholders?

The shareholders at Meridian Energy have a strong interest in sustainable practices and renewable energies, because long-term sustainability will provide security of investment. Furthermore, every project will have to have a very strong business case before it gets approved which ensures a certain amount of security for shareholders when big investments into sustainability are made.

9. What is Meridian's future strategy regarding sustainability?

Meridian's future strategy regarding sustainability is to continue the sustainability 'journey'. Furthermore, Meridian is committed to further development of sustainability policies and sustainable practices.

10. What kind of strategic or market analysis is the future strategy based on?

Meridian's future strategy is based on intensive research undertaken in 2004 which showed that sustainability is the way forward. Since 2004 onwards Meridian is 
committed to renewables only. Furthermore, Meridian decided it would not be good to rely on imports such as oil and LED (Gas) and therefore focuses on renewable energies only.

The strategic sustainability framework can be applied in order to see where Meridian Energy has its strength and where it could improve parts of its organisation (Figure 24).

Figure 21: Meridian Energy SSF. Blue, goo; red, room for improvement.

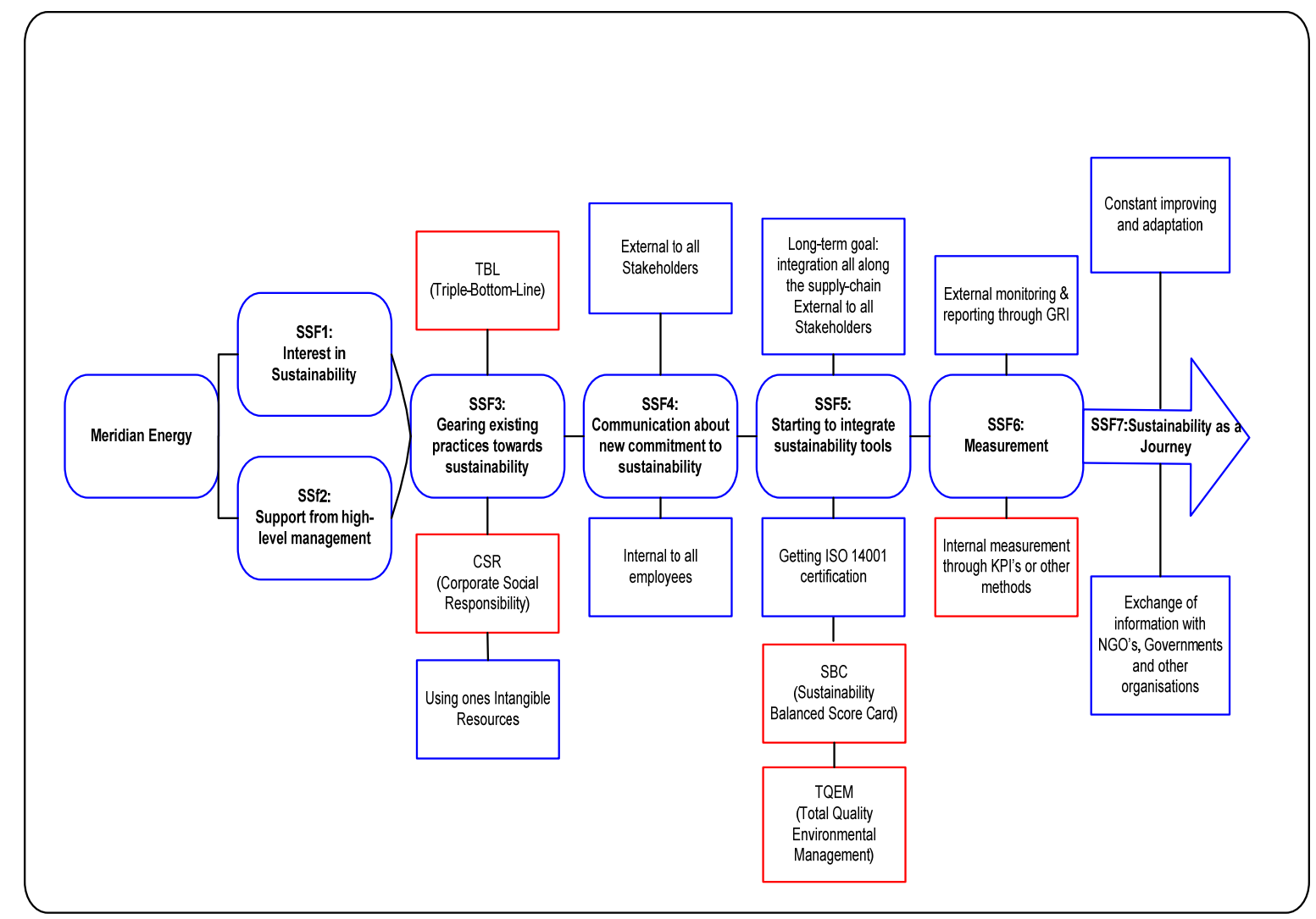

Meridian Energy has integrated sustainability very well into their business, because they had high level commitment from their CEO from the very beginning. Most steps are integrated perfectly and as we can see there is just minimal room for improvement. Areas for improvement indicated in Figure 24 will be discusses below, using the Check Box. 
Table 6: Meridian Energy SSF Check-Box

\begin{tabular}{|l|l|}
\hline \multicolumn{2}{|c|}{ SSF Check-Box } \\
\hline Company & Meridian Energy \\
\hline 1. Interest in Sustainability & $\mathrm{V}$ \\
\hline 2. Support from high level Mgmt & $\mathrm{V}$ \\
\hline $\begin{array}{l}\text { 3. Gearing existing practices towards } \\
\text { Sustainability }\end{array}$ & $\mathrm{V}$ \\
\hline 3a. CSR & $\mathrm{x}$ \\
\hline 3b. TBL & $\mathrm{x}$ \\
\hline $\begin{array}{l}\text { 4. Communication about new } \\
\text { commitment to sustainability }\end{array}$ & $\mathrm{V}$ \\
\hline 4a. Internal & $\mathrm{V}$ \\
\hline 4b. External & $\mathrm{V}$ \\
\hline $\begin{array}{l}\text { 5. Starting to integrate sustainability } \\
\text { tools }\end{array}$ & $\mathrm{V}$ \\
\hline 6. Measurement & $\sqrt{ }$ \\
\hline 6a. Internal & $\mathrm{x}$ \\
\hline 6b. External & $\sqrt{ }$ \\
\hline 7. Sustainability Journey & $\mathrm{J}$ \\
\hline
\end{tabular}

\section{Interest in Sustainability}

Meridian Energy's interest and commitment to sustainability has been very high from the very day of their foundation. Meridian Energy is relying 100\% on renewable energy sources. Thus sustainable thinking is an inherit part of Meridian. $\boldsymbol{J}$

\section{Support from high level Management}

Due to Meridian's Chief Executive's commitment to sustainability, very high commitment from Day one was given. $J$

\section{Gearing existing practices towards Sustainability}

Meridian did not have to gear existing practices towards sustainability, because the whole company's focus was geared towards sustainability from Day one. $\mathbf{J}$

\section{3a. CSR}

Till recently Meridian did not actively practice CSR and, therefore, could not use it as part of their sustainability strategy. The New Zealand government recently showed 
interest in CSR at Meridian Energy which will probably lead to Meridian considering paying CSR activities more attention. $\mathbf{x}$

3b. TBL

Triple Bottom Line activities at Meridian Energy are non-existing. $\mathbf{x}$

\section{Communication about new commitment to sustainability}

Meridian Energy communicates their commitment to sustainability very well through media and their actions.

\section{4a. Internal}

Internally they have a team which works solely on sustainability issues and with their new green building in Wellington everyone is aware of sustainability due to their work environment. $\checkmark$

\section{4b. External}

Externally sustainability is well communicated to all stakeholders especially now with the new approach of integrating sustainability into every aspect of their supply chain. $\boldsymbol{J}$

\section{Starting to integrate sustainability tools}

Several sustainability tools have been integrated successfully at Meridian of which one is ISO 14001. TQEM and the SBSC have not been used due to Meridian's sustainability commitment going back 9 years. The SBSC is very useful to help integrate sustainability into businesses which haven't yet fully integrated it. TEQM on the other hand might prove to be a useful tool for Meridian and might be approached as a tool in the future. $\sqrt{ } \mathbf{x}$

\section{Measurement}

\section{6a. Internal}

Internal measurements are few at Meridian Energy if it comes to measuring the success of their sustainable activities. Waste reduction is measured on a yearly base though, which is now moved to December, due to some facilities being too isolated in winter. Internal measurements such as KPIs might be introduced in the near future. $\mathbf{x}$ 


\section{6b. External}

External measurement happens through the GRI on a yearly base which offers worldwide, very well accepted reporting standards. J

\section{Sustainability journey}

Meridian Energy is committed to sustainability and works very actively at constantly adapting their sustainability efforts to the ever-changing environment. Sustainability is for Meridian Energy a never-ending journey which sees sustainability as their most important goal. $\mathbf{J}$

\subsubsection{Conclusion}

Meridian Energy has done a great job implementing sustainability into their core business from day one in 1999. From then on sustainability and renewable energies have been the main focus of the company, which makes it the sustainability champion it is today. Areas on which Meridian should work in the future are internal measurement in order to measure their sustainability outcomes in more detail, implementing CSR activities which will help the company to work even better with communities and the government.

The findings of Meridian Energy's commitment to sustainability are reflected in the Greenpeace 'Clean Energy Guide ${ }^{27}$, which ranks New Zealand's energy companies according to their current energy practice, energy generation and future plans on how to generate energy. The 'Clean Energy Guide' was conducted as an independent survey for Greenpeace in 2005. Meridian Energy is ranked as the cleanest energy company in New Zealand due to their generation of only renewable energy and future commitment to continue to do so.

\footnotetext{
${ }^{27}$ Source: http://www.cleanenergyguide.org.nz/ceg/info.asp , accessed on the $6^{\text {th }}$ of August 2008.
} 


\subsection{Analysis and Interpretation}

Earlier this thesis looked at Germany's and New Zealand's energy markets and related government policies. The information about Germany and New Zealand are presented here in a comparative study. Furthermore, the sustainability framework will be applied to a German energy company to get an idea on how New Zealand companies and German companies compare.

\subsubsection{A comparison of Germany's and New Zealand's energy and sustainability policies}

Here I compare Germany and New Zealand and their energy consumption, production, their policies regarding sustainability and $\mathrm{CO}_{2}$ emissions as well as their renewable energy markets. Germany's and New Zealand's energy indicators are compared in Table 7 as well as their policies regarding $\mathrm{CO}_{2}$ emissions and sustainability.

Table 7: Energy indicators and policies in Germany and New Zealand

\begin{tabular}{|l|l|l|}
\hline \multicolumn{1}{|c|}{ Indicators } & \multicolumn{1}{|c|}{ Germany } & \multicolumn{1}{c|}{ New Zealand } \\
\hline Population & $82,369,548$ & $4,173,460$ \\
\hline $\begin{array}{l}\text { Total energy } \\
\text { consumption }\end{array}$ & 545.5 billion kWh & 37.39 billion kWh \\
\hline Electricity production & 579.4 billion kWh & 42.06 billion kWh \\
\hline $\begin{array}{l}\text { Energy consumption } \\
\text { per capita }\end{array}$ & $\begin{array}{l}4.23 \text { metric tons (of oil } \\
\text { equivalent) }\end{array}$ & 4.43 metric tons (of oil equivalent) \\
\hline $\begin{array}{l}\text { Energy Consumption } \\
\text { by }\end{array}$ & 69,989 metric tons (30\%) & 5,239 metric tons (39\%) \\
\hline Sector: Industry & 68,286 metric tons (28\%) & 4,832 metric tons (37\%) \\
\hline Transportation & 2,703 metric tons (1\%) & 337 metric tons (3\%) \\
\hline Agriculture & 23,569 metric tons (10\%) & 1,376 metric tons (11\%) \\
\hline Commercial \& Public & 63,515 metric tons (26\%) & \\
\hline Residential & (10) & \\
\hline
\end{tabular}




\begin{tabular}{|c|c|c|}
\hline Other & 11,680 metric tons $(5 \%)$ & 333 metric tons $(3 \%)$ \\
\hline Electricity imports & 56.86 billion $\mathrm{kWh}$ & 0.00 \\
\hline Electricity exports & 61.43 billion $\mathrm{kWh}$ & 0.00 \\
\hline Oil consumption & 2.618 million barrels/day & $156,000 \mathrm{bbl} /$ day \\
\hline Oil production & $141,700 \mathrm{bbl} /$ day & $25,880 \mathrm{bbl} /$ day \\
\hline Oil imports & 2.953 million bbl/day & $140,900 \mathrm{bbl} /$ day \\
\hline Oil exports & $518,700 \mathrm{bbl} /$ day & $15,720 \mathrm{bbl} /$ day \\
\hline Oil reserves & 367.2 billion bbl & 55.5 million bbl \\
\hline $\begin{array}{l}\text { Natural gas } \\
\text { consumption }\end{array}$ & 96.84 billion cu m & 3.7 billion cu m \\
\hline $\begin{array}{l}\text { Natural gas } \\
\text { production }\end{array}$ & 19.9 billion cu m & 3.9 billion cu m \\
\hline Natural gas imports & 86.99 billion cu m & 0.00 \\
\hline Natural gas exports & 9.42 billion cu $\mathrm{m}$ & 0.00 \\
\hline Natural gas reserves & 246.5 billion $\mathrm{cu} \mathrm{m}$ & 29.67 billion cu m \\
\hline $\mathrm{CO}_{2}$ emissions & $\begin{array}{l}10.2 \text { metric tons per } \\
\text { person (2004) }\end{array}$ & 8.3 metric tons per person (2004) \\
\hline $\mathrm{CO}_{2}$ reduction targets & 21\% reduction 2008-2012 (Holzer, 2005) & $\begin{array}{l}\text { To reduce } \mathrm{CO}_{2} \text { emissions back to the level } \\
\text { of } 1990 \text { by } 2012\end{array}$ \\
\hline Energy market & Liberalised & (Liberalised) \\
\hline $\begin{array}{l}\text { Government-related } \\
\text { energy policies }\end{array}$ & $\begin{array}{l}\text { - Renewable Energy Source Act (EEG) } \\
\text { - European Emission Trading Scheme } \\
\text { (EETS) } \\
\text { - Research for Sustainability } \\
\text { framework }\end{array}$ & $\begin{array}{l}\text { - } \text { Energy Efficiency and Conservation } \\
\text { Act } \\
\text { - } \quad \text { New Zealand Energy Efficiency and } \\
\text { Conservation Strategy } \\
\text { - } \quad \text { Climate Change Response Act }\end{array}$ \\
\hline $\begin{array}{l}\text { Overall percentage of } \\
\text { renewable energy }\end{array}$ & - $14.2 \%$ of electricity production & $\begin{array}{ll}\text { - } & 60-70 \% \\
\text { - } & \text { Target by } 2025 \text { to generate } 90 \% \text { of its } \\
& \text { Energy from renewable energy }\end{array}$ \\
\hline
\end{tabular}




\section{Table Analysis}

In Table 7, seven key themes were chosen to compare Germany and New Zealand. The first is population because due to a country's population certain amounts of energy will have to be produced. The second theme is electricity followed by oil and gas consumption. The last three indicators are $\mathrm{CO}_{2}$ emissions, energy market and government related policies. All these themes were chosen because they will reveal important information about both Germany's and New Zealand's energy markets, their energy consumption, emissions and government policies.

\section{a) Population}

Germany's population is many times bigger than New Zealand's which is due to its location and its history. Germany is historically a fairly old country and has over 80 million people in comparison to New Zealand which is still a fairly young country with just over 4 million people. This difference will show in energy and resource consumption.

\section{b) Electricity}

The total electricity consumption in Germany (2004) has been 545.5 billion kWh in comparison to New Zealand which used 37.39 billion kWh of total electricity. We can see here that if we would multiply New Zealand's electricity consumption by 20 (the factor Germany's population is bigger than New Zealand's) New Zealand would consume 759.4 billion kWh, over 200 billion kWh more. This fact also shows in the per capita consumption, where New Zealand is consuming 0.20 metric tons of oil equivalent more than Germany does. One reason for the higher amount of electricity used could be better insulation in German houses as well as standard central heating in every home, which New Zealand lacks.

Germanys and New Zealand's energy consumption is showing by sector in Figure 22. 
Figure 22: A, Germany's and B, New Zealand's energy consumption by sector, 1999 (Earth Trends ${ }^{28}$

Energy Consumption by Sector, Germany, 1999

\author{
Energy Consumption by Sector, New Zealand, 1999
}

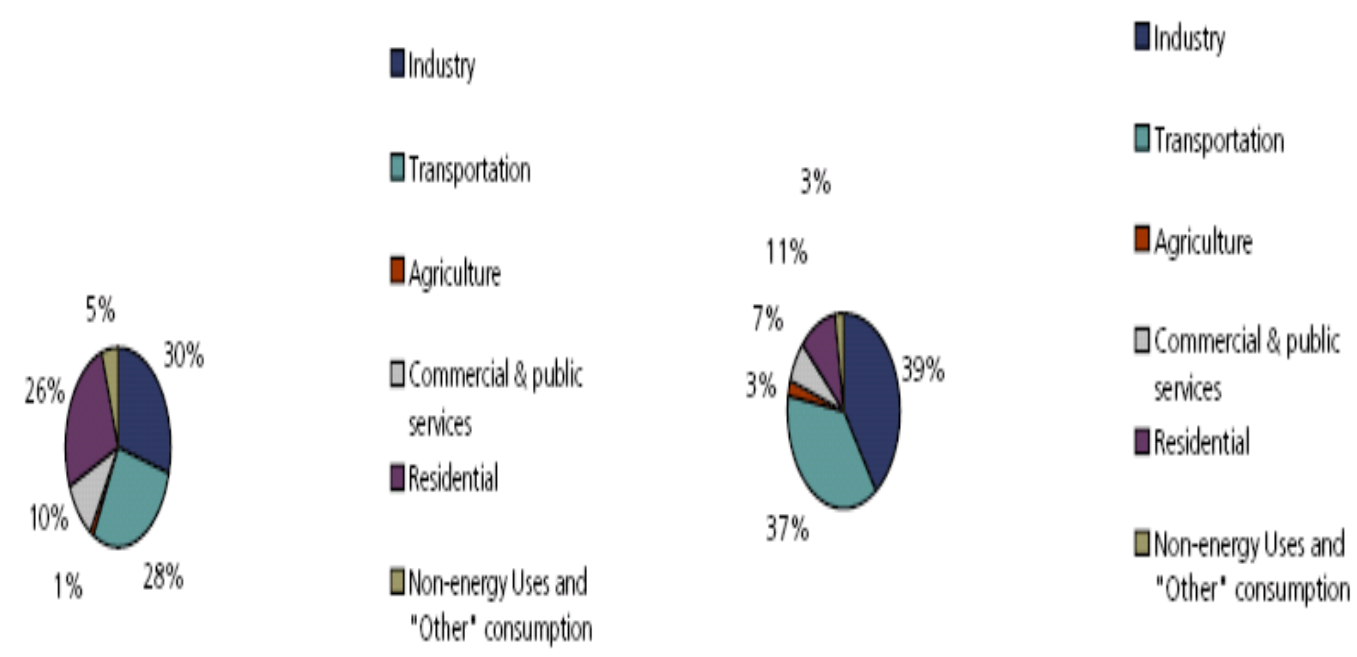

Germany is importing 56.86 billion kWh of electricity per year from neighbouring countries like France but is also exporting 61.43 billion $\mathrm{kWh}$ of electricity to neighbouring countries; therefore the imports of electricity are non-significant. In fact we can subtract 4.53 billion kWh of electricity of Germany's overall electricity consumption which brings its total electricity consumption down to 540.97 billion kWh. New Zealand neither imports nor exports electricity because it is isolated from other countries which makes import or export impossible.

\title{
c) Oil
}

Germany's oil consumption is 2.618 million barrels/day in comparison to New Zealand which consumes 156,000 bbl/day. If we would multiply New Zealand's oil consumption by 20 (population factor) New Zealand would likely consume an estimated 3,120 million bbl/day. One fact that would make this estimate believable is that New Zealand consumes 751 litres of petrol per person/year in comparison to Germany with only 465

\footnotetext{
${ }^{28}$ Source: http://earthtrends.wri.org/pdf_library/country_profiles/cli_cou_276.pdf , accessed on the $6^{\text {th }}$ of August 2008.

http://earthtrends.wri.org/pdf_library/country_profiles/cli_cou_554.pdf, accessed on the $6^{\text {th }}$ of August 2008.
} 
litres of petrol/year. This is very likely explained by better infrastructure and public transport in Germany and New Zealand’s comparatively rural population.

In order to cover Germany's oil consumption the country is importing 2.953 million bbl/day, which is more than their daily consumption. Of those imports Germany is exporting an estimate of 518,700 bbl/day to neighbouring countries like Poland and Russia. Germany's oil production is about $141,700 \mathrm{bbl} /$ day with oil reserves of about 367.2 billion bbl total.

New Zealand's oil imports are 140,900 bbl/day which is slightly under their daily consumption of oil. New Zealand main oil production comes from the Maui oil fields where estimates of 25,880 bbl/day are produced. The excess oil of $15,720 \mathrm{bbl} /$ day is exported to countries like Australia and countries within Asia. New Zealand's oil reserves are an estimated 55.5 million bbl.

\section{d) Gas}

Germany's natural gas consumption is 96.84 billion $\mathrm{m}^{3}$ which is higher than New Zealand's which is 3.7 billion $\mathrm{m}^{3}$, even on a per-person basis. Germany has to import its major (86.99 billion $\mathrm{m}^{3}$ ) gas supply from Russia and only produces a fairly small amount of gas from its overall consumption (19.9 billion $\mathrm{m}^{3}$ ). New Zealand on the other hand produces all its natural gas (3.9 billion $\mathrm{m}^{3}$ ) and neither imports nor exports gas because isn't 'land-locked'. Germany's gas exports are fairly small (9.42 billion $\mathrm{m}^{3}$ ) due to its high consumption of gas. Germany's natural gas resources are an estimated 246.5 billion cu m and New Zealand's natural gas resources are 29.67 billion $\mathrm{m}^{3}$. Therefore, New Zealand's need to discover new gas resources is very high because it only has reserves for the next seven and a half years, and that is if the gas consumption does not rise.

\section{e) $\mathrm{CO}_{2}$ Emissions}

$\mathrm{CO}_{2}$ emissions have been declining in both countries over the last couple of years. In New Zealand that is due to fulfilling the standards of the Kyoto protocol; where NZ is trying to reduce its emissions back to the level of 1990. In 2004 New Zealand emissions 
were 8.3 tonne per person. Germany’s C02 emissions are slightly higher at 10.2 metric tons per person (2004) which is mainly due to Germany having more heavy industry. Germany has to fulfil Kyoto standards as well as European Union standards which demands that Germany has to lower its emissions by 21\% between 2008 and 2012 .

\section{f) Energy market}

Energy markets in both Germany and New Zealand are liberalised. In Germany there are many different power companies as well as energy distributors that create a lot of competition on price, which benefits the end user. New Zealand, on the other hand, has three major power companies which are still partly state-owned and only one Power Company which is partly owned by an Australian power company. Due to the fairly small market and only a handful of suppliers the competition is not very high, which results in fairly high energy prices in comparison with Germany (O’Donnell, 2007).

\section{g) Government related energy policies}

Germany has three main policies regarding the energy market and sustainability which are: The Renewable Energy Source Act (EEG), European Emission Trading Scheme (EETS) and the Research for Sustainability Framework.

New Zealand also has three main policies regarding the energy sector and sustainability: New Zealand Energy Efficiency and Conservation Strategy, The Energy Efficiency and Conservation Act, and Climate Change Act.

\section{h) Percentage of renewable energy}

Germany currently produces $14.3 \%$ of its overall electricity use from renewable energies and is expected to reach 30\% by 2020 (Blue, 2008). The main renewable sources in Germany are wind energy, hydro, geothermal and bio-mass. New Zealand, on the other hand, produces currently between 60 and $70 \%$ of its overall electricity consumption from renewable energy sources, according to Contact Energy (Contact Energy, 2007). Those sources are mainly hydro (60\%) and geothermal (7\%) with a small percent of wind energy (less than 1\%), which is expected to increase over the oncoming years (Contact, 2008). New Zealand's target is to generate $90 \%$ of its energy 
from renewable energy sources by 2025. Whether that is a realistic target remains to be seen.

\subsubsection{Conclusion:}

This analysis has shown that Germany's energy market currently is very sustainable in its energy usage as well as in the promotion of renewable energies. Germany's energy sector seems to have a lot of government-driven incentives for the industry in order to become more sustainable. Furthermore, by guaranteeing the renewable energy sector certain feed-in tariffs, the country produced a climate which encourages the usage of renewable energy sources over fossil fuels. Between 1990 and 2005 Germany's greenhouse gases declined by $18 \%$ and the German government introduced an eco-tax to discourage the usage of fossil fuels (Blue, 2008). New Zealand's energy market does not have many government-driven incentives to encourage the use of renewable energy sources. Having said that, the New Zealand government seems determined to increase the use of renewable energy sources as much as Germany does. With a renewable energy production of around 45\% [(Greenpeace, 2007), (formerly 70\%)], New Zealand certainly has the right 'set-up' to become one of the worlds most clean and green country. One of the current issues with New Zealand's renewable energy is that most is generated from hydro power. The lack of storage capacity and the year-on-year variation in snow-melt and rainfall often lead to energy shortages in New Zealand. The variation in energy security can be up by $19 \%$ in wet years and down by $13 \%$ in dry years. This indicates that New Zealand should work on their energy security in future years as well as investigating more options in wind and geothermal energy. New Zealand has a fairly small population in comparison to other countries and is rich in all resources needed for renewable energy production. Finally, it might be good for the New Zealand government to start international cooperation with countries like Germany to help the country to reach its renewable energy targets because there are a lot of valuable lessons to be learned for both Germany and New Zealand. 


\subsection{Applying the Strategic Sustainability Framework to RWE}

The sustainability framework is now applied to RWE one of Germany's biggest energy companies, compare how that company does in comparison with New Zealand energy companies (Figure 23).

Figure 23: RWE SSF. Blue, good; red, room for improvement.

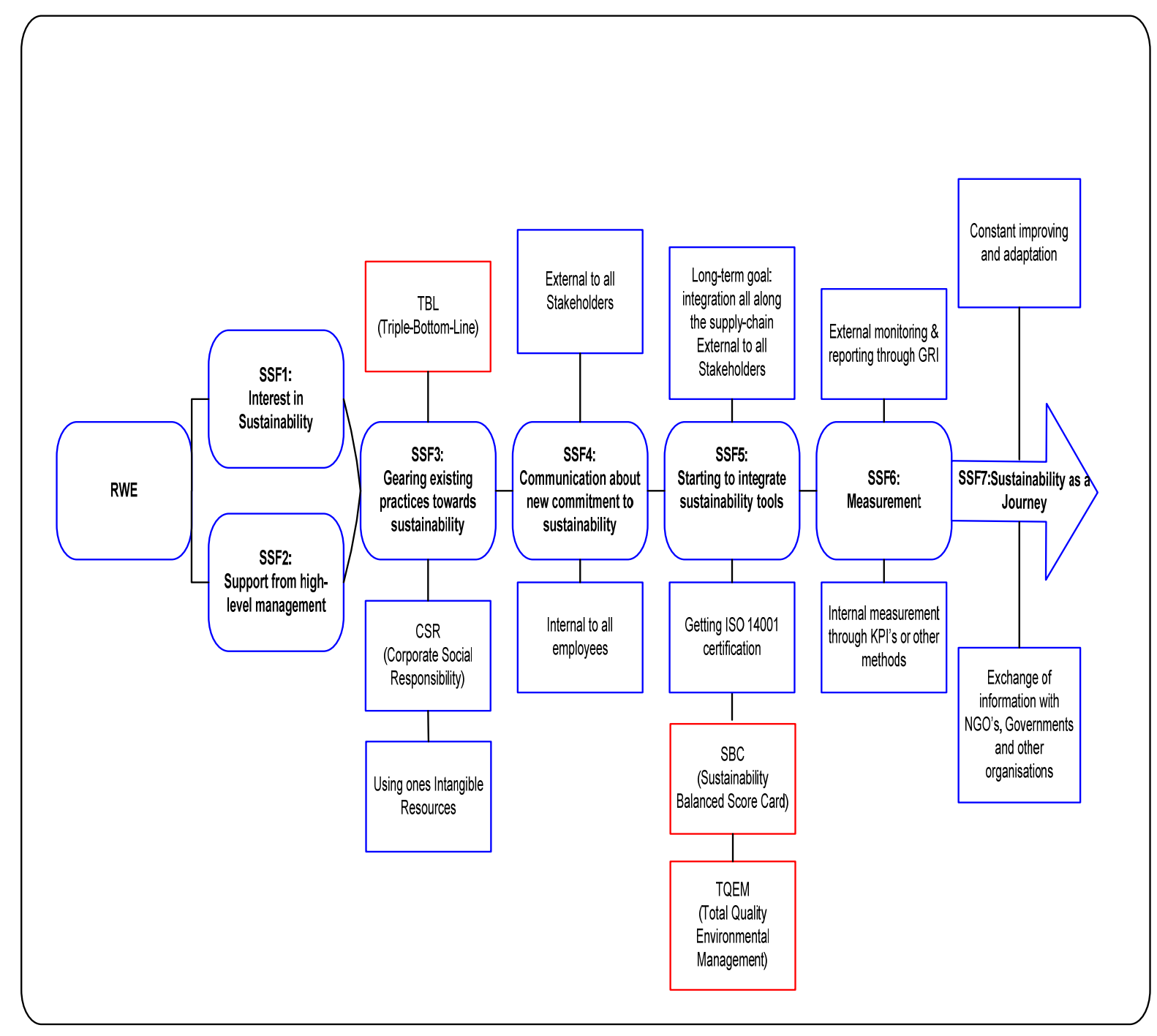

RWE has incorporated most steps in the sustainability framework, similar to Meridian energy and Contact Energy. The Check Box is used to look into each step of the 5 SF in more detail (Table 8). 
Table 8: RWE SF Check-Box

\begin{tabular}{|l|c|}
\hline \multicolumn{1}{|c|}{ SSF Check-Box } \\
\hline \multicolumn{1}{|c|}{ Company } & RWE \\
\hline 1. Interest in Sustainability & $\checkmark$ \\
\hline 2. Support from high level Mgmt & $\checkmark$ \\
\hline $\begin{array}{l}\text { 3. Gearing existing practices towards } \\
\text { Sustainability }\end{array}$ & $\checkmark$ \\
\hline 3a. CSR & X \\
\hline 3b. TBL & $\checkmark$ \\
\hline $\begin{array}{l}\text { 4. Communication about new commitment to } \\
\text { sustainability }\end{array}$ & $\checkmark$ \\
\hline 4a. Internal & $\checkmark$ \\
\hline 4b. External & $\checkmark$ \\
\hline 5. Starting to integrate sustainability tools & $\checkmark$ \\
\hline 6. Measurement & $\checkmark$ \\
\hline 6a. Internal & $\checkmark$ \\
\hline 6b. External & $\checkmark$ \\
\hline 7. Sustainability Journey & $\checkmark$ \\
\hline
\end{tabular}

\section{Interest in Sustainability}

RWE has been interested in sustainability issues for a very long time and has made efforts to reduce its effect on the environment as far back as 1979. RWE has got their own sustainability task-force which is monitoring each step of the business in order to protect the environment and communities as much as possible. RWE's efforts towards sustainability were rewarded by becoming part of the Dow Jones Sustainability Index, as well as belonging to the silver class of sustainability leaders 2007/2008. $\checkmark$

\section{Support from high level Management}

Support from high-level management was given at RWE as far back as the early 1980s. $\checkmark$ 


\section{Gearing existing practices towards sustainability}

Existing practices have been geared successfully towards integrating sustainability.J

\section{3a. CSR}

CSR activities have been practiced at RWE for some time, which helped RWE to incorporate sustainability issues as well as community issues into the company. $\checkmark$

\section{3b. TBL}

No known Triple-Bottom-Line activities are practiced at RWE. $\mathbf{x}$

\section{Communication about new commitment to sustainability}

Communication about RWE's commitment to sustainability seems to be very good. $\checkmark$

\section{4a. Internally}

Internally employees are aware about sustainability matters even more than the toplevel management expected, which might be due to public education about sustainability matters in Germany. $\mathbf{J}$

\section{4b. Externally}

Externally the commitment to sustainability and renewable energy sources has been well communicated to all stakeholders and it is even integrated into RWE's supply chain, which makes all their suppliers sustainable businesses as well. $\mathbf{J}$

\section{Starting to integrate sustainability tools}

Sustainability tools such as ISO 14001 have been integrated successfully into all facilities since 1998. Implementing other tools like the SBCS and TQEM might be advisable for RWE. $\boldsymbol{J}$

\section{Measurement}

\section{6a. Internally}

RWE is currently using KPIs to measure their CSR activities as well as their sustainability activities. $\checkmark$

\section{6b. Externally}

External measurement is successfully done through the GRI. $\checkmark$ 


\section{Sustainability journey}

RWE is committed to sustainability and their focus on renewable energies and will constantly adapt their sustainable commitment to changing government policies and environments. $\sqrt{ }$

\subsubsection{Conclusion}

As we can see RWE has been committed to sustainability even longer than Meridian Energy (1999). Meridian Energy has been one of the first companies in New Zealand to embrace sustainability to such a degree, due to Germany being an older and more industrialised country, companies in Germany have been confronted with issues such as sustainability, environmental protection and emission control for far longer than NZ companies, which might explain why some German companies already use KPIs. This thesis will now look at the differences between the German energy sector and the New Zealand energy sector in order to point out the differences and what might be learned from them. 


\section{General Conclusion, Recommendations \& Limitations}

In this last chapter I will review the thesis and the seven steps of the SSF, as well as making recommendations along the lines of sustainability and reflecting back on the objectives this thesis sought to achieve. Furthermore, the limitations of the SSF, the case study and the findings will be considered. Finally, recommendations for future research will be made.

\subsection{Concluding remarks on the seven steps of the SSF}

This section will look one final time at the SSF and make concluding remarks and recommendations about each step.

\section{SSF 1: Interest in Sustainability}

Interest in sustainability is one of the most important steps this thesis identified in the framework, because without it integrating sustainability is near impossible. Furthermore, it is important that the interest is genuine and not just a short-term initiative. Integrating sustainability does not come easily and therefore genuine interest and commitment are crucial starting points before an integration process can or should be attempted.

Both New Zealand case studies, as well as the German energy companies seem to be committed to sustainability, which might just be one factor for their success of integration.

\section{SSF 2: Support from high-level management}

Support from high-level management is essential in order to have enough manpower and resources at hand for a successful integration. This can only be achieved if high-level management is standing in full support behind an ever on going project such as committing to sustainability. 
The companies looked at in this research might not have achieved such a deep level of sustainability integration and commitment without top-level management. Therefore, it is crucial for any company to have such commitment before attempting to integrate sustainability into their core business.

\section{SSF 3: Gearing existing practices towards sustainability}

This step can be very useful to help integrate sustainability into any given business because it is using already existing practices, which are known to the company, and only a sustainability component has to be added to the existing practice, i.e., CSR or TBL. Therefore, it is recommended that companies wanting to integrate sustainability practices into their company start using already existing tools which they should try and adapt towards sustainability before integrating new practices which are not known as well as the already existing ones.

\section{SSF 4: Communication about new commitment to sustainability}

Communication was found to be another very important step within the framework, especially at the beginning of the integration phase, in order to make everyone aware of the new commitment as well as to why the company commits to it. This not only applies to management but to all levels of employees because sustainability needs the commitment of all employees throughout the company. In the long run it should be the main goal to integrate sustainability into the entire supply chain. This will ensure that every item entering the business was produced in a sustainable way which creates fewer carbon emissions in the lifecycle of the product.

Meridian Energy as well as RWE in Germany are in the process of successfully implementing sustainable practices all along their supply chain.

As mentioned earlier in this thesis, integration along the supply chain should be the major goal for any company which wants to integrate sustainability 
successfully, because a company can only be truly sustainable if all suppliers and vendors along the supply chain, including all materials, work along sustainable principles.

\section{SSF 5: Starting to integrate sustainability tools}

After having managed the first four steps successfully, sustainability tools should be integrated in order to make the integration process easier. Most companies have integrated the ISO 14001 as a main standard but are missing some other helpful tools like the TQEM or the SBSC. For any given company these tools can prove very helpful in the processes of integrating sustainability, as described previously. TQEM would especially be helpful for all companies using TQM (Total Quality Management) because they would have to only add one dimension to an already existing tool. The same applies to the SBSC. If a company is already using a BSC (Balanced Score Card), adding one more dimension is easier than implementing a totally new and maybe unknown tool. Therefore, always try and use existing tools to start your implementation of sustainability before implementing new tools.

\section{SSF 6: Measurement}

After having integrated sustainability, measurement becomes very important. All companies which were looked at in this thesis did a great job of external reporting and measurement through the GRI. The only company which is currently using KPIs in order to measure CSR and sustainability is RWE. Not knowing if sustainable practices pay off or how they measure against other practices might lead to failure of the integration process as well as the entire sustainability journey. Every company will have to create their own measurements because the outline of every company is slightly different, but in the long run every company should come up with some precise measurements in order to know whether the integration process went well and if the company is gaining profit from it. 
The integration process of sustainability is nothing that can be done quickly or without effort because it will be an ongoing journey of adaptation to an ever changing environment. Nothing is static; especially the business markets in which companies operate as well as government regulations regarding the environment and pollution. Therefore, companies will constantly have to adapt their sustainability commitment to new regulations, dwindling resources and new customer demands.

Generally the companies which were looked at in this thesis did a good job of integrating sustainability into their business. Each company had a slightly different approach due to different situations they found themselves in or different reasons why they committed to sustainability in the first place. The integration process will therefore be slightly different for every other company as well, but this thesis might help companies to make more sense of sustainability as well as giving some aid as to how to integrate sustainability into their companies.

Finally, it is very important to reflect on the initial interest in sustainability after a while, because sustainability is a journey of constant improving and change. Therefore, it can be very useful to reflect on past implementation actions in order to improve the company’s learning curve. 
Figure 24: SSF.

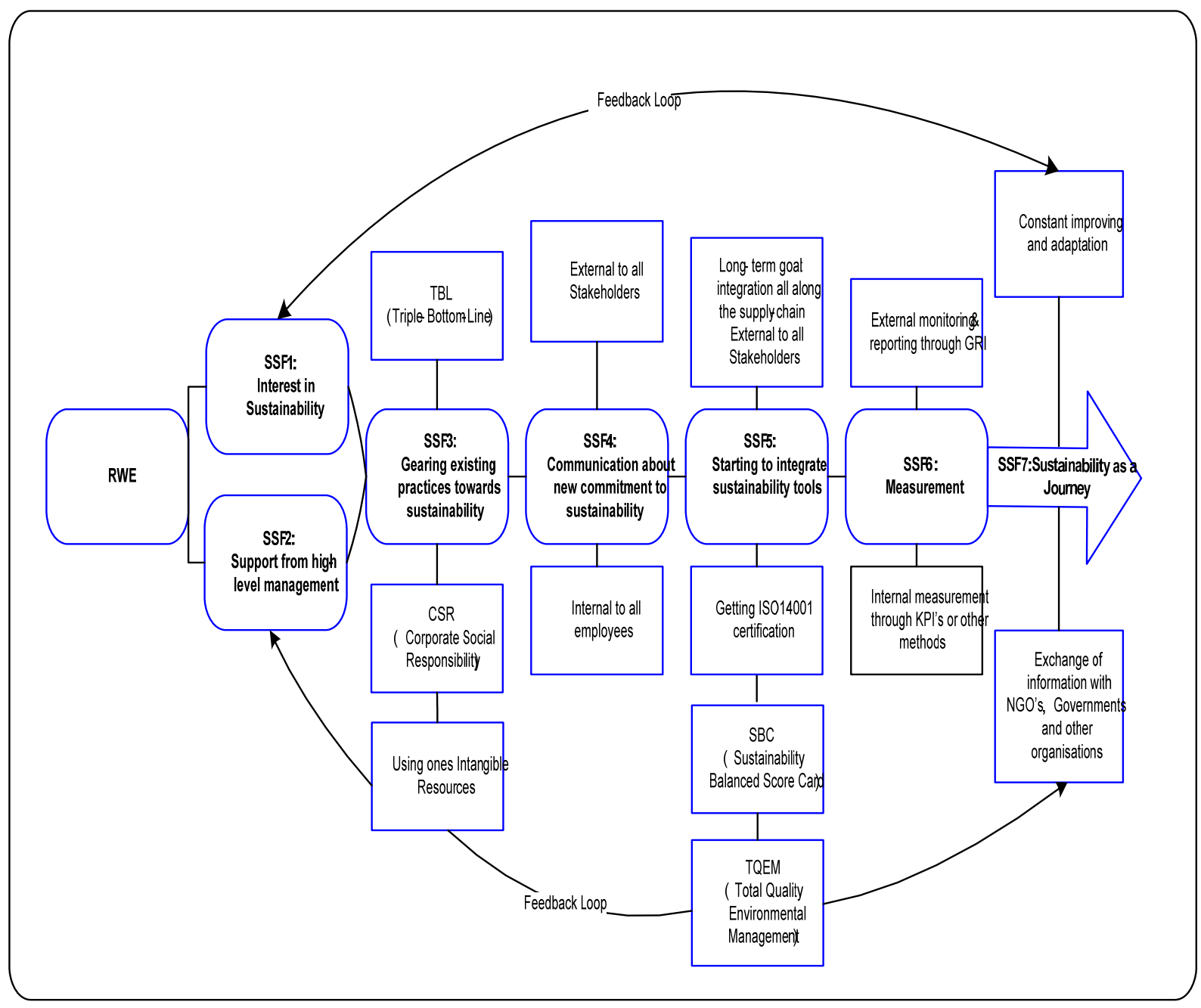

\section{Feedback-Loop}

As we can see in the Figure 24, the first feedback loop is going from SSF7 (constant improving and adaptation) back to SSF1 (interest in sustainability) in order to reflect on the sustainability journey taken so far. If sustainability or the integration of sustainable practices is seen as a journey it is often helpful for everyone to reflect upon one's actions in order to see if certain implementations were successful and where integration processes were difficult or did not pay off, as well as creating valuable data for other companies.

The second feedback loop goes from SSF7 (exchange of information with NGOs, governments and other organisations) back to SSF2 (support from high level management). In order for a company to exchange information and deal with 
governments and NGOs, high-level management support is needed. This feedback loop is therefore making sure that high-level management is still supporting sustainability as much as on Day one.

In fact it would be very useful to look back after each step taken in order to see whether or not it was successful and if everything went as planned. This way it is less likely that the effort of integrating sustainability will fail, or steps of the integration process do not pay off. Integrating sustainability into any business in a strategic way can be a process that requires a lot of manpower as well as resources. Therefore, looking back on each and every step taken makes sure that neither manpower nor resources are wasted along the way, which can save the company valuable time and money.

\subsection{Overall summary}

Apart from having developed a framework for the integration of sustainable practices, this thesis has reached a variety of conclusions. Having looked at sustainability in more detail this thesis has found that sustainable practices are still fairly new to companies and governments alike and, therefore, need more methodologies on how to approach the topic successfully. Furthermore, the comparative study between Germany and New Zealand has shown that countries approach sustainability differently, and they might learn from each other by examining each other's approaches. Another finding of this thesis points out that companies have different motivations behind their integration of sustainability: some see at as a strategic approach; others consider sustainability to be their core value. Overall this thesis has taught me that sustainability is a very complex topic including many different literature streams, academic opinions and practical applications. This thesis has contributed to the existing literature by combining most existing streams into one thesis and by doing so has shown their connection and future research possibilities. In the New Zealand context this thesis has pointed out that international collaboration on sustainability issues might well be worthwhile, as well as having looked at the New Zealand energy sector and, thus, provided new insights into this field of study. 


\subsection{Research objectives revisited}

\section{Objective one:}

To contribute to building knowledge and theory for the area of corporate sustainability in the New Zealand energy sector, by developing a strategic sustainability framework from existing literature

This Thesis contribution:

This thesis has developed a strategic sustainability framework (SSF) by combining the most common literature streams of corporate sustainability. Each step of the framework was developed on the basis of the reviewed literature, and those steps can now guide corporations to better approach the strategic integration of sustainable practices.

This thesis has closed an important 'gap' within the literature of corporate sustainability by creating a framework organisations can use as a guide-line on how to incorporate sustainable practice.

\section{Objective two:}

To understand what benefits a company can expect by embracing corporate sustainability

This Thesis contribution:

This thesis has highlighted through both literature and case studies that using sustainable practices within an organisation can benefit the companies' image as well as revenue. Moreover, this thesis has illustrated that following such a strategy is often in the best interest of all stakeholders, and is frequently initiated by them. In the case of Contact energy, for example, revenue increased directly after their announcement of investing more into sustainable energy production.

The literature has also confirmed that organisations following sustainable practices often attract higher skilled employees and that organisations using those practices perform better financially. 


\section{Objective three:}

To find out what challenges companies come across when implementing corporate sustainability

This Thesis contribution:

This thesis' literature has demonstrated that incorporating new practices, especially sustainable practices, can often be expensive and hard to measure. Therefore, this thesis has shown that in order to avoid expensive new investments into sustainability, existing practices can be adapted to incorporate an element of sustainability. Moreover, incorporating sustainable practices has now been simplified by the framework developed in this thesis, which companies can now use as a guideline.

\subsection{Limitations of the case study \& findings}

\section{National Limitation}

This research and its findings are limited to the New Zealand energy sector, because the case study was conducted within New Zealand and that energy sector might be different from other energy sectors around the world. Furthermore this thesis only took New Zealand, and Germany's energy policies into account, which will probably not be transferable to other countries.

\section{Timeline}

The findings of the comparison between Germany and New Zealand only apply to those two countries and only reflect current situations which might change in the future. Therefore, the findings only represent current facts and situations.

\section{Data collection}

Further limitations might be connected to the data gathering. When interviewing people about strategic topics like sustainability as well as the motivation behind their actions 
the researcher has no other chance but to trust in their honesty. One limitation, therefore, might be that not all data gathered in this research actually reflects the respondents'/companies' values and beliefs.

\section{Sample Size}

Additionally, the number of interviews conducted together with the comparative study was sufficient for the research of this thesis, but to receive even more extensive results, the number of interviews (sample-size) as well as the number of participating companies should be increased.

\section{Time and scope of a master's thesis}

This thesis is restricted by a timeframe of 12 months which is usual for any master's thesis. Due to the time restriction and a maximum length of approximately 150 pages for a finished thesis, the thesis is restricted in itself to a certain degree; a doctoral thesis would have allowed greater scope and size.

\subsection{Limitations of the SSF}

The Strategic Sustainability Framework was established through an extensive literature review and the research gap of proper implementation of sustainability within companies. However, some limitations of the SSF must be pointed out:

\section{Linear framework}

It is a very linear framework which will help companies from all industries to integrate sustainability. It is on the other hand just one approach of integrating sustainability, which probably only occurs under perfect circumstances. Sustainability can be integrated through different means or just by using parts of the Sustainability Framework. As mentioned earlier, the companies which were looked at in this thesis had different motivations for integrating sustainability; their timing of integration was also very different. Therefore, each company will have to choose the right time and 
reason for integration by itself, and the framework then can be a very useful tool to guide the integration process.

\section{Different companies need different approaches}

As we have seen in this thesis, different companies use different approaches to strategically implement sustainability. Some companies wait until they have a sustainable financial footing before implementing sustainability into the company; other companies make it their main goal from Day one. Therefore, this framework does not show one right or perfect path but many different ways on how to integrate sustainability, and each company's implementation will probably look slightly different due to environments, policies and opportunities.

\subsection{Recommendations for future research}

Regarding future research of sustainability concepts and methodology, it can be said that there is a definite need for additional research in this field. The field of sustainability is still fairly new and not a lot of research has been undertaken to shed more light on business cases, especially in the New Zealand context. Several areas were found to need further research.

\section{Implementation of sustainability}

One area of research that has been widely neglected so far is how to best implement sustainability into companies, which was the main focus of this thesis. So far there is very little literature on this topic and it would prove useful to both academia and industries if this topic was investigated further and in more depth. This thesis, therefore, could be seen as a foundation on which more research regarding this topic could be done. Advisable would be a case study where sustainability actually gets implemented as part of the research, which might provide very detailed and useful data about each step. 


\section{2. $\quad$ Bigger sample size and more case studies}

As mentioned before the sample size and the amount of case studies for this research were sufficient. It is to be recommended for future research, though, that a bigger sample size and more cases are chosen for future research in order to get more in-depth data.

\section{Quantitative approach}

This thesis chooses a qualitative approach and case studies in order to gather data. A quantitative approach might provide interesting and different data which might help to shed more knowledge on the area of sustainability.

\section{National limitation}

This thesis was limited mainly to New Zealand and Germany in the comparative study. For future research it might be good to look at energy companies throughout several countries in order for the findings to have a heavier implication.

\section{Timeline}

This thesis was restricted to a timeline of one year as part of a master thesis. For future research it is advisable to extend it to a doctoral level, which would extend the timeline by up to two years and could come up with more comprehensive data.

\section{Data collection}

Future research of this kind should incorporate more in-depth interviews at the case study site in order to provide richer data. Furthermore, incorporating more cases in the case study would decrease some of the weaknesses associated with case studies as well as providing more valid data. 


\subsection{Contributions of this thesis to the literature}

This thesis contributes to the current management and strategy literature in the field of sustainability in a number of substantial ways.

1. This thesis contributes to current literature because it combines various streams of sustainability literature (i.e., CSR, TBL, sustainable development, reporting, and strategy) in one place and by doing so gains new insights into the broader context of sustainability.

Combining all these important aspects of sustainability as well as the social and environmental perspectives makes this thesis unique in the sense that it combines all related topics in one place, which contributes to current literature by coming up with new insights on how sustainability and its practices might be integrated into corporations and government in New Zealand. This thesis, therefore, provides new insights in the New Zealand context as well as a good summary of sustainability literature to any researcher.

2. More than just combining all aspects of sustainability and social aspects, this research shows clear links between the various topics and how they might influence one another.

Demonstration of links between the topics of the literature review and in the SSF might spark other researchers' interest in investigating those links further. The links between CSR, TBL and sustainability, for example, were clearly shown, but how exactly they relate or could be used together might be a good area to be researched in the future.

3. New light has been shed on how to best implement sustainable practices into any given company using a strategic sustainability framework. This framework can be used by itself or in addition with other literature in order to better understand how to integrate sustainability.

Researchers interested in sustainability can benefit on the new insights this thesis reached or by looking at sustainability from a fresh and maybe different angle. To date 
there is not much research related to strategic implementation of sustainability. Therefore, this thesis might prove very useful to any researcher investigating this area.

4. This thesis provides valuable information for any researcher looking at government related energy policies.

The comparison between Germany and New Zealand has shown that different policies can create different environments for energy companies. This fact might prove useful for any government policy driven research. Clear differences between both countries were pointed out which might be a good starting point for future research in the field of energy related policies.

This thesis in itself was a journey of sustainability, its literature, new ideas and interesting case studies. It all started out with an interest in sustainability issues, which was then focused on strategy and the implementation of sustainable practices after a very interesting literature review which showed me just how big the field of sustainability really is. The possibilities for future research in the area of sustainability are immense and this thesis could only focus on a certain aspect of it. Reflecting now from where the thesis originally started, I can say that it has taken me on a very interesting and 'eye opening' journey, and has produced valuable data for industries, governments and fellow researchers. 


\section{References}

Bamberg, I., \& Wrona, T. (1995). Der Ressourcenansatz und seine Bedeutung für die strategische Unternehmensführung. Universität Essen, Essen.

Bansal, P., \& Gao, J. (Writer) (2006). BUILDING THE FUTURE BY LOOKING TO THE PAST: Examining Research Published on Organizations and Environment.

Bassen, A., Jastram, S., \& Meyer, K (2005). Corporate Social Responsibility. Zeitschrift für Wirtschafts- und Unternehmensethik, 6(2), 231-236.

Beloff, B., Tanzil, D., \& Clarke-Whistler, K. (2007). Sustainable Development: A Competitive Factor. Industrial Management, 49(4), 8.

Berthelot, S., \& Coulmont, M. (2004). ISO 14000 - a profitable investment? CMA Management, 78(7), 36.

Blue, L. (2008). Lessons From Germany. Time International, 171(16), 44.

Borri, F., \& Boccaletti, G. (1996). From total quality management to total quality environmental management. The TQM Magazine, 7(5), 38.

Branco, M. C., \& Rodrigues, L. c. L. (2006). Corporate Social Responsibility and Resource-Based Perspectives. Journal of Business Ethics, 69, 111-132.

Byrch, C., Kearins, K., Milne, M., \& Morgan, R. (2007). Sustainable “what”? A cognitive approach to understanding sustainable development. Qualitative Research in Accounting \& Management, 4(1), 28.

Cetindamar, D., \& Husoy, K. (2007). Corporate Social Responsibility Practices and Environmentally Responsible Behavior: The Case of The United Nations Global Compact. Journal of Business Ethics, 76, 163-176.

Cheney, G. (2004). The corporate conscience and the triple bottom line. Accounting Today, 18(12), 12.

Colbert, B. A., \& Kurucz, E. C. (2007). Three Conceptions of Triple Bottom Line Business Sustainability and the Role for HRM. HR. Human Resource Planning, 30(1)(21).

Colman, R. (2004). SATISFIED STAKEHOLDERS. CMA Management, 78(1), 22.

Conference, S. C. (2007). Speech notes for German Sustainability Council conference Paper taken from the German Sustainability Council Conference.

Contact Energy, (2004). Annual Environmental Report (Annual Report). Wellington.

Contact Energy, (2007). Sustainability Report. Wellington: Contact Energy.

Contact Energy, (2008). Annual Environmental Report (Annual Report). Wellington 
Creswell, J. W. (2003). Research Design: Qualitative, Quantitative, and Mixed methods Approaches (2nd ed. Vol. 2). London: SAGE Publications

Davies, T. (2005). Strategic thinking. Supply Management, 10(15), 37.

Deegan, C. (1999). Implementing triple bottom line performance and reporting mechanisms. Charter, 70(4), 40.

Dempsey, J. (2007). Merkel confronts German energy industry with radical policy overhaul. International Heral Tribune p. 3, from http://www.iht.com/articles/2007/07/03/business/nuke.php, accessed on the $4^{\text {th }}$ of July 2008.

Diana, T. (2006). Doing Business The Socially Responsible Way. Business Credit;, 108(6), 45.

Dyson, R. G. (2000). Strategy, performance and operational research. Journal of Operational research, 51(5-11).

EECA (2007). New Zealand Energy Efficiency and Conservation Strategy. Wellington: EECA.

EISENHARDT, K. M. (1989). Building Theories from Case Study Research. Academy o/Management Review,, 14(4), 532-550.

Electricity Group, (2008). CHRONOLOGY OF NEW ZEALAND ELECTRICITY REFORM (Report): Electricity Group, Energy \& Communications Branch.

Elkington, J. (1999). Triple bottom line revolution--reporting for the third millennium. Australian CPA, 69(11), 75.

Elkington, J., \& Rowlands, I. H. (1999). [Cannibals with forks: the triple bottom line of 21st century business]. Alternatives Journal, 25(4), 42.

E.ON Energy, (2007). Annual Report 2007 (Report). Duesseldorf: E.ON.

E.ON Energy, (2007). Annual Report 2007: E.ON Energy.

Federal Ministry of Education and Research, (2005). Research for Sustainability, Berlin.

Figge, F., Hahn, T., Schaltegger, S., \& Wagner, M. (2002). The Sustainability Balanced Scorecard - linking sustainability management to business strategy. Business Strategy and the Environment, 11(5), 269.

Fombrun, C. \& Shaneley G., (1990). What's in a name? Reputation building and corporate strategy. Academy of Management journal, 33(2), 233.

Fox, A. (2007). Corporate Social Responsibility Pays Off. [Journal Article]. HRMagazine, 52(8), 43. 
Franceschini, F., Galetto, M., \& Maisano, D. (2007). Management by measurement Designino key indicators and performance measurement systems (Vol. 1). Heidelberg: Springer Verlag Berlin Heidelberg.

Franceschini, F., Galetto, M., Maisano, D., \& Mastrogiacomo, L. (2008). On-line diagnostics in the Mobile Spatial coordinate Measuring System (MScMS). Precision Engineering, In Press, Corrected Proof.

Freeman, R. E., Andrew, C. W., \& Bidhan, P. (Writer) (2004). Stakeholder Theory and "The Corporate Objective Revisited".

Friedman, M. (1970). The Social Responsibility of Business is to Increase its Profits. The New York Times Magazine.

German Sustainability Council, (2007). Speech notes for German Sustainability Council Conference Berlin.

Gerring, J. (2007). Case Study Research: Principles and Practice.Cambridge University Press.

González-Benito, J., \& González-Benito, Ó. (2006). A Review of Determinant Factors of Environmental Proactivity. Business Strategy and the Environment, 15, 87-105.

Greenpeace (2007). New Zealand Energy Revolution: HOW TO PREVENT LIMATE CHAOS, Auckland.

Griffiths, K. (2006). Corporate Sustainability Reporting in New Zealand [Research Paper]. 46.

Hart, S. L. (1995). A Natural-Resource-Based View of the Firm. The Academy of Management Review,, 20(4), 33.

Hart, S. L., \& Milstein, M. B. (2003). Creating sustainable value. Academy of Management Executive, 17(2), 13.

Henriques, I., \& Sadorsky, P. (1999). THE RELATIONSHIP BETWEEN ENVIRONMENTAL COMMITMENT AND MANAGERIAL PERCEPTIONS OF STAKEHOLDER IMPORTANCE. Academy of Management Journal, 42(1), 87-99.

Helio (2000). General Overview of German Energy Sector: Helio.

Hemenway, C. G., \& Hale, G. J. (1996). The TQEM-ISO 14001 connection. Quality Progress, 29(6), 29.

Henkel, E. (2008). Renewables: An essential part of Germany's future. Power Engineering International, 16(2), 2. 
Holzer, V. L. (2004). Ecological Objectives and the Energy Sector- the German Renewable Energies Act and the European Emissions Trading System -. Unpublished Diskussionsbeitrag, University of Potsdam Berlin.

Holzer, V. L. (2005). The Promotion of Renewable Energies and Sustainability: A Critical Assessment of the German Renewable Energies Act. Intereconomics, 40(1), 36.

Jayathirtha, R. V. (2001). Combating environmental repercussions through 'TQEM' and 'ISO 14000'. Business Strategy and the Environment, 10(4), 245.

Jonker, J., \& Witte, M. d. (2006). The challenge of organizing and implementing corporate social responsibility. New York, Palgrave Macmillan.

Johnstone, H. (2008). Progress in offshore wind power moving forward at a rate of knots. Power Engineering International, 16(2), 2.

Jung, S. (2007). “Key Performance Indicators - Instrumente zur Steuerung interner Dienstleistungseinheiten”. Luoinde: Österreichisches Controller-Institut.

Kaplan, R., \& Norton, D. (1992). The Balanced Score Card - measures that drive performance. Harvard Business Review(Januar), 71-79.

Kaplan, R., \& Norton, D. (1997). Balanced Scorecard: Strategien erfolgreich umsetzen Stuttgard Schaffer-Poschel.

Kettinger, W., Grover, V., Subashish, G., \& Segars, A. H. (1994). Strategic information systems revisited: A study in sustainability and performence. MIS Quarterly, 18(1), 31.

Kirschner, E. (1992). Incorporating the Green Angle. Cemical Week, 60(2), 12.

Knox, S., Maklan, S., \& french, P. (2005). Corporate Social Responsibility: Exploring Stakeholder Relationships and Programme Reporting across Leading FTSE Companies Journal of Business Ethics, 61(1), 22.

KPMG (2005). KPMG International Survey of Corporate Responsibility Reporting 2005. Amsterdam: University of Amsterdam.

Landler, M. (2008). Solar Valley Rises in an Overcast Land. New York Times, p. C.1, from http://proquest.umi.com/pqdweb?did=1479446491\&Fmt=7\&clientId=7511\&RQT $=309 \&$ VName $=$ PQD , accessed on the $3^{\text {rd }}$ of July 2008.

Langenwalter, G. A. (2007). Sustainability: The Next Competitive Edge. Manufacturing Engineering, 139(4), 20.

Larcker, D. F. (2003). Coming up short on nonfinancial performance measurement. Harvard Business Review, 81(11), 8. 
Lawrence, M. (2000). Clean energy business incubators. In Business, 22(5), 25.

Lawrence, A. T. \& Weber, J, (2008). “Business \& Society - Stakeholders, Ethics, Public Policy” $12^{\text {th }}$ Edition, McGraw Hill, New York.

Luckman, P. (2006). KiwiGrow - A new approach to sustainable development reporting. Australasian Journal of Environmental Management, 13(4), 261.

Macharzina, K. (1999). Klaus Macharzina: Unternehmensfuehrung: das internationale Managementwissen: Gabler.

Mahler, D. (2007). The Sustainable Supply Chain. Supply Chain Management Review, 11(8), 59.

Marcoux, A. M. (2000). Business Ethics gone wrong”. Cato Policy Report, 22(3).

Marshall, C., \& Rossman, G. B. (2006). Designing Qualitative Research (4 ed.): Sage.

McDonough, W., \& Braungart, M. (2002). Cradle to Cradle: Re-Making the Way we Make Things. New York: North Point Press.

Meridian Energy, (2001). Sustainability Report 2001. Wellington.

Meridian Energy, (2005). Annual report 2005. Wellington.

Meridian Energy, (2006). Hydro Energy Fact Sheet (Report). Wellington.

Meridian Energy, (2007). Annual Report 2007. Wellington.

Meridian Energy, (2008). Annual Report 2008 (Annual Report). Wellington.

Milne, M. J., Ball, A., \& Gray, R.(2001). Wither Ecology? The Triple Bottom Line, the Global Reporting Initiative, and the Institutionalization of Corporate Sustainability Reporting. [Working Paper]. 27.

Milne, M., Tregidga, H., \& Walton, S. (2003). The Triple-Bottom-Line: Benchmarking New Zealand's Early Reporters University of Auckland Business Review, 5(2).

Ministry for the Environment, (2001). Triple Bottom Line reporting in the Public Sector. from http://www.mfe.govt.nz/publications/ser/triple-bottom-linedec02.html, accessed on the $4^{\text {th }}$ of August 2008.

Ministry for the Environment, (2003). Enterprise3.Your Business and the Triple Bottom Line; Economic, Environmental and Social Performance. Wellington Ministry of the Environment

Ministry for the Environment, (2006). New Zealand's Fourth National Communication under the United Nations Framework Convention on Climate Change (Report). Wellington: Ministry of the Environment. 
Newswire (2008). New German Renewable Energies Law Strengthens Sector Investment. PR Newswire Europe Including UK Disclose.

Newswire (2008). Renewable Energy Europe 2008: Clean-Tech and Energy Efficiency Major Players in German Economy. PR Newswire Europe Including UK Disclose.

O'Donnell, A. (2007). ASSESSING THE TURMOIL IN NEW ZEALAND'S ELECTRIC INDUSTRY. Public Utilities Fortnightly, 145(2), 71.

O’Leary, Z. (2004). THE ESSENTIAL GUIDE TO DOING RESEARCH. Sage Publications, London.

Paladino, A., Widing, R., \& Whitwell, G. (1996). Synthesising the resource based view and market orientation to understand organizational performance. University of Melbourne

Panda (2008). Die 100 Nachhaltigsten Unternehmen der Welt. Frankfurt: Panda Investment Management

Parmenter, D. (2002). Winning KPIs. CA Charter, 73(10), 66.

Parmenter, D. (2007). Key Performance Indicators: Developing, Implementing, and Using Winning KPIs. New Jersy John Wiley \& Sons Inc.

Paul, S. (2006). A BRIEF HISTORY OF SUSTAINABLE DEVELOPMENT (Peport).

Peel, P. (2005). Learning lessons on renewable energy. Utility Week, 24(6), 15.

Placet, M., Anderson, R., \& Fowler, K. M. (2005). STRATEGIES FOR SUSTAINABILITY. Research Technology Management, 48(5), 32.

Porter, M. (1999). Creating advantage. Executive Excellence, 16(11), 13.

Porter, M., \& Linde, C. v. d. (1995). An underlying logic links the environment, resource productivity, innovation and competitiveness. . Harvard Business Review.

Post, J. E., \& Preston, L. E. (2002). Redefining the Corporation: Stakeholder Management and Organizational Wealth. Stanford: Stanford University Press.

Quinn, L. A. (2002). Examining community stakeholder relationships from a communication perspective. Unpublished Ph.D., The University of Texas at Austin, United States -- Texas.

Roberts, P. W., \& Dowling, G. R. (2002). Corporate reputation and sustained superior financial performance. Strategic Management Journal, 23(11), 16.

RWE (2008a). Annual report 2008.DO IT. The new RWE: RWE Energy.

RWE (2008b). RWE-Environmental Report. Dortmund: RWE Energy. 
Savitz, A. W., \& Weber, K. (2006). THE TRIPLE BOTTOM LINE: How Today's BestRun Companies are Achieving Economic, Social, and Environmental Success And How You Can Too John Wiley \& Sons.

Shrivastava, P. (1995). The role of corporations in achieving ecological sustainability. Academy of Management. The Academy of Management Review, 20(4), 936.

Sisaye, S., Bodnar, G., \& Christofi, P. (2005). TQM AND SUSTAINABILITY: INSIGHTS FROM ENVIRONMENTAL RESOURCES MANAGEMENT. Internal Auditing, 20(4), 27.

Stake, R. E. (1995). The art of case study research: Thousand Oaks

Tschopp, D. J. (2003). The sustainability advantage: seven business case benefits of a triple bottom line by Bob Willard, 2002. New Society, 203 pp (pbk). ISBN 086571-451-7. Business Strategy and the Environment, 12(6), 405.

Tuttle, T., \& Heap, J. (2007). Green productivity: moving the agenda. International Journal of Productivity and Performance Management, 57(1), 14.

University, R. (2001). Global Sustainability: The History / Time Line of an Idea: RMIT University.

Vordank, T. (2007). Zur Praxis der Einbeziehung von immateriellen Ressourcen in betriebliche Mess- und Bewertungssysteme“ in Moldaschl. München \& Mering: Rainer Hampp Verlag.

Wade, M., \& Hulland, J. (2004). The resource-based view and information systems research: review, extension and suggestions for future research. MIS Quarterly, 28(1), 107-142.

Welford, R. J., Meaton, J., \& Young, W. (2003). Fair Trade as a Strategy for International Competitiveness. International Journal of Sustainable Development and World Ecology, 10(1-13).

Willard, B., \& Lovins, H. (2005). The Next Sustainability Wave: Building Boardroom Buy-In New Society Publishers.

Wilson, M. (2003). Corporate sustainability: What is it and where does it come from? Ivey Business Journal, March/April 2003.

Yeoman, I., Lennon, J., Blake, A., Galt, M., Greenwood, C., McMahon-Beattie, U. (2006) Oil depletion: What does this mean for Scottish tourism? Tourism Management, 28(5).

Yin, R. K. (2003). Case study research: Design and Methods: Sage

Yin, R. K. (2008). Case Study Research: Design and Methods (4 ed.): Sage 


\title{
Appendix
}

\author{
Question \& Answers
}

Figure 25: Questions \& Answers (Meridian \& Contact)

\begin{tabular}{|c|c|c|c|}
\hline Questions & Meridian Energy & Contact Energy & $\begin{array}{l}\text { Links to } \\
\text { Literature }\end{array}$ \\
\hline $\begin{array}{l}\text { 1. What does } \\
\text { sustainability mean to } \\
\text { Meridian/Contact? }\end{array}$ & $\begin{array}{l}\text { - Core Values } \\
\text { - Chief executives values were high } \\
\text { on sustainability } \\
\text { - "Part of the DNA" }\end{array}$ & $\begin{array}{l}\text { - Its more than just the environment } \\
\text { - Ensuring resources for future generations } \\
\text { - Expanding sustainability with } \\
\text { (shareholders, customers, emplyees.etc) }\end{array}$ & $\begin{array}{l}\text { - Links back to the } \\
\text { sustainability } \\
\text { literature. How is } \\
\text { sustainability } \\
\text { interpreted? }\end{array}$ \\
\hline $\begin{array}{l}\text { 2. What sustainable } \\
\text { business practices does } \\
\text { Meridian/Contact } \\
\text { employ? }\end{array}$ & $\begin{array}{l}\text { - Climate Change Team } \\
\text { - "Is something everyone lives and } \\
\text { does" } \\
\text { - Selling Carbon Credits through } \\
\text { their wind-farms } \\
\text { - GRI }\end{array}$ & $\begin{array}{l}\text { - CSR/Sustainability } \\
\text { - 50\% Renewable from Hydro Geothermal } \\
\text { - 50\% - 65\% renewables in the next 5-6 } \\
\text { years }\end{array}$ & $\begin{array}{l}\text { - Links back to CSR, } \\
\text { TBL and reporting } \\
\text { literature. }\end{array}$ \\
\hline $\begin{array}{l}\text { 3. When did } \\
\text { Meridian/Contact start } \\
\text { to consider and employ } \\
\text { sustainable business } \\
\text { practices? }\end{array}$ & - From the very beginning (1999) & $\begin{array}{l}\text { - from } 1996 \text { (Increased focus on } \\
\text { renewables) } \\
\text { (Feb. 2007) }\end{array}$ & $\begin{array}{l}\text { - Links to } \\
\text { sustainability } \\
\text { timeline in order to } \\
\text { see when } \\
\text { implementation took } \\
\text { place. }\end{array}$ \\
\hline $\begin{array}{l}\text { 4. Why did } \\
\text { Meridian/Contact } \\
\text { begin to investigate } \\
\text { sustainable business } \\
\text { practices? }\end{array}$ & $\begin{array}{l}\text { - Inheritance of renewable assets } \\
\text { and a sustainable vision for the } \\
\text { future from the start } \\
\text { - Values }\end{array}$ & $\begin{array}{l}\text { - Viable for the future } \\
\text { - Delivering good 'economics' to the } \\
\text { shareholders } \\
\text { - High fuel prices; they will continue to rise } \\
\text { - Strong obligation to shareholders, } \\
\text { renewables are the future (Carbon } \\
\text { emissions will cost) } \\
\text { - Delivering Value }\end{array}$ & $\begin{array}{l}\text { - Links to } \\
\text { sustainability debate } \\
\text { to see why they } \\
\text { implemented } \\
\text { sustainability. Value } \\
\text { based or monetary } \\
\text { based decision? }\end{array}$ \\
\hline $\begin{array}{l}\text { 5. What resources does } \\
\text { Meridian/Contact } \\
\text { invest in sustainable } \\
\text { business practices? }\end{array}$ & $\begin{array}{l}\text { - Sustainability Integration } \\
\text { Specialist } \\
\text { - Many more people are involved } \\
\text { with sustainability issues }\end{array}$ & $\begin{array}{l}\text { - Capital expenditure plan (2billion NZ\$ } \\
\text { just recently) } \\
\text { - New renewable energy projects }\end{array}$ & $\begin{array}{l}\text { - Links to framework } \\
\text { in order to see how } \\
\text { committed the } \\
\text { companies are. }\end{array}$ \\
\hline $\begin{array}{l}\text { 6. Is Meridian/Contact } \\
\text { using any external } \\
\text { reporting standards? }\end{array}$ & $\begin{array}{l}\text { - GRI/ Carbon Zero Programmes } \\
\text { - ISO } 14064\end{array}$ & $\begin{array}{l}\text { - GRI } \\
\text { - ISO } 14001 \text { ( All generation sites) } \\
\text { - Investigation to take that ISO accreditation } \\
\text { to the next level }\end{array}$ & $\begin{array}{l}\text { - Links to TBL } \\
\text { reporting literature as } \\
\text { well as reporting } \\
\text { standards and tools }\end{array}$ \\
\hline $\begin{array}{l}\text { 7. Does } \\
\text { Meridian/Contact use } \\
\text { any internal } \\
\text { measurement systems } \\
\text { in order to measure the } \\
\text { costs and benefits of } \\
\text { using sustainable } \\
\text { practices? }\end{array}$ & $\begin{array}{l}\text { - Robust Business Case } \\
\text { - Emission reduction plan for } \\
\text { Carbon Zero, pointed out } 11 \text { areas } \\
\text { which had to be measured } \\
\text { - Is aiming to be "the global } \\
\text { reference company in the area of } \\
\text { sustainability" }\end{array}$ & $\begin{array}{l}\text { - Internal programmes (NO KPI's) } \\
\text { - Rubbish initiatives which are measured } \\
\text { - Paper and Compost recycling system } \\
\text { which are measured as to their impact. } \\
\text { - Reduced landfill from office waste by } \\
50 \% \\
\text { - } 2008 \text { report will be way more focused on } \\
\text { measurement }\end{array}$ & $\begin{array}{l}\text { - Links back to PM } \\
\text { literature and internal } \\
\text { measurement }\end{array}$ \\
\hline $\begin{array}{l}\text { 8. How does } \\
\text { Meridian/Contact } \\
\text { balance the costs of } \\
\text { sustainable business } \\
\text { practice with ensuring } \\
\text { returning an } \\
\text { investment to } \\
\text { shareholders? }\end{array}$ & $\begin{array}{l}\text { - Any project that gets approved, } \\
\text { has to have a very sound bases } \\
\text { (strong business case) } \\
\text { - Shareholders themselves are very } \\
\text { interested to further develop } \\
\text { sustainability }\end{array}$ & $\begin{array}{l}\text { - By investing into sustainability we } \\
\text { guarantee return for shareholders }\end{array}$ & $\begin{array}{l}\text { - Links back to the } \\
\text { stakeholder literature }\end{array}$ \\
\hline $\begin{array}{l}\text { 9. What is } \\
\text { Meridian/Contacts' } \\
\text { future strategy } \\
\text { regarding } \\
\text { sustainability? }\end{array}$ & $\begin{array}{l}\text { - To continue the sustainability } \\
\text { 'journey' } \\
\text { - Further development of } \\
\text { sustainable policies } \\
\text { - Sustainable Development Policy }\end{array}$ & $\begin{array}{l}\text { - Focus is on renewable } \\
\text { - Investing into Wind Energy }\end{array}$ & $\begin{array}{l}\text { - Links back to } \\
\text { framework } \\
\text { (sustainability } \\
\text { journey) }\end{array}$ \\
\hline $\begin{array}{l}\text { 10. What kind of } \\
\text { strategic or market } \\
\text { analysis is the future } \\
\text { strategy based on? }\end{array}$ & $\begin{array}{l}\text { - Renewables only ' after intensive } \\
\text { research in 2004' } \\
\text { - Relying on imports wouldn't be } \\
\text { good (Oil, LED), therefore } \\
\text { renewables only }\end{array}$ & $\begin{array}{l}\text { - } 1 \text { billion NZ\$ in wind energy } \\
\text { - Analysing of proposals extensively } \\
\text { - Where do we see carbon and Fuel prices } \\
\text { going etc. } \\
\text { - Geothermal is the best option } \\
\text { - What is the electricity demand is going to } \\
\text { be? } \\
\text { - Carbon constraint environment, time of } \\
\text { coal fired power stations are over. }\end{array}$ & $\begin{array}{l}\text { - General question to } \\
\text { see what their future } \\
\text { strategy is based on }\end{array}$ \\
\hline
\end{tabular}




\section{Meridian Energy's Tip's and Trick's}

The following tips and tricks below by Meridian Energy can help every household to cut down energy consumption:

\section{Figure 26: Average NZ power consumption}

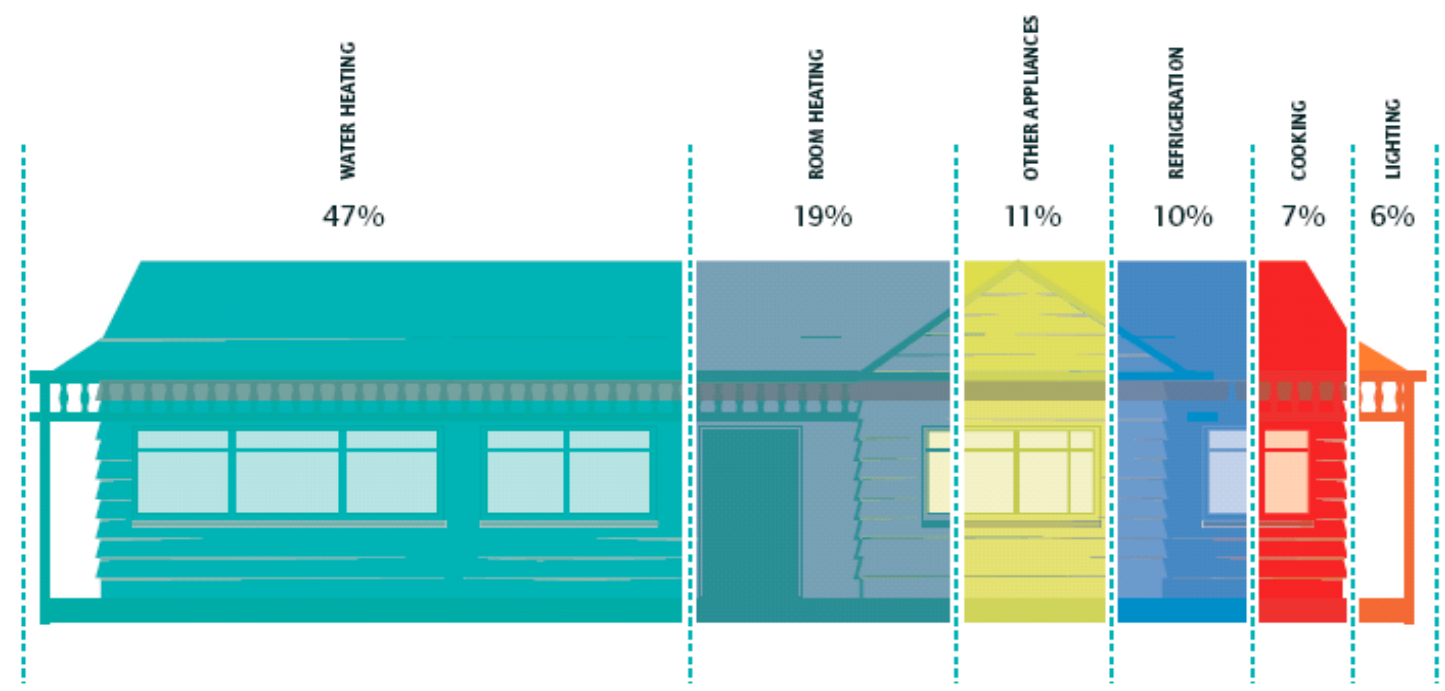

(Meridian Energy, 2006)

1. Water heating $47 \%$ :

In order to save power from water heating one should: shower wisely; long hot showers take a lot of energy to heat the water and ideally use a dishwasher that can heat its own water; this is a lot more efficient.

\section{Room heating 19\%:}

In order to use less power for room heating, one should try and capture as much sunlight as possible during daytime, it keeps the house warm. Installing double glaze windows is also very helpful, they keep the house warmer and less energy is lost. 
Doors of rooms that are being heated should be closed and curtains should be closed when it becomes dark, so that the heat lingers longer in the heated rooms. Furthermore does it pay off to only heat the room you are currently using.

\section{Other Applications 11\%:}

In order to save power from all other application, turn off the power at the plug when not in use, because even little stand-by lights use a lot of power during the year. If you normally use an electric blanket at night, try to use a hot water bottle instead, it is a lot more energy efficient.

When buying new applications make sure they have an Energy Star label, which indicates that they use less power. Lastly, try and use power saving light bulbs, which use a lot less energy and often have a longer life-span.

\section{Refrigerator $10 \%$ :}

In order to make sure your refrigerator is running efficiently, it shouldn't be older than 10 years; it will save power when buying a newer more power efficient model. All cooked foods should be allowed to cool down before they are put into the fridge; this will save energy and will stop the fridge from frosting up. Furthermore shouldn't fridges be overstocked and opened to often because the fridge will need to cool down again.

\section{Cooking 7\%:}

Power can easily be saved when cooking water for example, just put a lid on a pot and it will save you a lot of energy. Using a kettle can often be more energy efficient than boiling water in a pot, especially with energy efficient appliances. Lastly, using a microwave instead of an oven or hot-elements saves energy as well. 


\section{Lighting 6\%:}

In order to save some energy used for lighting one should turn off the lights whenever possible. Furthermore can motion sensors be installed so only the rooms in use lit-up. Finally, paint your walls in light colours; they need less light to lighten the room.

These are just some recommendations on how to save power, for more information see: http://www.meridianenergy.co.nz/YourHome/Energy+and+cost+savings/

Following Meridian Energy's energy saving advice for businesses will be introduced, with which businesses could save up to $15 \%$ of their energy costs. Those steps to save energy were put together with the help of the Energy Efficiency and Conservation Authority (EECA).

\section{Hot Water and Insulation:}

In order to save energy with insulation and hot water, thermostats should be adjusted so that water at the tap is 55 degrees. Any dripping taps should be repaired so that no unnecessary water is lost.

Automatic door closure should be installed in order to minimize the loss of warm air. If possible buildings should be insulated, this is especially important for old building because they normally only have basic insulation, if any.

\section{Heating and Air Conditioning:}

Portable heaters should be avoided because they use too much power, if installed use central heating. All unnecessary lighting should be switched off, especially at night when not in use. Time controls for heating systems can be used, which start 30 minutes before staff arrive and stop 30 minutes after staff leave, this guarantees optimum heating and no unnecessary power is wasted. 
Install Shades for and awnings to prevent sun glare and overheating and arrange regular maintenance checks for the air conditioning system, it can use too much power if not properly programmed.

\section{Lighting:}

Motion sensors should be installed in rooms that aren't constantly used (i.e. bathroom, meeting room). In shops with a big shop front which are constantly lit, it would pay off to install motion sensors which are only triggered when people walk past and the lighting is actually needed.

In order to get the optimum out of your lighting you should regularly clean lights and fittings, because dust and dirt can reduce light efficiency by $30 \%$.

\section{Kitchen:}

Staff should be encouraged to use the microwave instead of oven or stovetop, it uses less energy. Furthermore, make sure that the freezer/fridge is defrosted once or twice a year to assure it is running efficiently.

When replacing any kitchen applications make sure you replace them with models which have a good energy star rating. Another important tip is to wait till the dishwasher is full before turning on, it saves energy and water.

\section{Computers and office equipment:}

In order to save power in offices, all equipment should be turned off when not needed.” If it doesn't need to be on switch it off." Computer monitors should be switched off if they are not being used in the next 15 minutes or longer. Moreover, should you turn off your computer at the end of the day, it can save you up to $100 \$$ per computer per year. Lastly, as mentioned before when buying or leasing equipment, always ask about energy efficient models. 
The five steps above are just some of the tips and tricks on how to save energy and costs for your business, for more information see:

http://www.meridianenergy.co.nz/YourFarm/Energy+and+cost+savings/At+work/ 